\title{
Host model uncertainties in aerosol radiative forcing estimates: results from the AeroCom Prescribed intercomparison study
}

\author{
P. Stier ${ }^{1}$, N. A. J. Schutgens ${ }^{1}$, N. Bellouin ${ }^{2, *}$, H. Bian ${ }^{3,4}$, O. Boucher ${ }^{5}$, M. Chin ${ }^{4}$, S. Ghan ${ }^{6}$, N. Huneeus ${ }^{5}$, S. Kinne ${ }^{7}$,

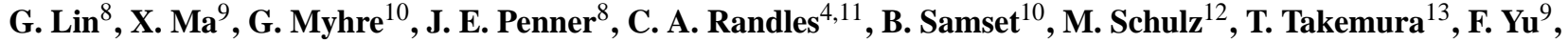 \\ H. Yu ${ }^{4,14}$, and C. Zhou $^{8}$ \\ ${ }^{1}$ Department of Physics, University of Oxford, Parks Road, OX1 3PU, Oxford, UK \\ ${ }^{2}$ Hadley Centre, Met Office, Exeter, UK \\ ${ }^{3}$ Joint Center for Earth Systems Technology, University of Maryland at Baltimore County, Baltimore, USA \\ ${ }^{4}$ NASA Goddard Space Flight Center, Greenbelt, Maryland, USA \\ ${ }^{5}$ Laboratoire de Météorologie Dynamique, IPSL, CNRS/UPMC, Paris, France \\ ${ }^{6}$ Pacific Northwest National Laboratory, Richland, USA \\ ${ }^{7}$ Max Planck Institute for Meteorology, Hamburg, Germany \\ ${ }^{8}$ Department of Atmospheric, Oceanic and Space Sciences, University of Michigan, Michigan, USA \\ ${ }^{9}$ Atmospheric Sciences Research Center, State University of New York, Albany, USA \\ ${ }^{10}$ Center for International Climate and Environmental Research Oslo (CICERO), Oslo, Norway \\ ${ }^{11}$ GESTAR/Morgan State University, Baltimore, Maryland, USA \\ ${ }^{12}$ Norwegian Meteorological Institute, Oslo, Norway \\ ${ }^{13}$ Research Institute for Applied Mechanics, Kyushu University, Fukuoka, Japan \\ ${ }^{14}$ Earth System Science Interdisciplinary Center, University of Maryland, College Park, Maryland, USA \\ *now at: Department of Meteorology, University of Reading, Reading, UK \\ Correspondence to: P. Stier (philip.stier@physics.ox.ac.uk)
}

Received: 30 July 2012 - Published in Atmos. Chem. Phys. Discuss.: 25 September 2012

Revised: 11 February 2013 - Accepted: 12 February 2013 - Published: 20 March 2013

\begin{abstract}
Simulated multi-model "diversity" in aerosol direct radiative forcing estimates is often perceived as a measure of aerosol uncertainty. However, current models used for aerosol radiative forcing calculations vary considerably in model components relevant for forcing calculations and the associated "host-model uncertainties" are generally convoluted with the actual aerosol uncertainty. In this AeroCom Prescribed intercomparison study we systematically isolate and quantify host model uncertainties on aerosol forcing experiments through prescription of identical aerosol radiative properties in twelve participating models.

Even with prescribed aerosol radiative properties, simulated clear-sky and all-sky aerosol radiative forcings show significant diversity. For a purely scattering case with globally constant optical depth of 0.2 , the global-mean all-sky top-of-atmosphere radiative forcing is $-4.47 \mathrm{Wm}^{-2}$ and the inter-model standard deviation is $0.55 \mathrm{Wm}^{-2}$, correspond-
\end{abstract}

ing to a relative standard deviation of $12 \%$. For a case with partially absorbing aerosol with an aerosol optical depth of 0.2 and single scattering albedo of 0.8 , the forcing changes to $1.04 \mathrm{Wm}^{-2}$, and the standard deviation increases to $1.01 \mathrm{~W}^{-2}$, corresponding to a significant relative standard deviation of $97 \%$. However, the top-of-atmosphere forcing variability owing to absorption (subtracting the scattering case from the case with scattering and absorption) is low, with absolute (relative) standard deviations of $0.45 \mathrm{Wm}^{-2}$ $(8 \%)$ clear-sky and $0.62 \mathrm{Wm}^{-2}(11 \%)$ all-sky.

Scaling the forcing standard deviation for a purely scattering case to match the sulfate radiative forcing in the AeroCom Direct Effect experiment demonstrates that host model uncertainties could explain about $36 \%$ of the overall sulfate forcing diversity of $0.11 \mathrm{Wm}^{-2}$ in the AeroCom Direct Radiative Effect experiment. 
Host model errors in aerosol radiative forcing are largest in regions of uncertain host model components, such as stratocumulus cloud decks or areas with poorly constrained surface albedos, such as sea ice. Our results demonstrate that host model uncertainties are an important component of aerosol forcing uncertainty that require further attention.

\section{Introduction}

Atmospheric aerosol plays an important role in the global climate system through modifications of the global radiation budget: directly, by scattering and absorption of radiation (e.g. Ångström, 1962; McCormic and Ludwig, 1967; Forster et al., 2007); indirectly, by the modification of cloud properties and abundance (e.g. Twomey, 1974; Albrecht, 1989; Lohmann and Feichter, 2005); semi-directly, by the effect of the direct and indirect aerosol effects on cloud properties and abundance via the modification of the thermal structure of the atmosphere and the surface energy budget (Ångström, 1962; Graß1, 1975; Hansen et al., 1997).

Despite considerable progress in global aerosol modelling (Textor et al., 2006; Mann et al., 2013) and observationally guided methods (e.g. Bellouin et al., 2005; Yu et al., 2006; Myhre, 2009), the uncertainties in estimates of direct aerosol radiative effects remain persistently high (Schulz et al., 2006; Myhre et al., 2013).

The simulated multimodel "diversity" in aerosol direct radiative forcing estimates is often perceived as a measure of the uncertainty in the representation of aerosols on global scales (Forster et al., 2007). However, the variability in forcing efficiencies, i.e. radiative forcings normalised by perturbation strength, such as anthropogenic aerosol optical depth (AOD) (Schulz et al., 2006) as well as the sensitivity of radiative forcing to surface albedos reported in AeroCom Phase I (Stier et al., 2007), suggests that "host model" components may contribute an important, yet unquantified, part of the overall uncertainty in aerosol radiative effects.

Aerosol radiative effects depend on a wider range of atmospheric parameters and their representation in host models used in the forcing calculation, henceforth collectively referred to as "host model effects", in particular on:

- Surface albedo: representation of soil types; ice/snow cover; spectral dependence; angular dependence of reflectance

- Clouds: global and vertical distribution; radiative properties

- Radiative transfer: spectral resolution; accuracy of the method; molecular scattering

Generally, purely scattering aerosol enhances the backscattering of solar radiation to space, resulting in negative topof-atmosphere radiative forcings (cooling effect). For partially absorbing aerosol with a given single scattering albedo,

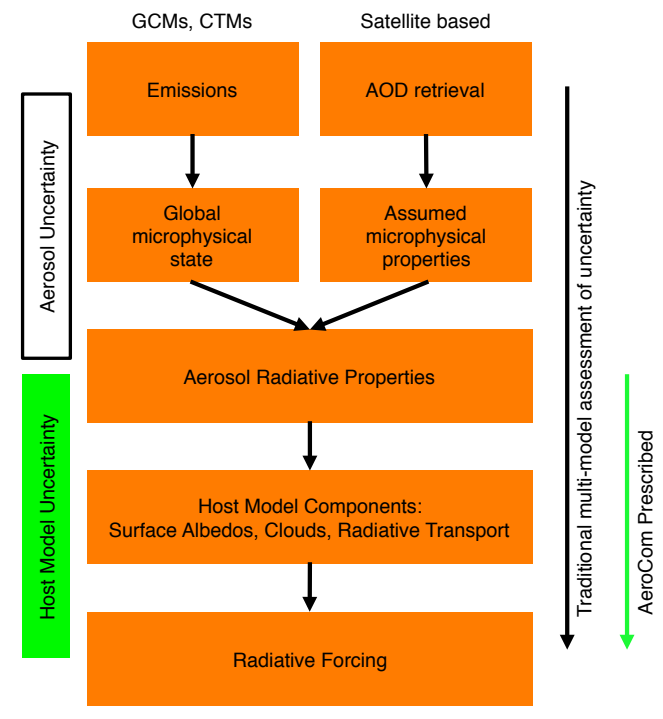

Fig. 1. Schematic of the steps involved in aerosol radiative forcing calculations from models and satellite observations, separating aerosol and host model processes.

there exists a critical surface albedo, for which the combined aerosol-surface system reflects less solar radiation back to space than the surface alone. For surface albedos below this critical value, the shortwave (SW) top-of-atmosphere (TOA) aerosol forcing is negative; above this value it becomes positive (e.g. Haywood and Shine, 1995).

Optically deep clouds under an aerosol layer also serve effectively as a high albedo surface. Thus, absorbing aerosols above a cloud layer have the potential to introduce positive TOA forcings (e.g. Chand et al., 2009). However, scattering and absorption associated with clouds above an aerosol layer reduce the available radiation and therefore reduce (negative or positive) aerosol radiative forcings (e.g. Liao and Seinfeld, 1998).

Previous assessments of the uncertainties in aerosol radiative forcing focused either in detail on the radiative transfer codes, performed for individual columns in idealised setup or at selected global locations (Boucher et al., 1998; Halthore et al., 2005; Oreopoulos et al., 2012). While of fundamental importance for the improvement of the process representation, it is generally difficult to scale uncertainties and identified errors in such idealised intercomparison setups performed for individual atmospheric columns to uncertainty in global estimates of aerosol radiative effects. Or at the other end of the spectrum, previous uncertainty assessments have widely used multi-model diversity in simulated aerosol fields and radiative forcing as proxy for uncertainties in aerosol radiative forcing (e.g. in successive IPCC assessments and previous AeroCom intercomparison studies: Forster et al., 2007; Kinne et al., 2006; Textor et al., 2006; Schulz et al., 2006), convoluting the uncertainty in simulated aerosol fields with the uncertainty in the forcing calculation. 
In this AeroCom Prescribed intercomparison study we aim to bridge these approaches through a systematic assessment of the effects of host model uncertainties on aerosol radiative forcing estimates. We isolate aerosol host model uncertainties through prescription of identical aerosol radiative properties in all participating models, including offline radiative forcing models used in satellite based assessments, chemical transport models (CTMs) and general circulation models (GCMs), taking away the uncertainty in aerosol processes, as illustrated in Fig. 1.

In an ideal world one could test the impact of perturbations through systematic sampling of the multi-dimensional parameter/configuration space. Specifically, it would be desirable to investigate the impact of structural model uncertainty through systematic variation of prescribed identical surface albedos, cloud radiative properties and ultimately radiative transfer codes in all models. Practically, constrained by participation and ease of implementation, only a subset of such runs is generally available. In our case we specify the aerosol radiative properties while leaving all other model parameters unchanged (different but not necessarily independent among the models). It should be noted that the implementation of identical cloud radiative properties, surface albedos and radiative transfer codes would be a non-trivial task for GCMs as they rely for physical consistency on a closed radiation balance that may not be able to be achieved with a prescribed set of parameters.

This study is closely geared with the detailed offline AeroCom Radiative Transfer Code Experiment (Randles et al., 2013) as well as the AeroCom Direct Radiative Effect study (“AeroCom Direct", Myhre et al., 2013).

\section{Methodology}

\subsection{Intercomparison protocol}

We approach the assessment of host model uncertainties with two complementary setups of different complexity:

- An idealised setup with globally constant profiles of aerosol radiative properties, where AOD is distributed linearly in height over the lowest two kilometers (FIX0, FIX2, FIX3)

- A realistic scenario with prescribed monthly varying, three-dimensional, spatially and spectrally resolved aerosol radiative properties (FIX1)

To maximise comparability, all simulations are performed in the same setup as used by the models in the submission to the AeroCom Direct experiment (Myhre et al., 2013) with model-specific aerosol distributions and radiative properties. The simulations were performed for one simulation year. Models report diagnostic instantaneous radiative fluxes, i.e. host model components other than aerosol radiative properties, such as clouds, are identical for all simulations by each
Table 1. Setup of the AeroCom Prescribed simulations. All parameters in FIX0, FIX2, FIX3 are assumed globally and seasonally invariant. Experiment names have historical order but are retained for consistency.

\begin{tabular}{|c|c|c|}
\hline Name & Parameters & Comment \\
\hline \multicolumn{3}{|c|}{ Idealised } \\
\hline FIX0 & $\begin{array}{l}\mathrm{AOD}=0.0 \\
\mathrm{SSA}=\mathrm{n} / \mathrm{a} \\
\mathrm{ANG}=\mathrm{n} / \mathrm{a} \\
\mathrm{ASY}=\mathrm{n} / \mathrm{a}\end{array}$ & specified at $550 \mathrm{~nm}$ \\
\hline FIX2 & $\begin{array}{l}\mathrm{AOD}=0.2 \\
\mathrm{SSA}=1.0 \\
\mathrm{ANG}=1.0 \\
\mathrm{ASY}=0.7\end{array}$ & $\begin{array}{l}\text { Linear by height over lowest } 2 \mathrm{~km} \\
\text { Purely scattering case } \\
\text { Used for spectral dependence of AOD } \\
\text { at other solar wavelengths } \lambda \\
\text { Solar-spectrally invariant } \\
\text { forward scattering }\end{array}$ \\
\hline FIX3 & $\begin{array}{l}\mathrm{AOD}=0.2 \\
\mathrm{SSA}=0.8 \\
\mathrm{ANG}=1.0 \\
\mathrm{ASY}=0.7\end{array}$ & $\begin{array}{l}\text { Linear by height over lowest } 2 \mathrm{~km} \\
\text { Absorbing case } \\
\text { Used for spectral dependence of AOD } \\
\text { at other solar wavelengths } \lambda \\
\text { Solar-spectrally invariant } \\
\text { forward scattering }\end{array}$ \\
\hline Realis & & \\
\hline FIX1 & $\begin{array}{l}\mathrm{AOD}_{\mathrm{PD}}=0.132 \\
\mathrm{SSA}_{\mathrm{PD}}=0.963 \\
\mathrm{AOD}_{\mathrm{PI}}=0.092 \\
\mathrm{SSA}_{\mathrm{PI}}=0.978\end{array}$ & $\begin{array}{l}\text { Present-day }(P D) \text { at } 545 \mathrm{~nm} \\
\text { AOD weighted mean } \\
\text { Pre-industrial }(P I) \\
\text { AOD weighted mean } \\
\text { Monthly 3-D distribution } \\
\text { early release of Kinne et al. (2013) }\end{array}$ \\
\hline
\end{tabular}

model. Radiative forcing (RF) is calculated from monthly mean flux difference between the respective simulations.

The setup of the AeroCom Prescribed simulation is outlined in Table 1. Readers are cautioned that experiments FIX0, FIX2, FIX3 are highly idealised, with unrealistic globally constant aerosol radiative properties, and that the resulting forcing fields of these experiments should not be mistaken for realistic aerosol forcings.

Results are generally summarised by global annual mean values, calculated as area weighted average of the annual mean fields plotted in the corresponding figures, and standard deviations (SD) of the global annual mean values. In addition, we also provide plots of multi-model mean fields and standard deviations. To allow for comparability in the "diversity" of different parameters, we also report the relative standard deviation $\mathrm{RSD}=\frac{|\sigma|}{|\mu|}$, where $\sigma$ is the standard deviation and $\mu$ the mean value of the respective parameter. We should caution that the sample size across the models is very limited so that standard deviation is used here simply as a measure of the inter-model spread and should not be interpreted based on the underlying assumption of a Gaussian distribution, e.g. in the sense of confidence intervals. 


\subsection{Description of participating models}

The aim of this study is to identify and quantify host model uncertainties in models commonly used for aerosol radiative forcing estimates.

Out of the 12 participating model variants (GOCART and INCA submitted in two configurations), all except MPI-2stream and GOCART-GEOS4 are directly comparable to submissions to the AeroCom Direct experiment (Myhre et al., 2013). Out of the 12 model radiation codes, 6 (CAM-PNNL RRTMG, GOCART, HadGEM2, MPI2stream, OsloCTM2, GEOS-CHEM) are directly comparable to their submission to the AeroCom Radiative Transfer Intercomparison (Randles et al., 2013).

The models used are up-to-date configurations and some of the host models are almost identical to model versions used in the Coupled Model Intercomparison Project study CMIP5 (Taylor et al., 2012). However, the representation of host model parameters such as clouds and surface albedos, depends on the exact model setup and will differ from CMIP5 runs, even if they were conducted with the same model version. Nonetheless, we believe that the conclusions of our study equally apply to the range of models used in CMIP5.

Table 2 lists the participating models and details about their radiation schemes, to be complemented for information about other used model parameterisations, including cloud and surface albedo schemes, provided in the listed references.

Out of 12 submitted configurations, 6 are General Circulation Models (GCMs), 5 are Chemistry Transport Models (CTMs) and 1, MPI-2stream, is an offline radiative transfer scheme. MPI-2stream prescribes cloud derived from the International Satellite Cloud Climatology Project as described in Kinne et al. (2013).

All models report diagnostic instantaneous radiative forcing, i.e. aerosol radiative effects do not feed back to the model meteorology, which remains identical for the radiative transfer calculations of the different simulations.

The shortwave spectral resolution varies from 2 to $19 \mathrm{SW}$ bands, and the complexity of the radiation parameterisations varies considerably. Model spatial resolutions vary from $4^{\circ} \times$ $5^{\circ}$ in the horizontal and 19 vertical levels to $1^{\circ} \times 1^{\circ}$ in the horizontal and 72 vertical levels.

\section{Results}

\subsection{Host model components}

Before proceeding with the presentation of the simulated radiative effects, we provide an overview of the key host model components affecting radiative forcing: cloud properties and albedos. Key results of this section are also summarised as zonal mean plots in the Appendix figures.
The annual-mean cloud fractions for the unperturbed case FIX0 are compared in Fig. 2. Significant regional differences are evident in the model cloud fractions, a known issue for global general circulation models documented in the literature (e.g. Pincus et al., 2008; Probst et al., 2012). Two models have cloud fractions (GOCART-GEOS4: 0.49 and LMDZ: 0.48 ) at the lower end of the observed range (Marchand et al., 2010) (although this quantity is generally not consistently defined between models and detection limited observations). The LMDZ-39L version with revised cloud scheme has significantly higher cloud fractions. The simulation of persistent high cloud-fraction stratocumulus decks off the western coasts of the Americas and Africa as well as in the stormtracks differs significantly among models.

The effective broadband short-wave surface albedos (derived as ratio of upward to downward SW radiative fluxes at the surface) shown in Fig. 3 show a broad agreement in the global mean with low oceanic surface albedos and high land surface albedos in arid regions and regions covered by snow and ice. Most models have a global mean close to the multimodel mean of 0.16 , except MPI-2stream that shows higher surface albedos at high northern latitudes (presumably snow cover) and a global mean of 0.203 .

The broadband short-wave top-of-atmosphere albedo shown in Fig. 4 includes the effects of surface albedo, cloud albedo and molecular scattering. While models agree on the large scale patterns and the global mean (except GOCARTGEOS4, which has an identified problem with cloud radiative properties), significant differences exist on regional scales. It should be noted that TOA albedo is a key parameter in the tuning of General Circulation Models to achieve radiation balance so that the global mean values generally reflect the model tuning (or the lack thereof).

\subsection{Radiative forcing}

In this section we present a detailed analysis of the simulated radiative forcings. Individual results are presented to allow visual attribution to differences in host model processes, such as clouds and surface albedos. The key findings are also summarised in Fig. 16 and Table 3.

\subsubsection{Scattering case: FIX2-FIX0}

The clear-sky and all-sky top-of-atmosphere radiative forcings for the scattering case with globally constant AOD $=0.2$ (FIX2-FIX0) are shown in Figs. 5 and 6, respectively. Models generally agree in the large scale negative forcing pattern for the clear sky case, with highest values over dark ocean surfaces and lowest values over areas with high land surface albedo. The global mean is $-7.11 \mathrm{Wm}^{-2}$ with a standard deviation of $0.53 \mathrm{Wm}^{-2}$ and a corresponding relative standard deviation (RSD) of $7 \%$. The forcing variability increases in the all-sky forcing fields with forcing patterns corresponding to surface albedos as well as clouds. The global mean 


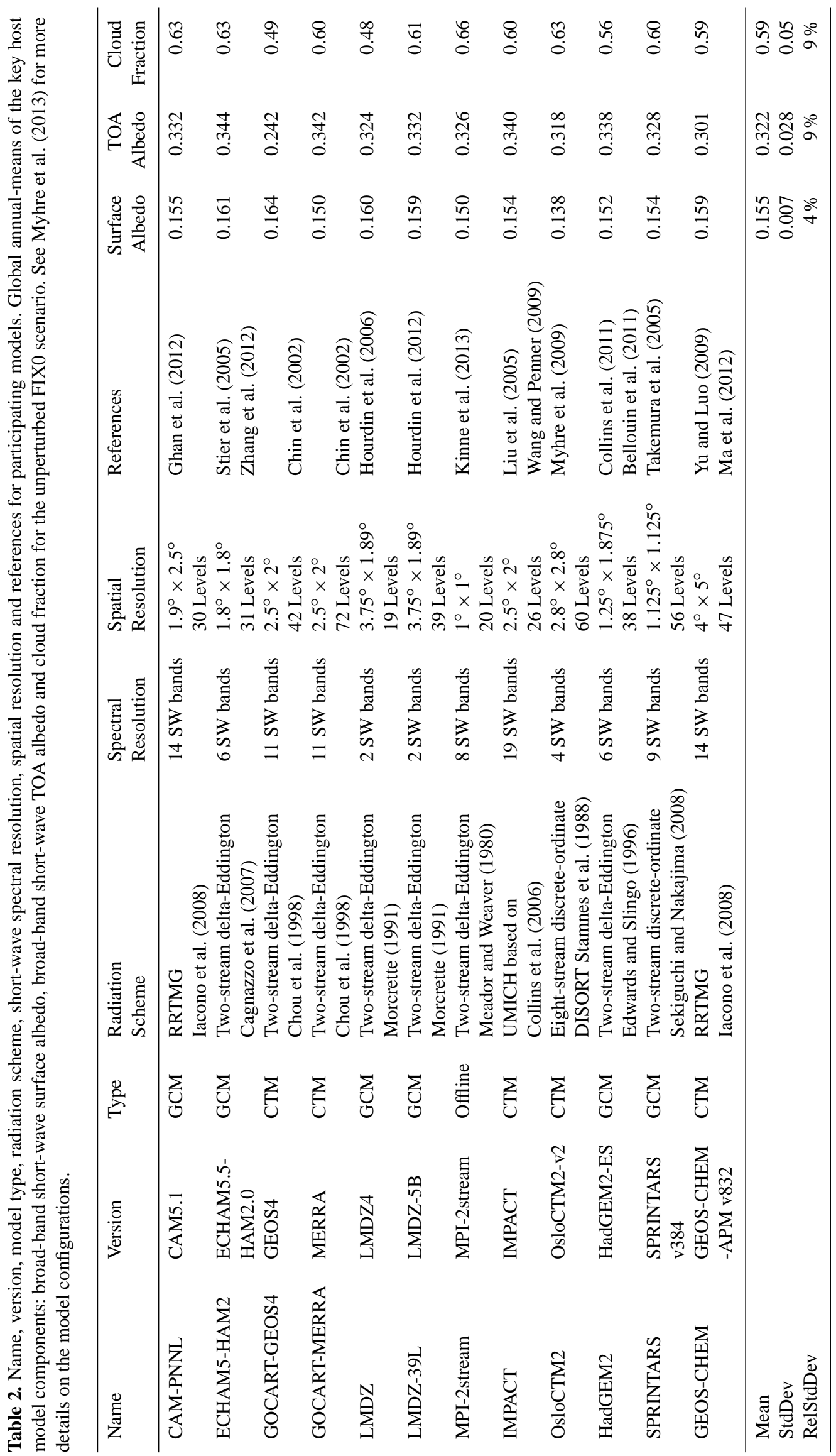



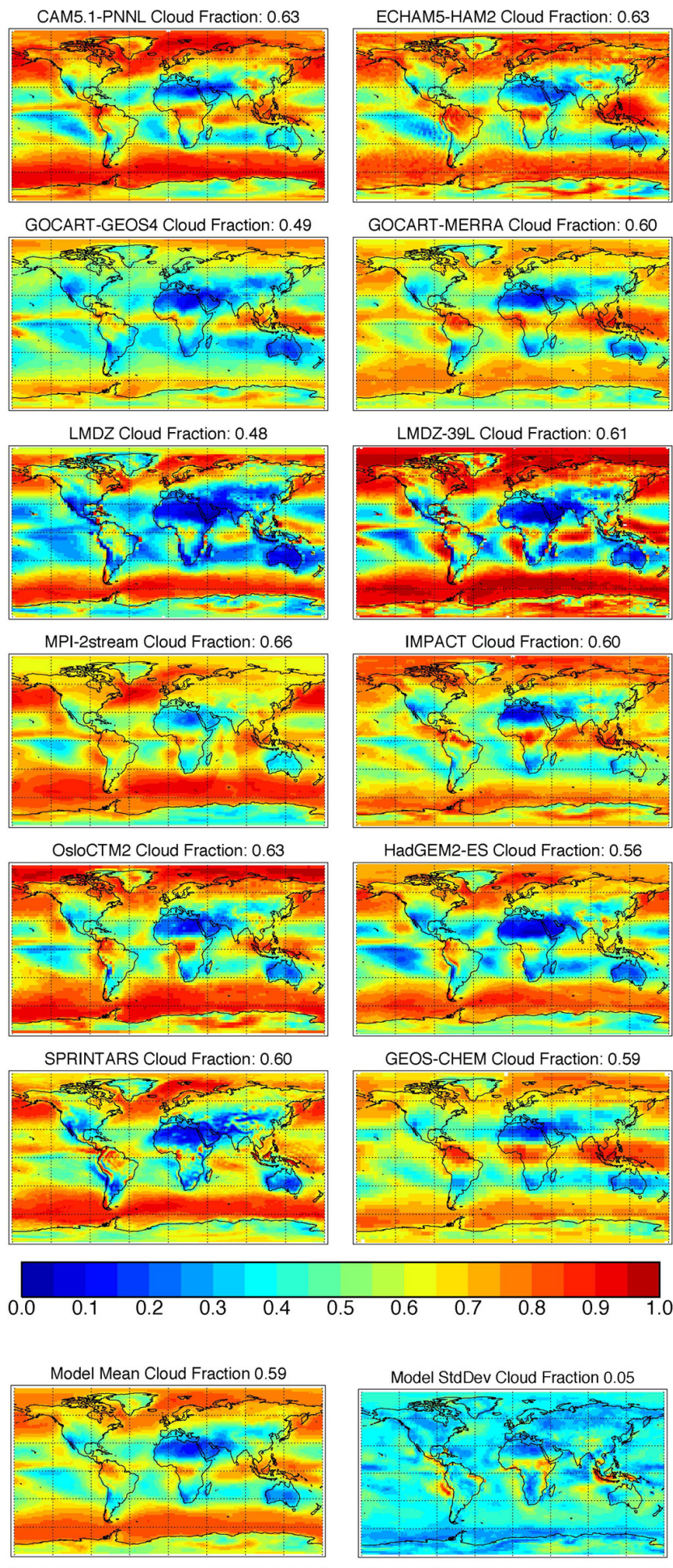

\begin{tabular}{llllllllllll}
\hline 0 & 01 & 0.2 & 0.3 & 0.4 & 0.5 & 0.6 & 0.7 & 0.8 & 0.9 & 10 & 0
\end{tabular}

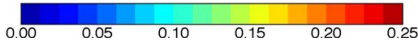

Fig. 2. Annual-mean cloud fractions for each of the models, annual multi-model mean and annual-mean multi-model standard deviation. Global annual means for each model and the mean and standard deviation of the multi-model global annual-means are given in the respective titles.
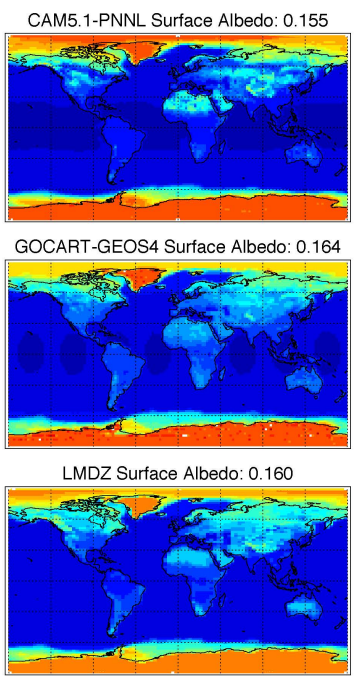

MPI-2stream Surface Albedo: 0.150
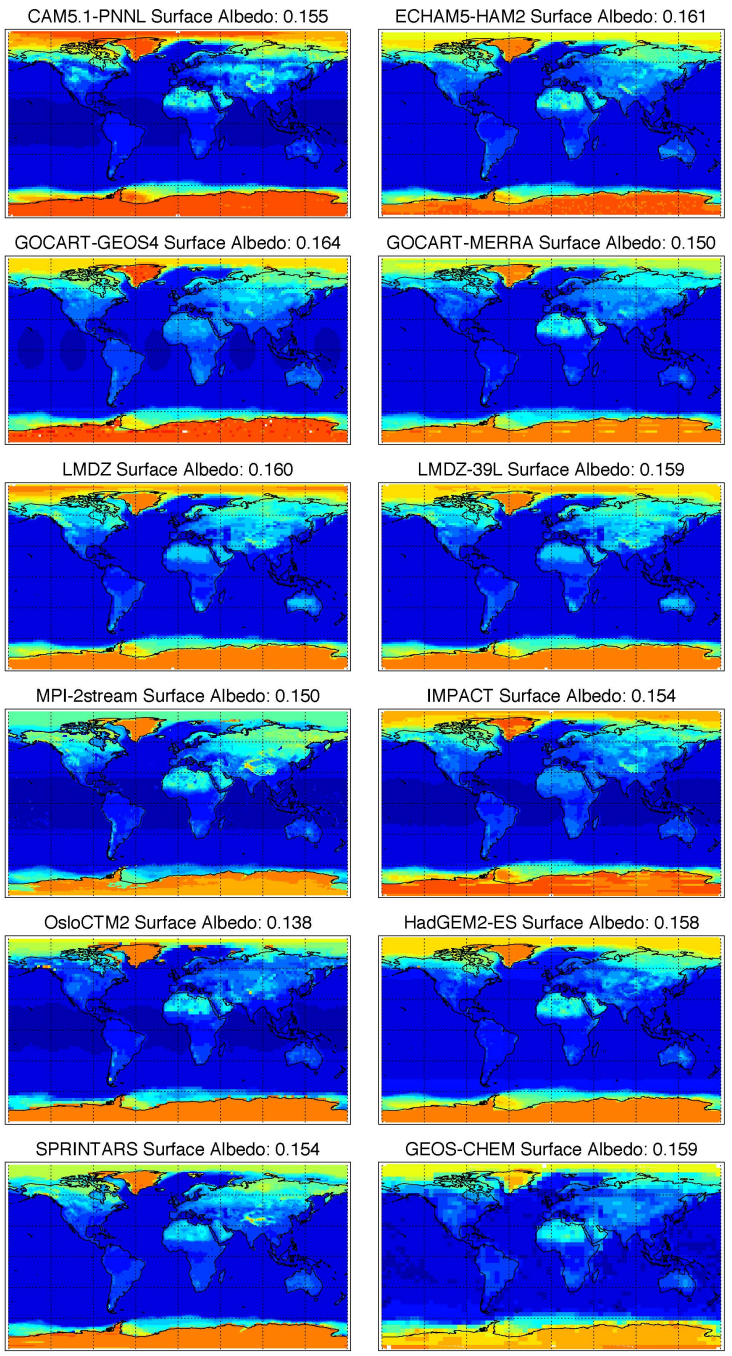

LMDZ-39L Surface Albedo: 0.159

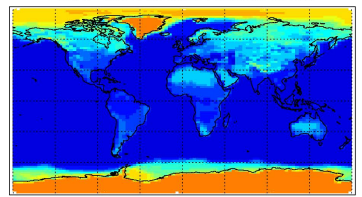

IMPACT Surface Albedo: 0.154

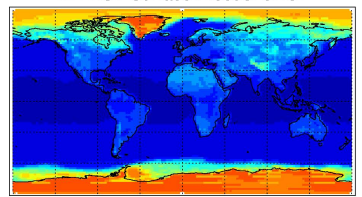

HadGEM2-ES Surface Albedo: 0.158

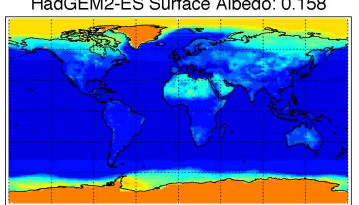

GEOS-CHEM Surface Albedo: 0.159
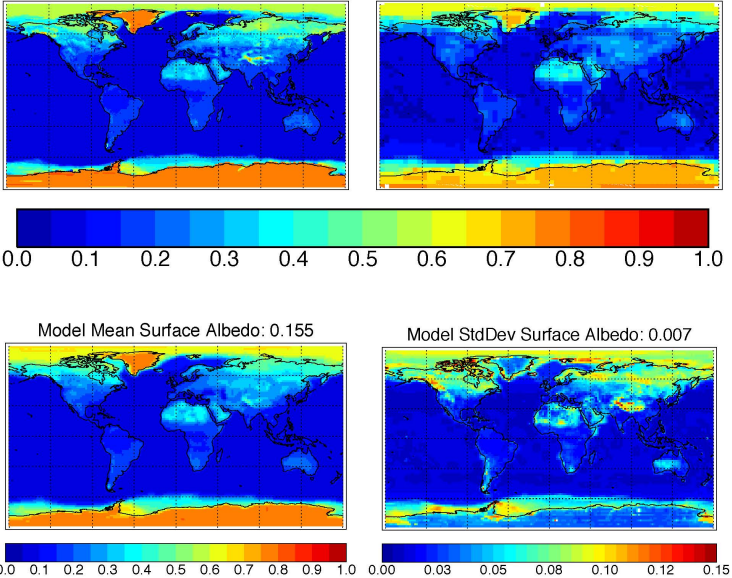

Fig. 3. Annual mean broadband short-wave surface albedos for experiment FIX0 $(\mathrm{AOD}=0.0)$.

is reduced to $-4.47 \mathrm{Wm}^{-2}$ while the standard deviation remains at $0.55 \mathrm{Wm}^{-2}$, corresponding to a RSD increase to $12 \%$.

For the purely scattering case discussed so far, aerosol absorption is by definition zero. Nonetheless, enhancement of molecular absorption through the enhancement of the photon path-length by aerosol scattering could potentially play a role for aerosol radiative forcing. 

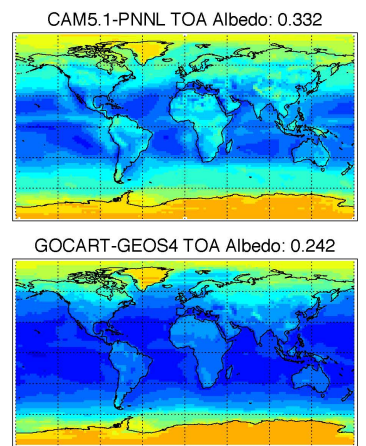

LMDZ TOA Albedo: 0.324

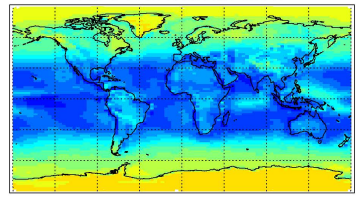

MPI-2stream TOA Albedo: 0.326

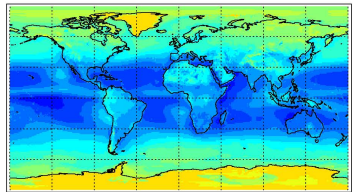

OsloCTM2 TOA Albedo: 0.318

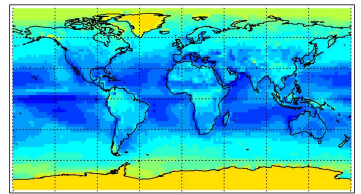

SPRINTARS TOA Albedo: 0.328
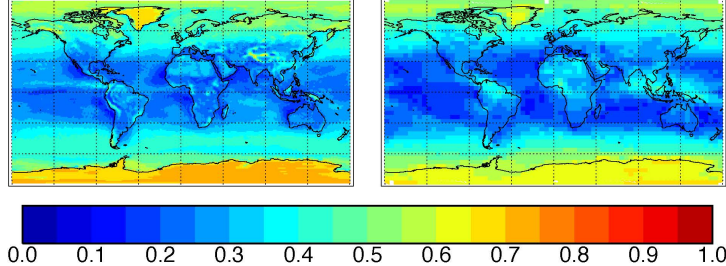

Model Mean TOA Albedo: 0.322

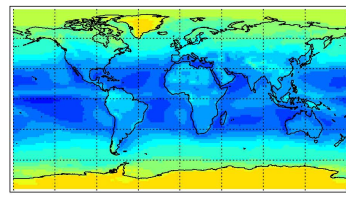

$\begin{array}{llllllllllll}0.0 & 0.1 & 0.2 & 0.3 & 0.4 & 0.5 & 0.6 & 0.7 & 0.8 & 0.9 & 1.0\end{array}$

Fig. 4. Annual mean broadband short-wave top-of-atmosphere albedos for experiment FIX0 (AOD = 0.0).

The atmospheric radiative forcing (i.e. column absorption) for the scattering case (FIX2-FIX0) is shown in Fig. 7. Generally, the absorption enhancement is small. However, LMDZ shows considerable clear-sky absorption in both configurations (0.95 and $\left.0.98 \mathrm{Wm}^{-2}\right)$ and also OsloCTM2 reaches a global mean of $0.76 \mathrm{Wm}^{-2}$. The strong correlation with the surface albedo is caused by the path-length enhancement associated with multiple scattering over bright surfaces.

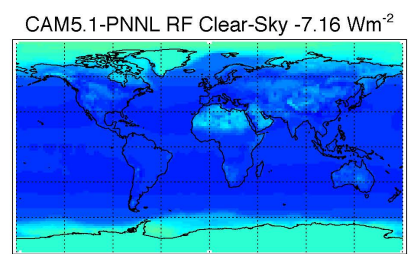

GOCART-GEOS4 RF Clear-Sky -7.22 Wm-2

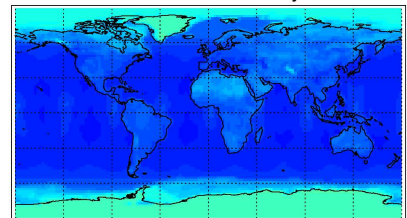

LMDZ RF Clear-Sky -6.49 Wm-2

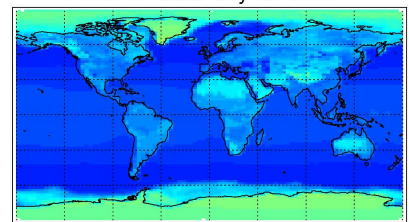

MPI-2stream RF Clear-Sky $-6.56 \mathrm{Wm}^{-2}$

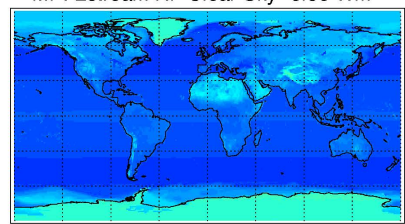

OsloCTM2 RF Clear-Sky $-8.14 \mathrm{Wm}^{-2}$

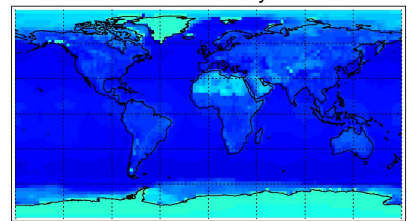

SPRINTARS RF Clear-Sky $-6.30 \mathrm{Wm}^{-2}$
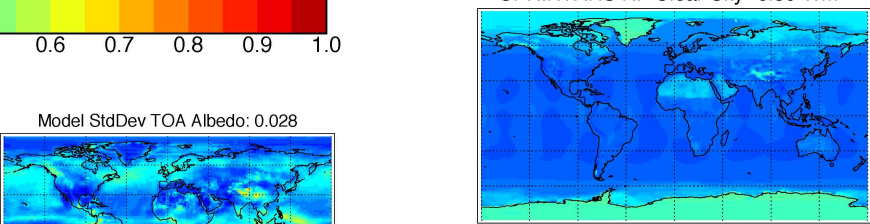

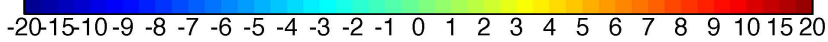
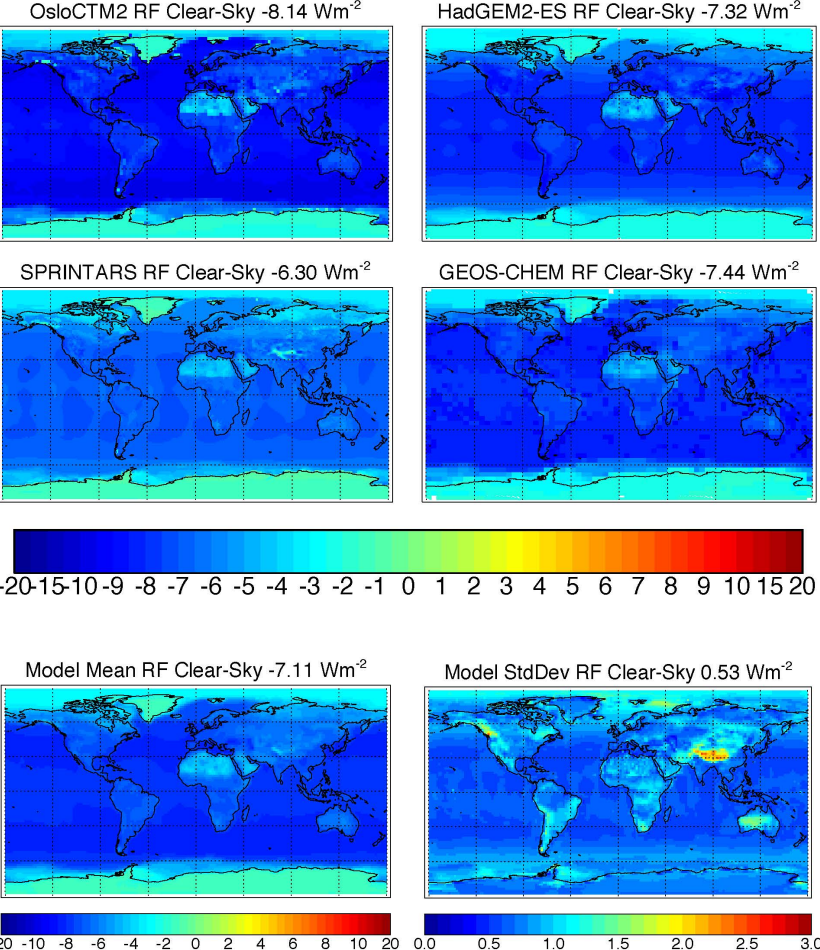

GEOS-CHEM RF Clear-Sky $-7.44 \mathrm{Wm}^{-2}$

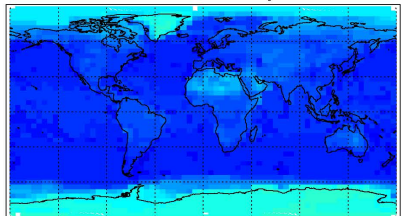

Fig. 5. Annual mean short-wave clear-sky top-of-atmosphere radiative forcing $(\mathrm{RF})$ between experiments with $\mathrm{AOD}=0.2$ and $\mathrm{AOD}=0.0$ distributed over the lowest two kilometers, holding $\mathrm{SSA}=1.0$ and $\mathrm{ANG}=1.0$ constant $(\mathrm{FIX} 2-\mathrm{FIX} 0)$. 


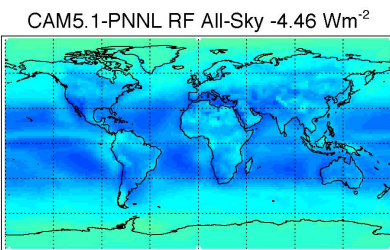

GOCART-GEOS4 RF All-Sky $-5.97 \mathrm{Wm}^{-2}$

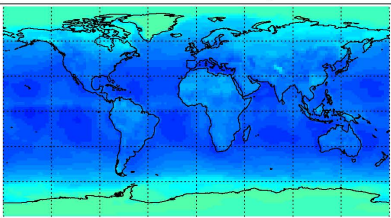

LMDZ RF All-Sky $-4.12 \mathrm{Wm}^{-2}$

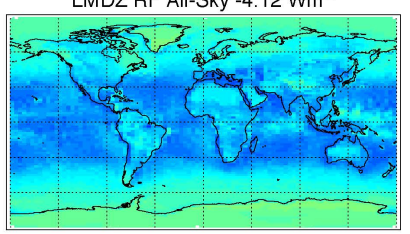

MPI-2stream RF All-Sky -4.03 Wm$^{-2}$

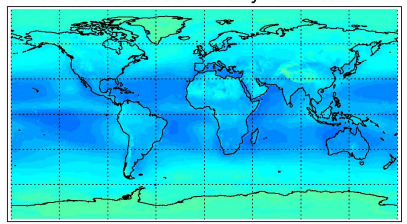

OsloCTM2 RF All-Sky $-4.50 \mathrm{Wm}^{-2}$

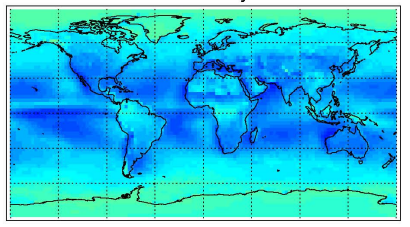

SPRINTARS RF All-Sky $-4.04 \mathrm{Wm}^{-2}$
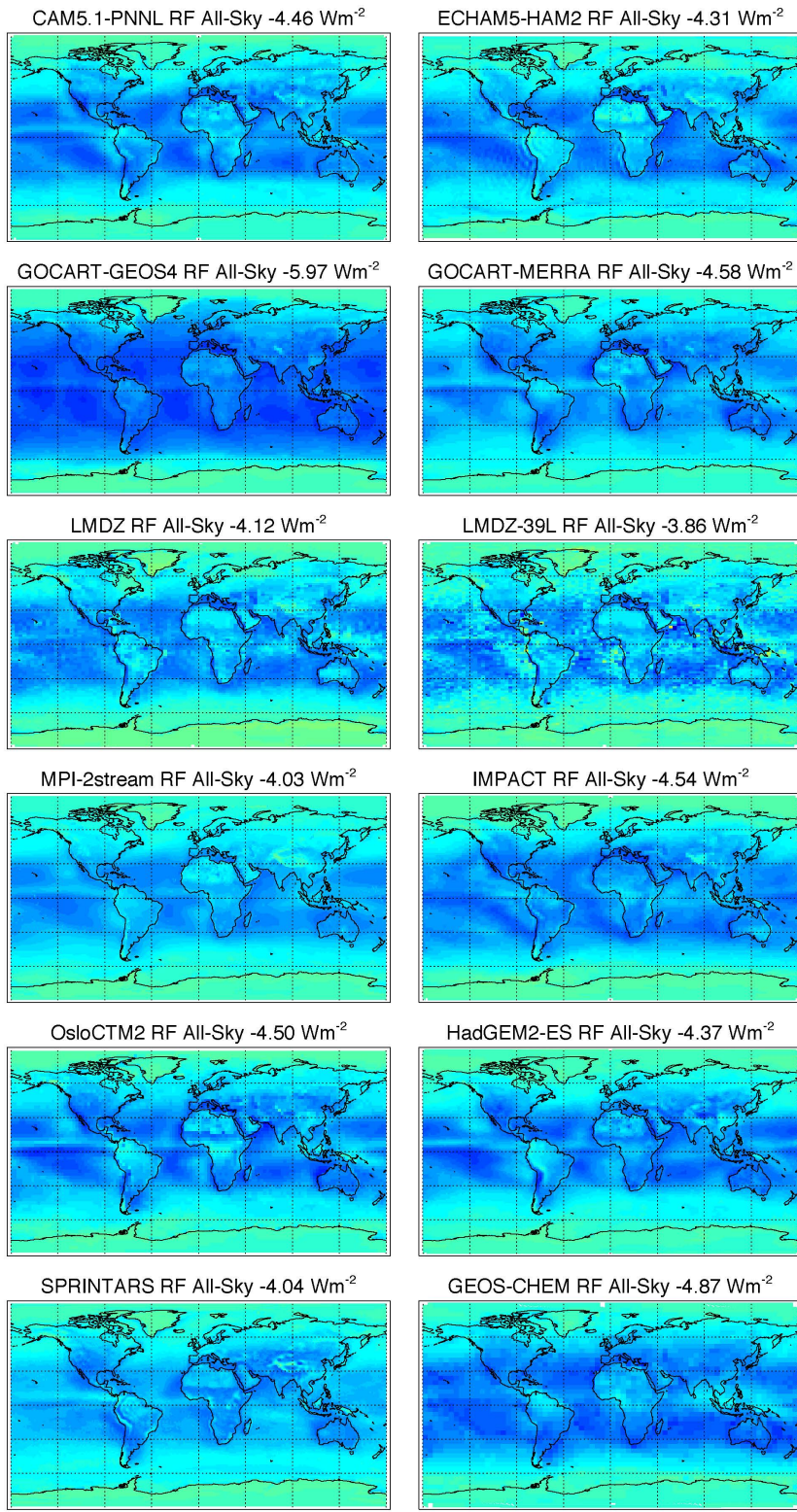

GOCART-MERRA RF All-Sky $-4.58 \mathrm{Wm}^{-2}$

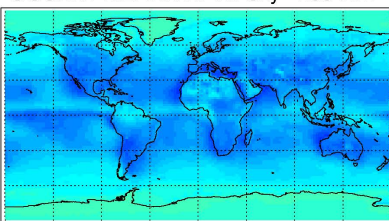

LMDZ-39L RF All-Sky -3.86 Wm

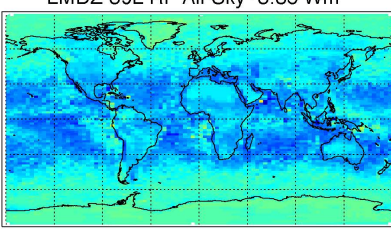

IMPACT RF All-Sky $-4.54 \mathrm{Wm}^{-2}$

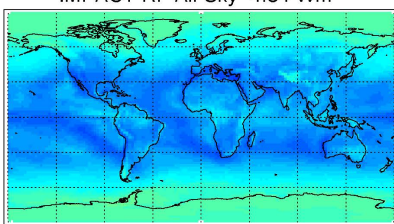

HadGEM2-ES RF All-Sky $-4.37 \mathrm{Wm}^{-2}$

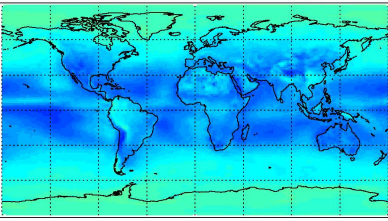

GEOS-CHEM RF All-Sky $-4.87 \mathrm{Wm}^{-2}$
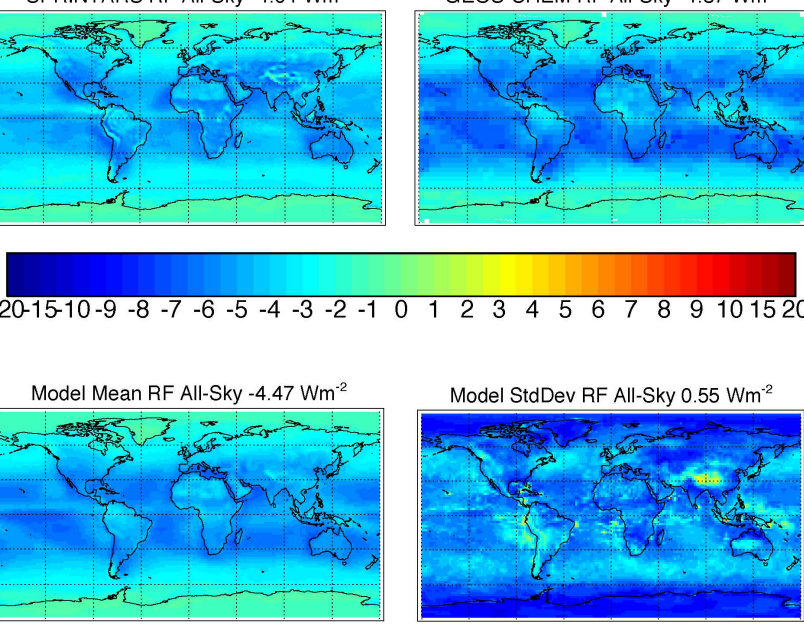

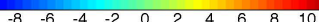

These results point to structural host model differences in the radiative transfer schemes. Results from the AeroCom Radiative Transfer Intercomparison (Randles et al., 2013) provide further insights: in this study, line-by-line benchmark models show stronger atmospheric absorption in the purely scattering case than most schemes used in GCMs and CTMs, except Oslo-DISTORT used in Oslo-CTM2, which supports the higher values reported by some models here. The second highest absorption enhancement in the scattering case of the AeroCom Radiative Transfer study is simulated by another multi-stream model GSFC-FL, highlighting potential structural limitations of radiative transfer schemes used in GCMs. As the aerosol extinction is generally low in spectral regions of strong water vapour absorption, differences in the treatment of ozone could be a contributor to these differences. This could in turn be affected by the spectral resolution of the models.

This absorption enhancement for the scattering case in LMDZ and OsloCTM2 is also discernible in the all-sky absorption, however, cloud shielding reduces the effect by about a factor of two (not shown).

\subsubsection{Absorbing Case: FIX3-FIX0}

Replacing the purely scattering aerosol layer in FIX2 by a partially absorbing layer with the same $\mathrm{AOD}=0.2$ but $\mathrm{SSA}=0.8$, shifts the clear-sky forcing over areas with high surface albedos to positive values, and reduces the negative forcings over the low-albedo oceans (Fig. 8). The global mean clear-sky radiative forcing is reduced to $-1.63 \mathrm{Wm}^{-2}$ while the standard deviation increases to $0.70 \mathrm{Wm}^{-2}$, corresponding to a RSD increase to $43 \%$.

The importance of clouds for radiative forcing becomes apparent in the all-sky radiative forcing fields, shown in Fig. 9. Except over high albedo surfaces where overlaying clouds reduce some of the absorption and positive forcings from the clear-sky case, forcings are generally more positive. The absorption enhancement is particularly pronounced in the storm tracks and areas with low-level clouds. Regional forcing differences across the models are significantly affected by differences in model clouds. For example, the strong forcing variability west of the coast of the Americas and Africa across models directly reflects the differences in the representation of low-level stratocumulus clouds (see Fig. 2).

Some of the diversity in the simulated top-of-atmosphere radiative forcings for the absorbing case will depend on differences in the calculated atmospheric radiative forcing (absorption), shown in Figs. 10 and 11.

The clear-sky atmospheric radiative forcing is a function of incoming solar radiation and surface albedo, which will act to enhance path-length and consequently absorption. The overall global distribution shows a background field decrease towards higher latitudes (reflecting incoming solar radiation) with enhancements of absorption over high albedo surfaces.

Fig. 6. Annual mean short-wave all-sky top-of-atmosphere radiative forcing $(\mathrm{RF})$ between experiments with $\mathrm{AOD}=0.2$ and $\mathrm{AOD}=0.0$ distributed over the lowest two kilometers, holding SSA $=1.0$ and $\mathrm{ANG}=1.0$ constant $($ FIX2-FIX0). 


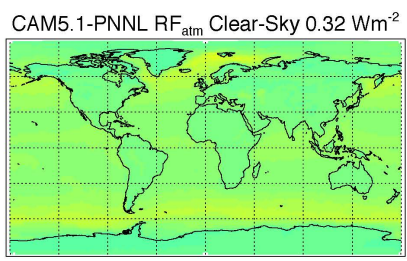

GOCART-GEOS4 $\mathrm{RF}_{\text {atm }}$ Clear-Sky $0.16 \mathrm{Wm}^{-2}$

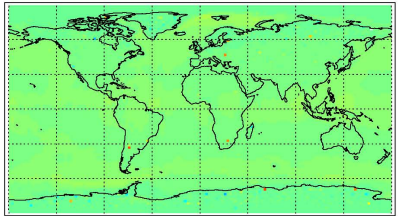

LMDZ RF $_{\text {atm }}$ Clear-Sky $0.95 \mathrm{Wm}^{-2}$

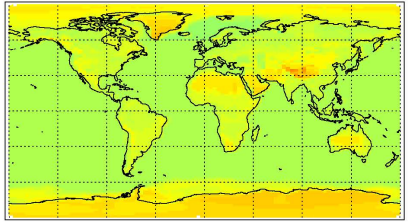

MPI-2stream RF atm Clear-Sky $0.03 \mathrm{Wm}^{-2}$

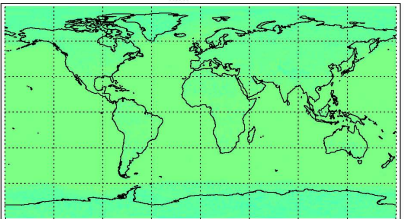

OsloCTM2 $\mathrm{RF}_{\text {atm }}$ Clear-Sky $0.76 \mathrm{Wm}^{-2}$

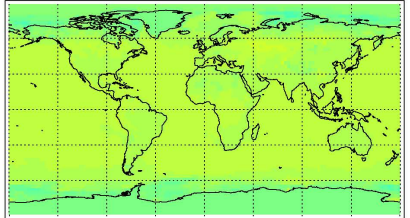

SPRINTARS RF $\mathrm{atm}_{\text {atm }}$ Clear-Sky $0.42 \mathrm{Wm}^{-2}$
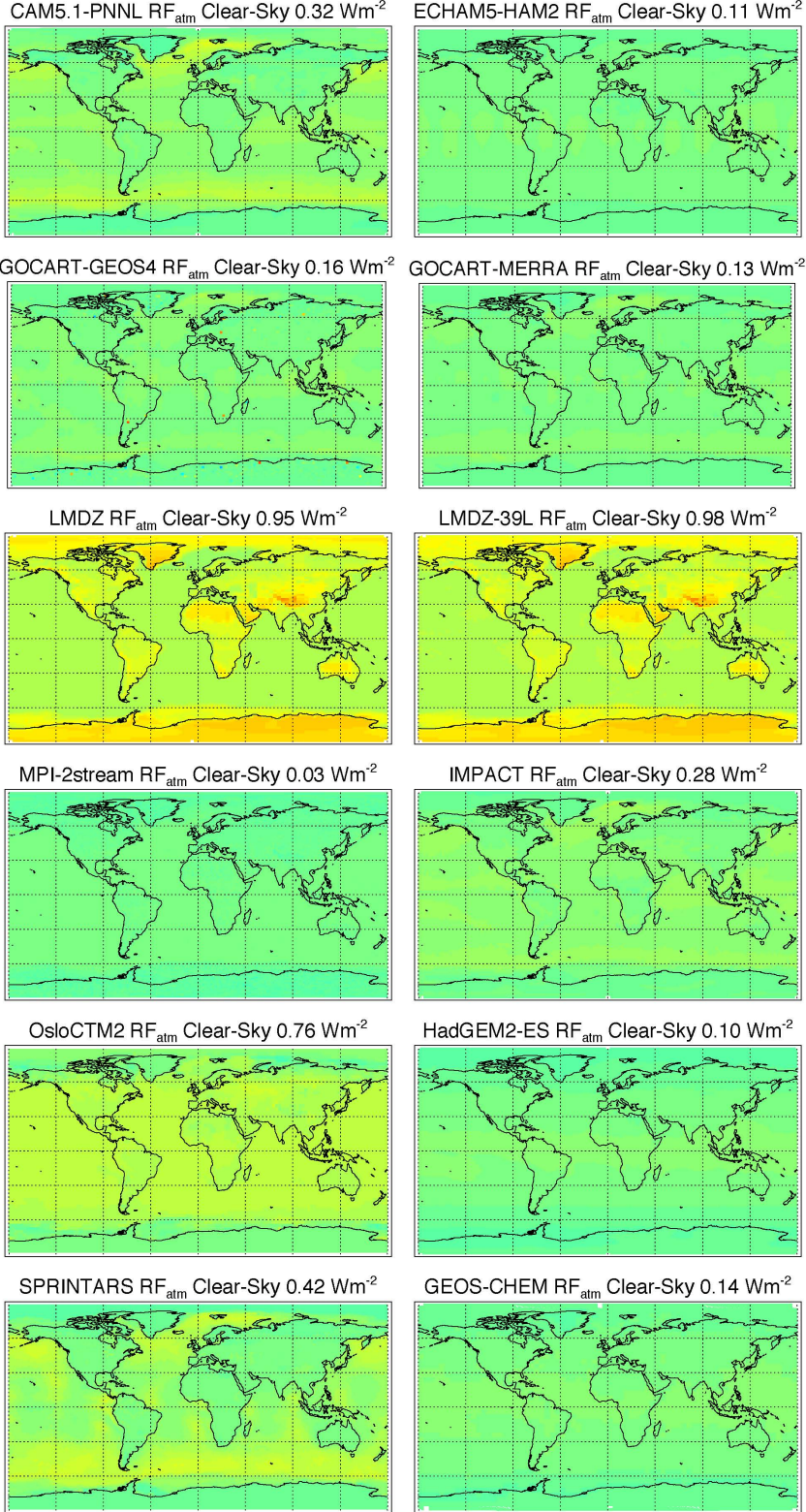

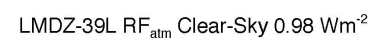

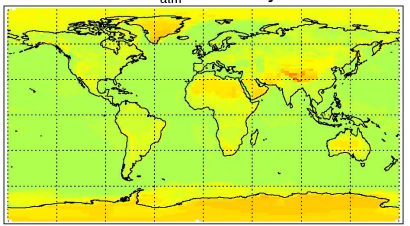

IMPACT RF ${ }_{\text {atm }}$ Clear-Sky $0.28 \mathrm{Wm}^{-2}$

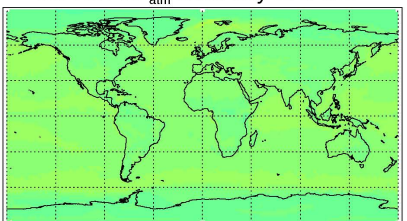

HadGEM2-ES RF $F_{\text {atm }}$ Clear-Sky $0.10 \mathrm{Wm}^{-2}$

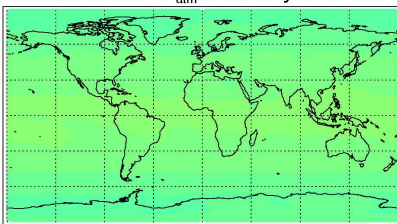

GEOS-CHEM RF ${ }_{\text {atm }}$ Clear-Sky $0.14 \mathrm{Wm}^{-2}$
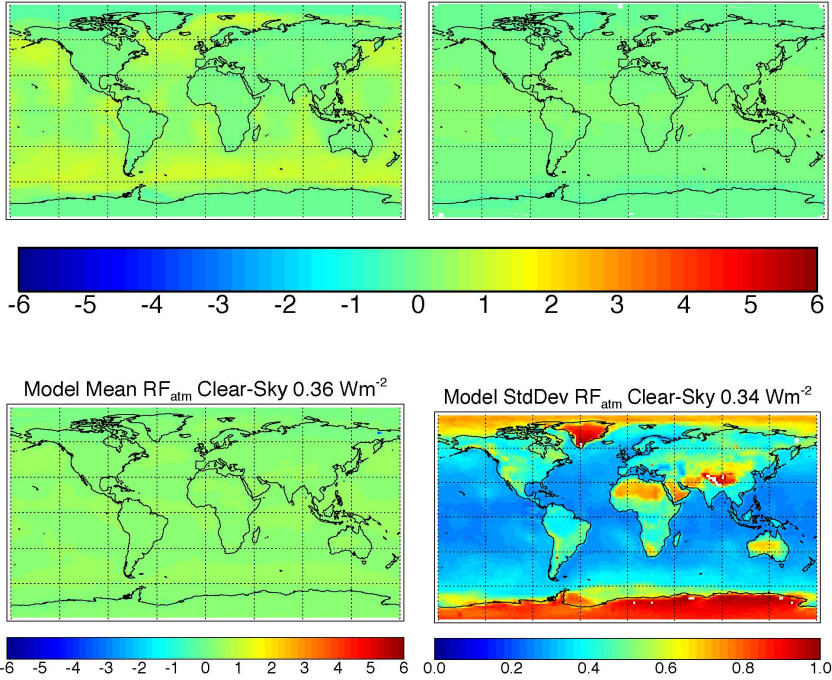

Fig. 7. Annual mean short-wave clear-sky atmospheric radiative forcing (absorption) between experiments with $\mathrm{AOD}=0.2$ and $\mathrm{AOD}=0.0$ distributed over the lowest two kilometers, holding $\mathrm{SSA}=1.0$ and $\mathrm{ANG}=1.0$ constant $(\mathrm{FIX} 2-\mathrm{FIX} 0)$.
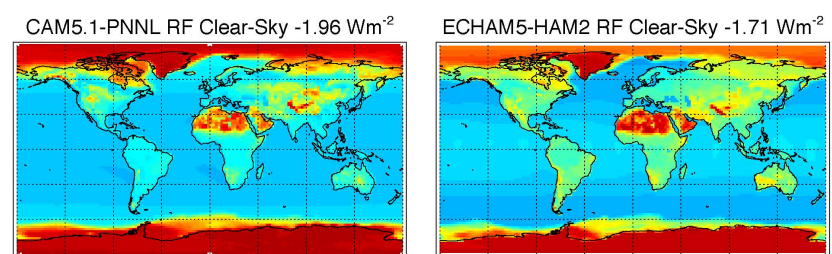

GOCART-GEOS4 RF Clear-Sky - $2.08 \mathrm{Wm}^{-2}$

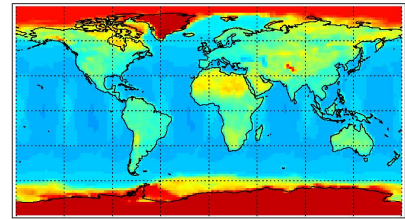

LMDZ RF Clear-Sky $-0.24 \mathrm{Wm}^{-2}$
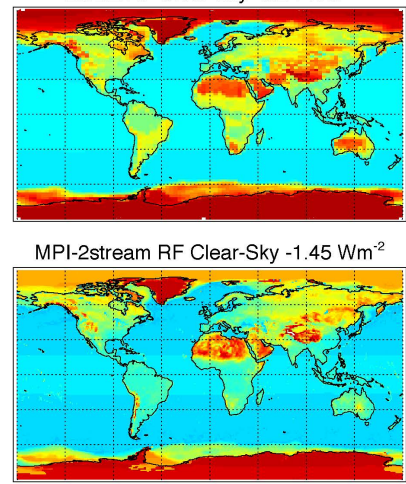

OsloCTM2 RF Clear-Sky -2.24 Wm-2

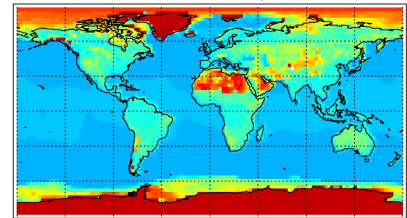

SPRINTARS RF Clear-Sky $-1.32 \mathrm{Wm}^{-2}$
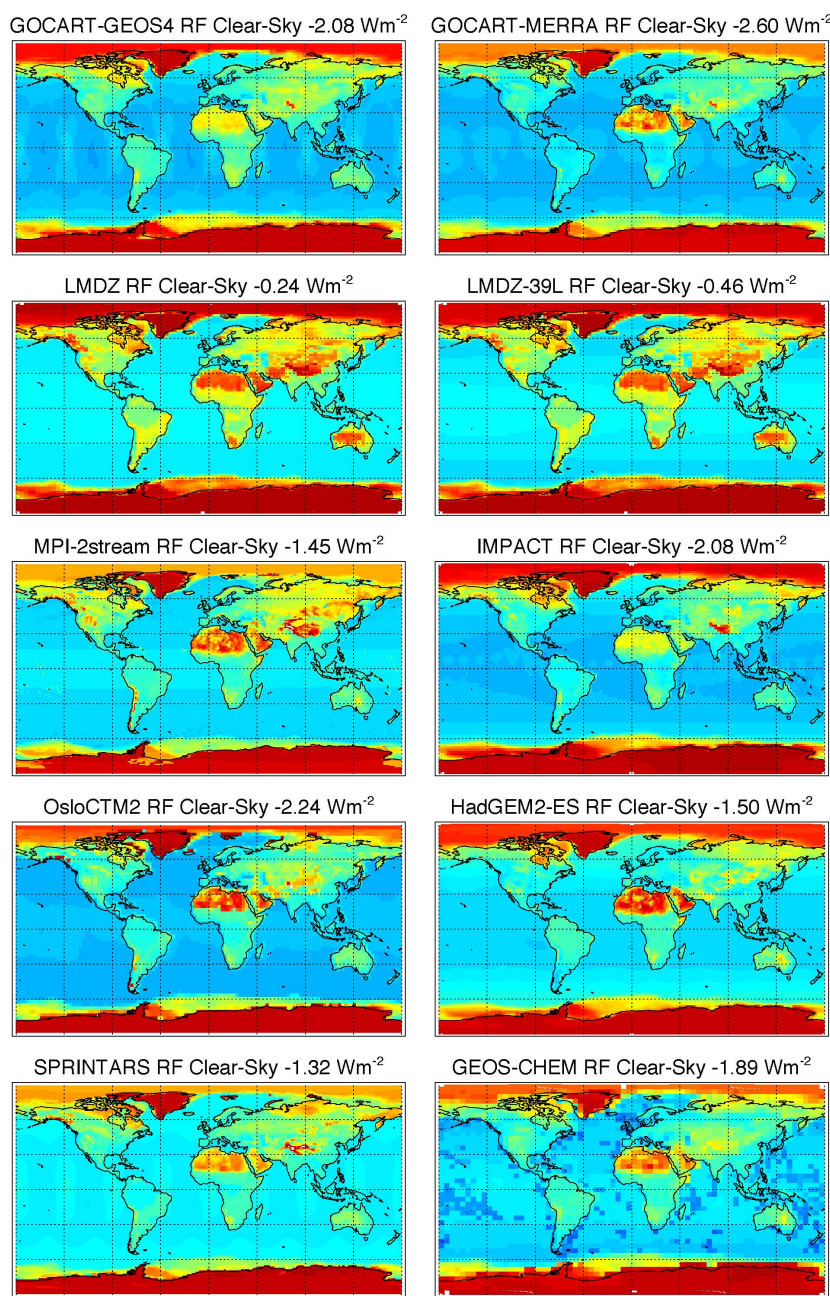

LMDZ-39L RF Clear-Sky - $0.46 \mathrm{Wm}^{-2}$

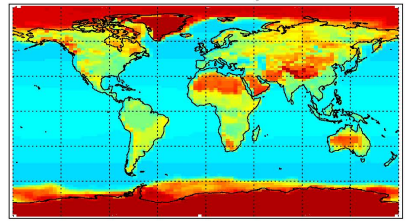

IMPACT RF Clear-Sky - $2.08 \mathrm{Wm}^{-2}$

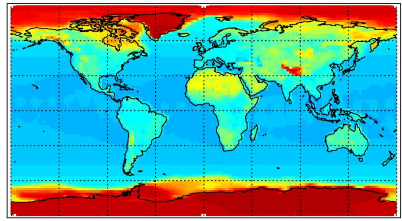

HadGEM2-ES RF Clear-Sky $-1.50 \mathrm{Wm}^{-2}$

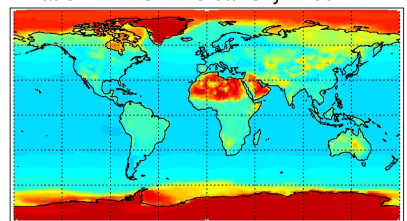

GEOS-CHEM RF Clear-Sky $-1.89 \mathrm{Wm}^{-2}$

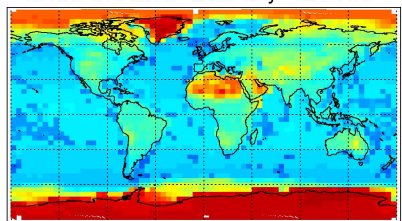

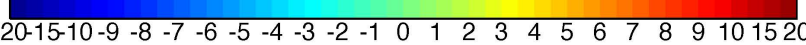
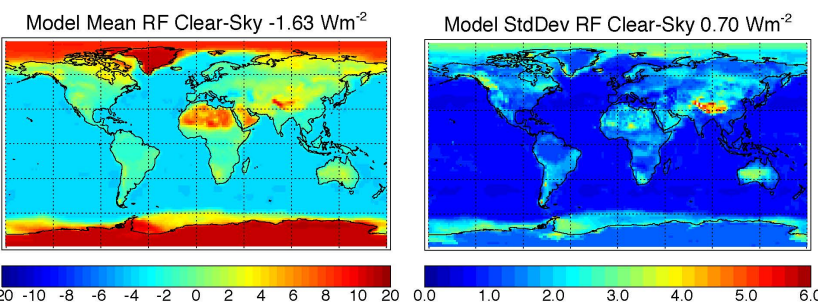

Fig. 8. Annual mean short-wave clear-sky top-of-atmosphere radiative forcing between experiments with $\mathrm{AOD}=0.2$ and $\mathrm{AOD}=0.0$ distributed over the lowest two kilometers, holding SSA $=0.8$ and $\mathrm{ANG}=1.0$ constant $($ FIX3-FIX0). 

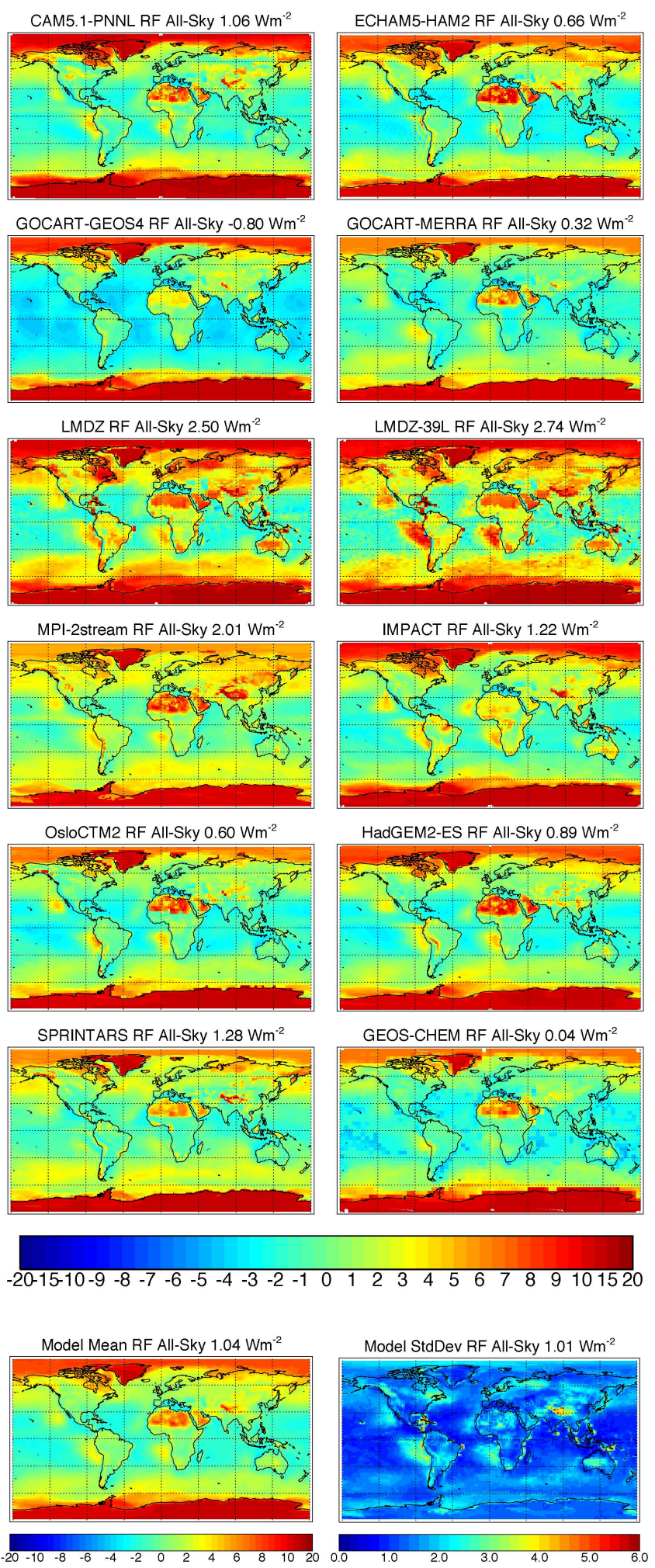

Fig. 9. Annual mean short-wave all-sky top-of-atmosphere radiative forcing between experiments with $\mathrm{AOD}=0.2$ and $\mathrm{AOD}=0.0$ distributed over the lowest two kilometers, holding SSA $=0.8$ and $\mathrm{ANG}=1.0$ constant (FIX3-FIX0).
As for the scattering case, the OsloCTM2, LMDZ and LMDZ-39L models show the largest clear-sky atmospheric radiative forcing $\left(17.77,17.92\right.$ and $17.72 \mathrm{Wm}^{-2}$, respectively, compared to the $16.17 \mathrm{Wm}^{-2}$ mean of the other models). While this strong absorption leads to fairly positive clear-sky TOA radiative forcings for the LMDZ models, in OsloCTM2 it is more than balanced by strong scattering, resulting in one of the most negative clear-sky forcings.

Clouds reduce the atmospheric radiative forcing in the all-sky global mean by $12 \%$. Regionally, low-level clouds can also enhance atmospheric absorption through increase of path-lengths, as evident in the atmospheric radiative forcings in models with extended areas of stratocumulus clouds in Fig. 11.

The relative standard deviation in atmospheric radiative forcing across models is with $7 \%$ clear-sky and $7 \%$ all-sky comparably small.

It should be re-iterated that the reduction of the single scattering albedo to SSA $=0.8$ in experiment FIX3 implies still significant effects of scattering, as evident in the negative TOA forcings over dark surface areas. Analysing the difference between experiments FIX3 and FIX2 provides a better insight into the representation and effects of aerosol absorption across the models.

Subtraction of the scattering case isolates the effect of absorption and shifts clear-sky and all-sky radiative forcings well into positive regimes (Figs. 12 and 13). Annual model means are $5.48 \mathrm{Wm}^{-2}$ clear-sky and $5.51 \mathrm{Wm}^{-2}$ all-sky.

As expected, atmospheric radiative forcings are very similar between the FIX3-FIX0 (scattering and absorption) and FIX3-FIX2 (absorption) scenarios (Figs. 10, 11, 14, 15). A notable exception is the reduction in atmospheric radiative forcings for the models that showed considerable absorption in the scattering only experiment (LMDZ, LMDZ-39L, OsloCTM2).

The results of AeroCom Prescribed for aerosol layers with an optical depth of $\mathrm{AOD}=0.2$ prescribed over the lowest $2 \mathrm{~km}$ are summarised for the three analysed scenarios, scattering, scattering and absorption, absorption, in Fig. 16.

Even for the purely scattering case (Fig. 16a), significant forcing diversity exists, with relative standard deviations of $7 \%$ clear-sky and $12 \%$ all sky.

The three models with significant enhancement of molecular scattering in the scattering scenario (LMDZ, LMDZ-39L, OsloCTM2) also show the strongest atmospheric radiative forcing in the two other scenarios including aerosol absorption.

For the case of scattering and absorption (Fig. 16b), the positive forcing contributions from scattering and negative contributions from absorption almost balance. The resulting TOA radiative forcings are with $-1.63 \mathrm{Wm}^{-2}$ small but negative for clear-sky and with $1.04 \mathrm{Wm}^{-2}$ small but positive for all-sky conditions, with increased absolute standard deviations of 0.70 and $1.01 \mathrm{Wm}^{-2}$ respectively, corresponding to 

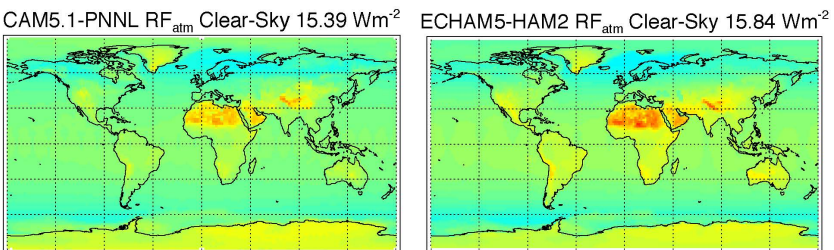

GOCART-GEOS4 $\mathrm{RF}_{\text {atm }}$ Clear-Sky $15.03 \mathrm{Wm}^{-2}$
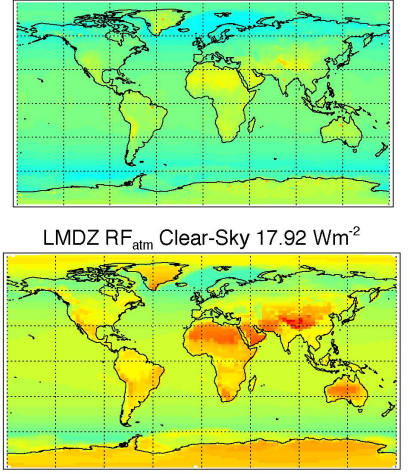

MPI-2stream $\mathrm{RF}_{\text {atm }}$ Clear-Sky $15.78 \mathrm{Wm}^{-2}$

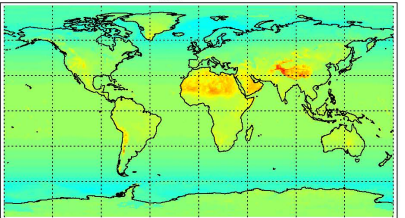

OsloCTM2 $\mathrm{RF}_{\text {atm }}$ Clear-Sky $17.77 \mathrm{Wm}^{-2}$

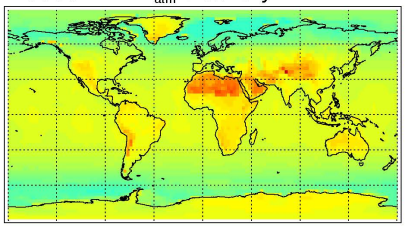

SPRINTARS RF ${ }_{\text {atm }}$ Clear-Sky $15.71 \mathrm{Wm}^{-2}$
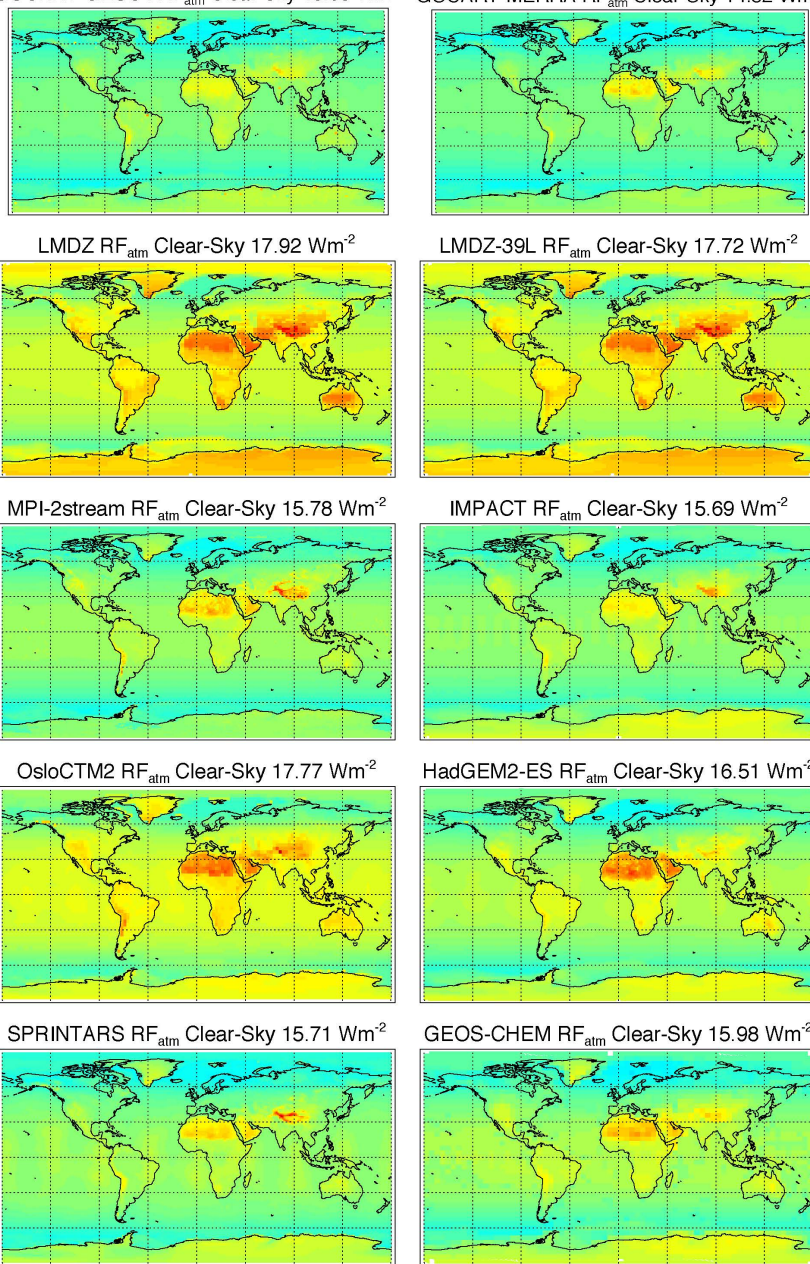

LMDZ-39L RF $F_{\text {atm }}$ Clear-Sky $17.72 \mathrm{Wm}^{-2}$

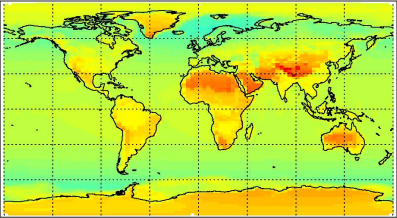

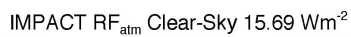

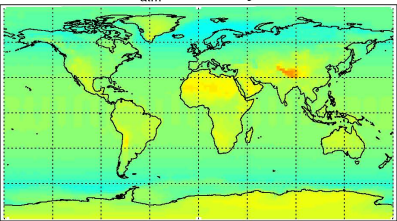

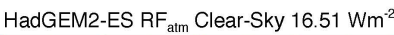

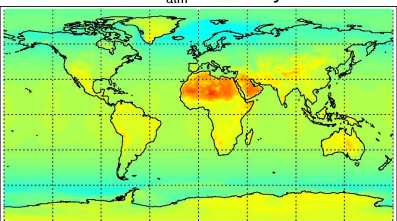

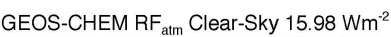
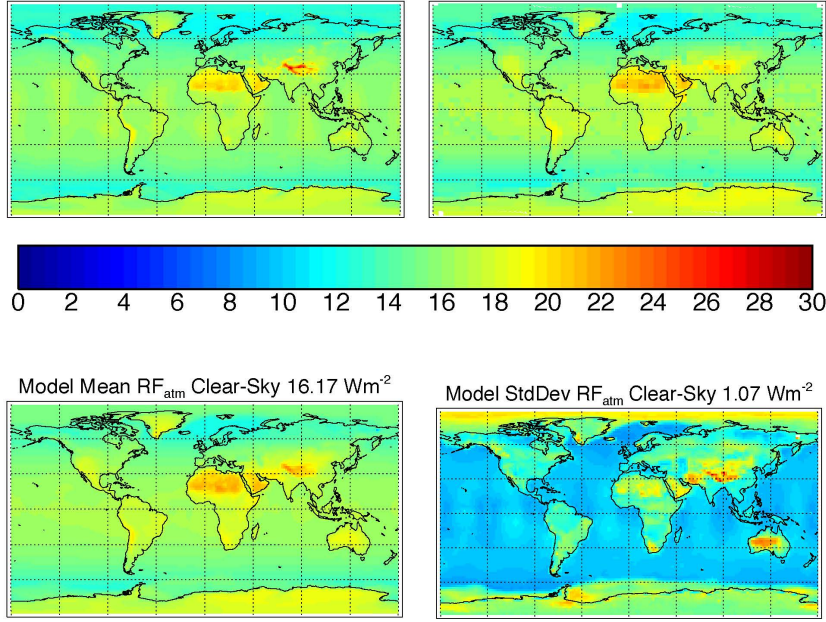

$\begin{array}{llllllllllll}2 & 5 & 7 & 10 & 12 & 15 & 17 & 20 & 22 & 25 & 27 & 30\end{array}$

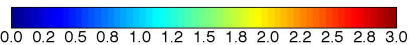

Fig. 10. Annual mean short-wave clear-sky atmospheric radiative forcing (absorption) between experiments with $\mathrm{AOD}=0.2$ and $\mathrm{AOD}=0.0$ distributed over the lowest two kilometers, holding $\mathrm{SSA}=0.8$ and $\mathrm{ANG}=1.0$ constant $(\mathrm{FIX} 3-\mathrm{FIX} 0)$.
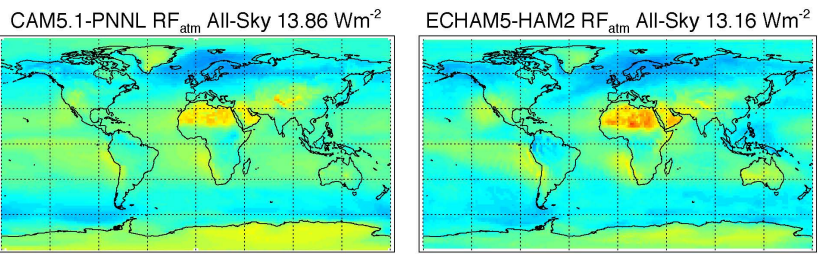

GOCART-GEOS4 $\mathrm{RF}_{\text {atm }}$ All-Sky $14.28 \mathrm{Wm}^{-2}$
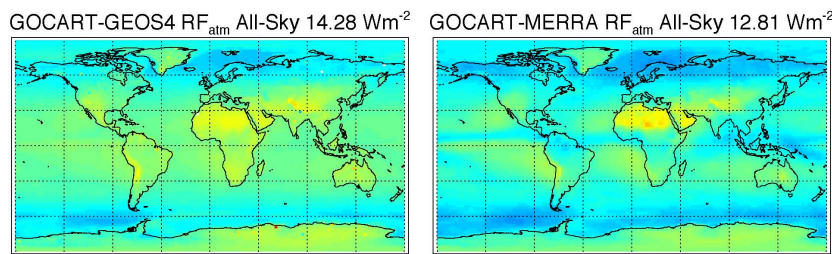

$\mathrm{LMDZ} \mathrm{RF}_{\text {atm }}$ All-Sky $15.95 \mathrm{Wm}^{-2}$

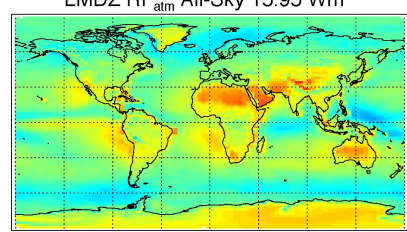

MPI-2stream $\mathrm{RF}_{\text {atm }}$ All-Sky $15.04 \mathrm{Wm}^{-2}$

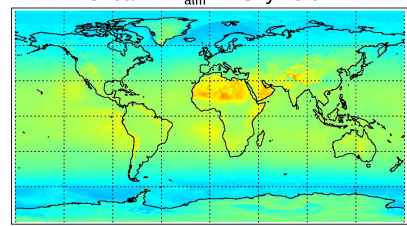

OsloCTM2 $\mathrm{RF}_{\text {atm }}$ All-Sky $14.07 \mathrm{Wm}^{-2}$
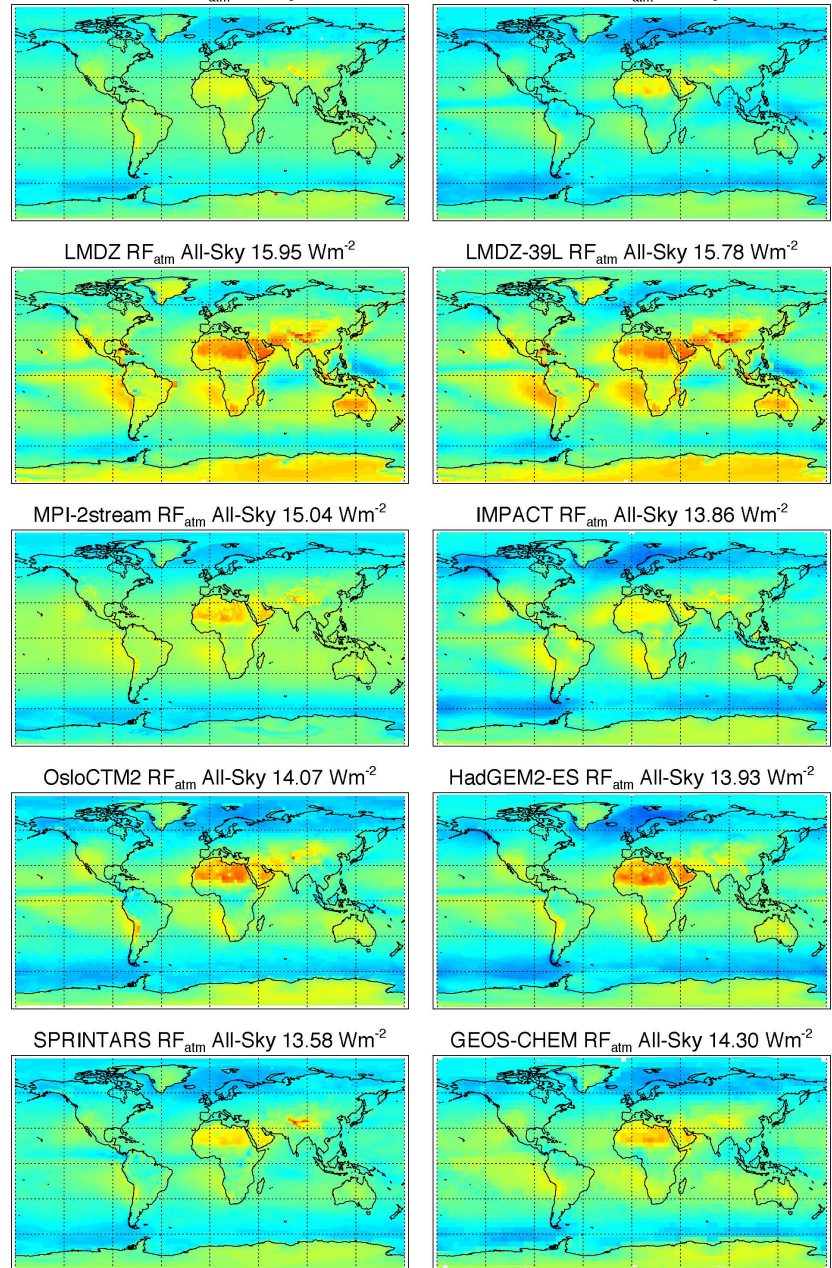

IMPACT RF atm All-Sky $13.86 \mathrm{Wm}^{-2}$

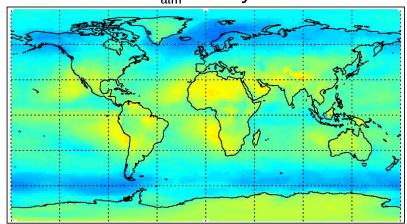

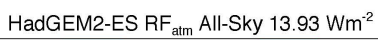

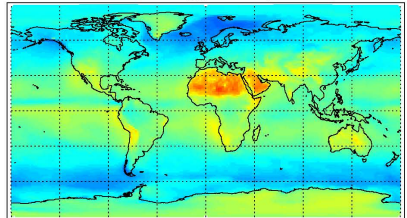

GEOS-CHEM RF atm All-Sky $14.30 \mathrm{Wm}^{-2}$
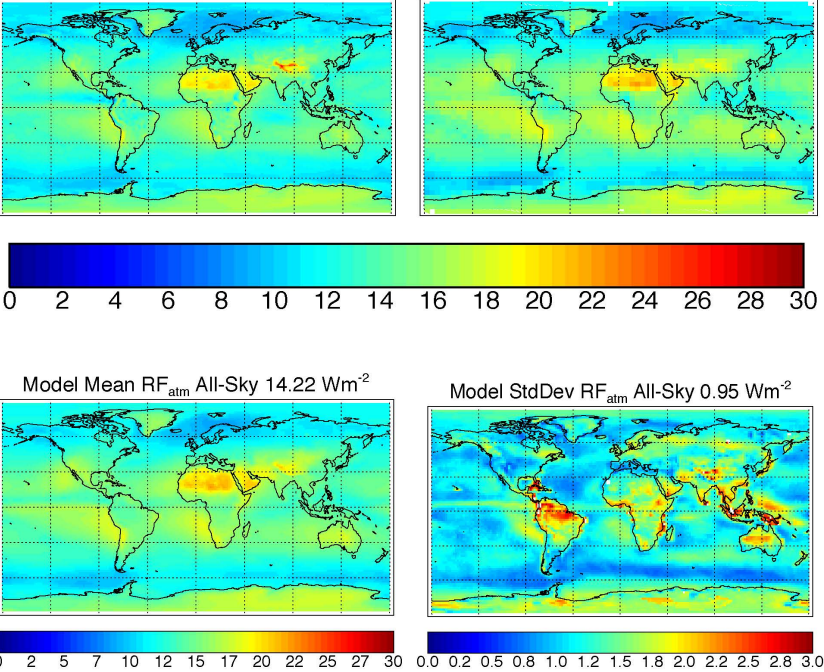

Fig. 11. Annual mean short-wave all-sky atmospheric radiative forcing (absorption) between experiments with $\mathrm{AOD}=0.2$ and $\mathrm{AOD}=0.0$ distributed over the lowest two kilometers, holding $\mathrm{SSA}=0.8$ and $\mathrm{ANG}=1.0$ constant $(\mathrm{FIX} 3-\mathrm{FIX} 0)$. 

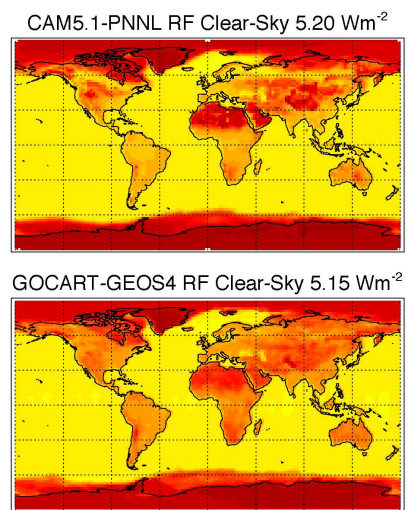

LMDZ RF Clear-Sky $6.25 \mathrm{Wm}^{-2}$

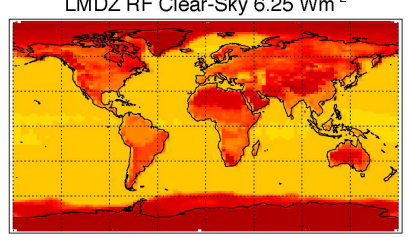

MPI-2stream RF Clear-Sky $5.10 \mathrm{Wm}^{-2}$
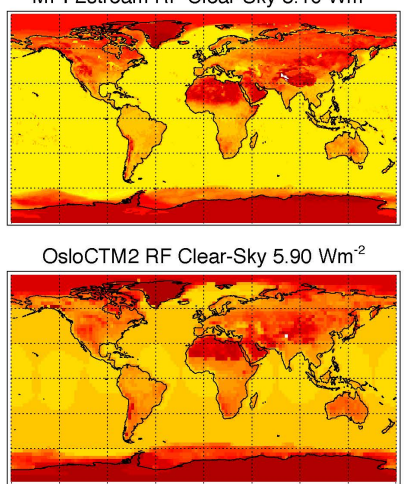

SPRINTARS RF Clear-Sky $4.98 \mathrm{Wm}^{-2}$
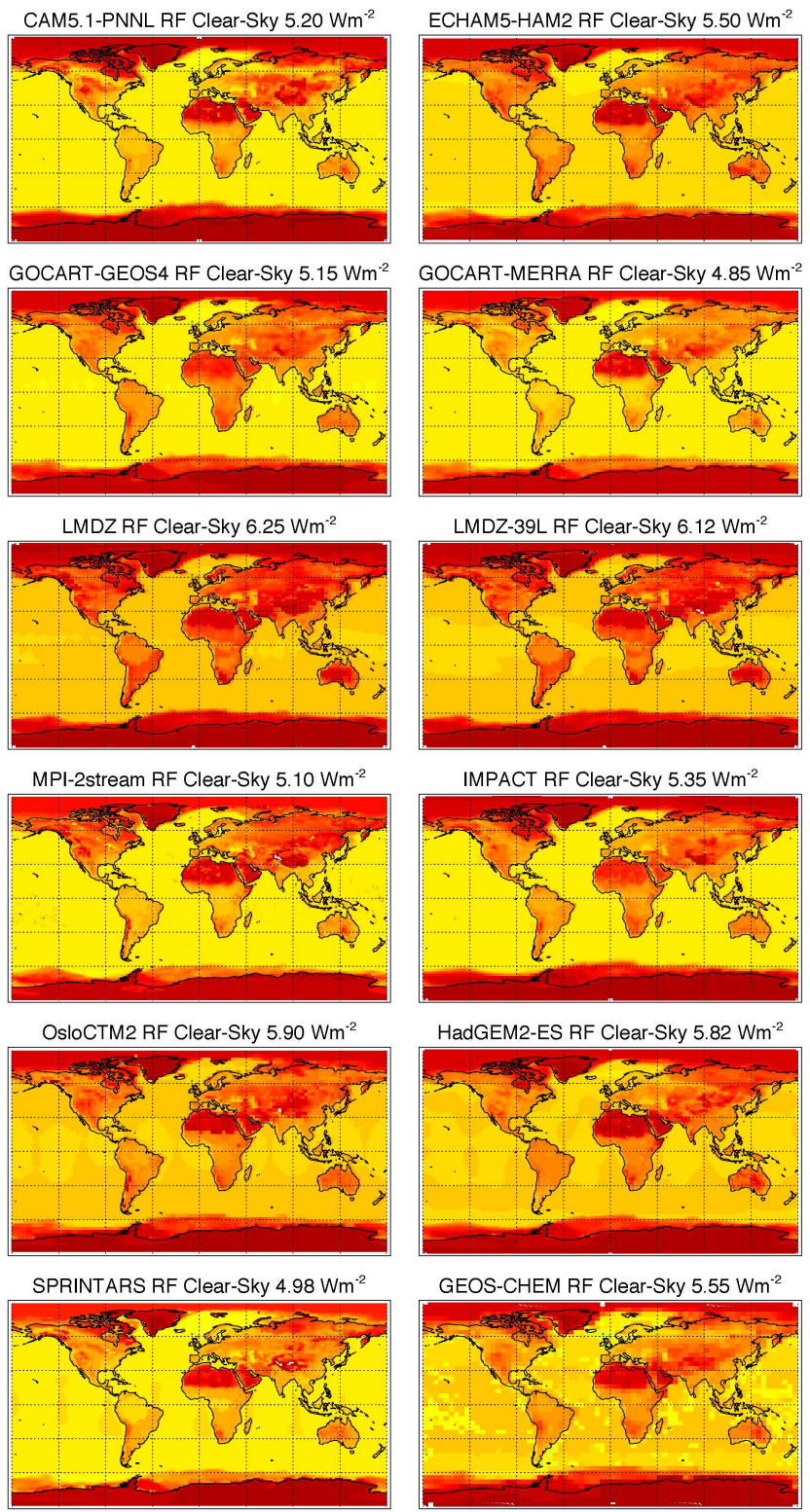

GOCART-MERRA RF Clear-Sky $4.85 \mathrm{Wm}^{-2}$

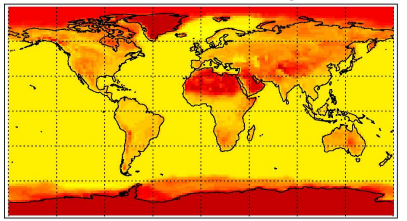

LMDZ-39L RF Clear-Sky $6.12 \mathrm{Wm}^{-2}$

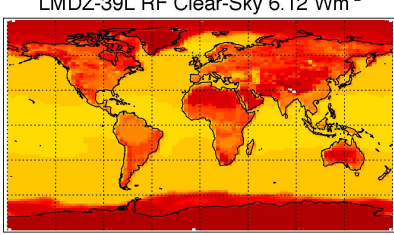

IMPACT RF Clear-Sky $5.35 \mathrm{Wm}^{-2}$

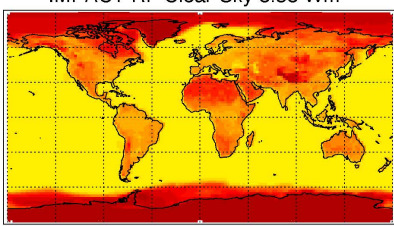

HadGEM2-ES RF Clear-Sky $5.82 \mathrm{Wm}^{-2}$

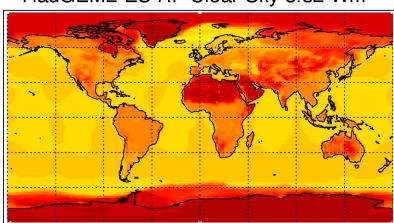

GEOS-CHEM RF Clear-Sky $5.55 \mathrm{Wm}^{-2}$

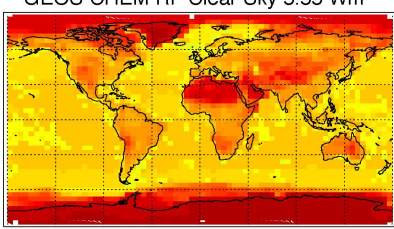

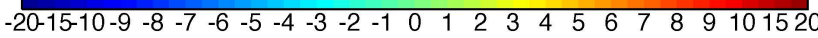
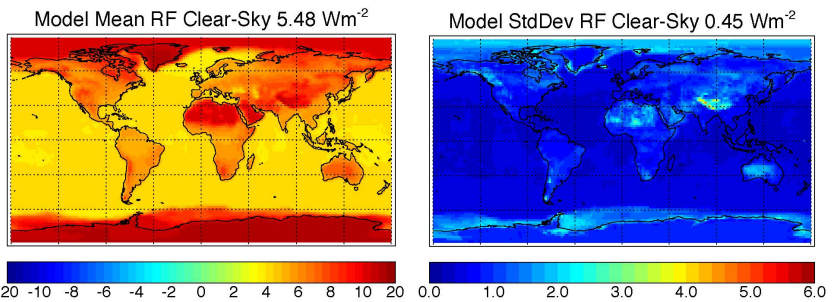

Fig. 12. Annual mean short-wave clear-sky top-of-atmosphere radiative forcing $(\mathrm{RF})$ with $\mathrm{AOD}=0.2$ distributed over the lowest two kilometers between experiments with $\mathrm{SSA}=0.8$ and $\mathrm{SSA}=1.0$ with holding $\mathrm{ANG}=1.0$ constant (FIX3-FIX2).
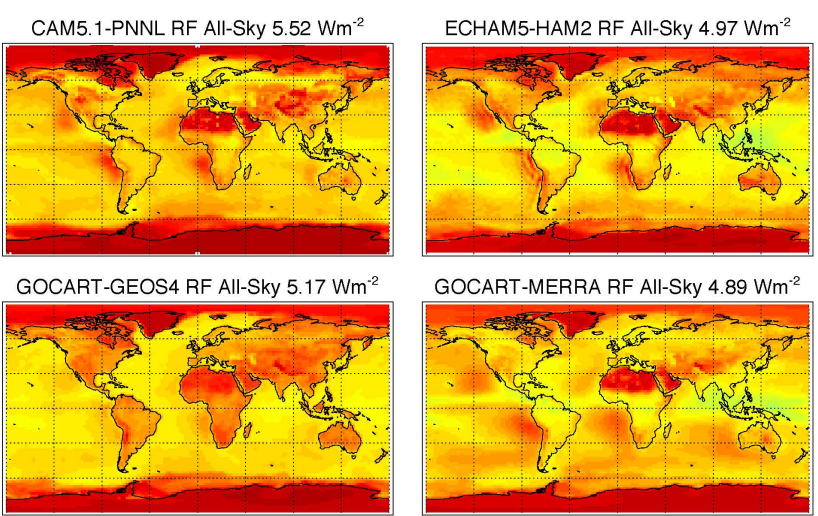

LMDZ RF All-Sky $6.62 \mathrm{Wm}^{-2}$

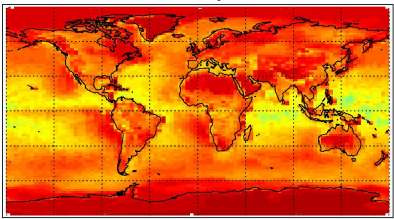

MPI-2stream RF All-Sky $6.04 \mathrm{Wm}^{-2}$

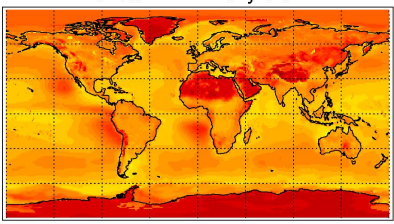

OsloCTM2 RF All-Sky $5.10 \mathrm{Wm}^{-2}$

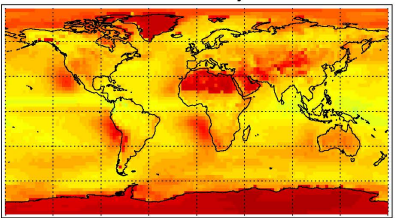

SPRINTARS RF All-Sky $5.31 \mathrm{Wm}^{-2}$
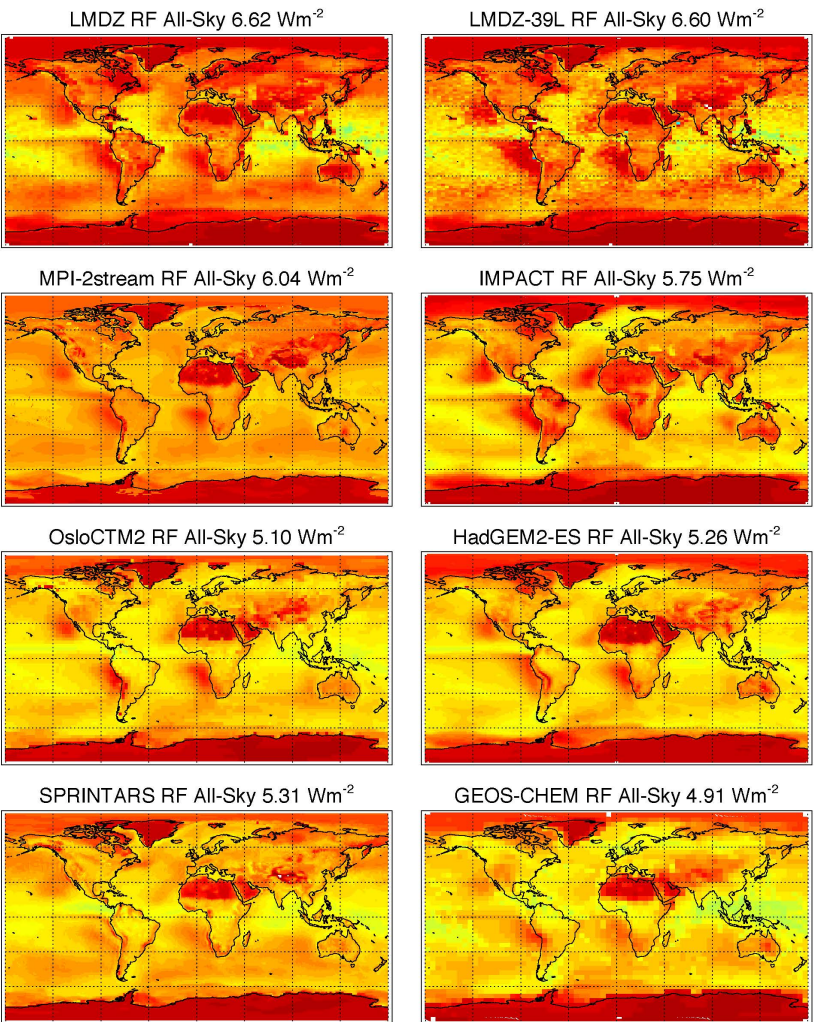

IMPACT RF All-Sky $5.75 \mathrm{Wm}^{-2}$

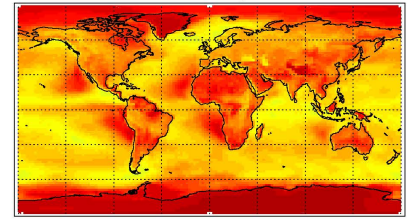

HadGEM2-ES RF All-Sky $5.26 \mathrm{Wm}^{-2}$

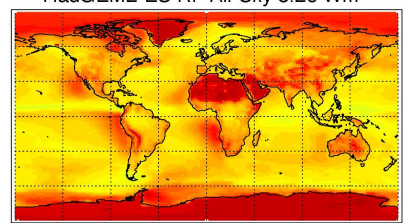

GEOS-CHEM RF All-Sky $4.91 \mathrm{Wm}^{-2}$

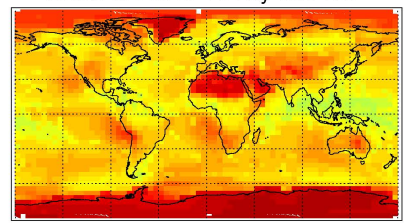

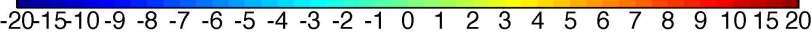
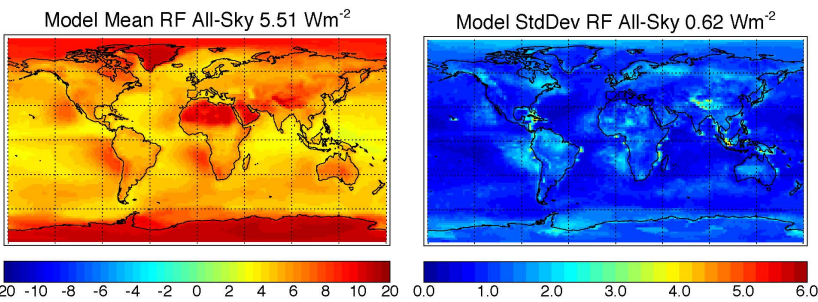

Fig. 13. Annual mean short-wave all-sky top-of-atmosphere radiative forcing $(\mathrm{RF})$ with $\mathrm{AOD}=0.2$ distributed over the lowest two kilometers between experiments with $\mathrm{SSA}=0.8$ and $\mathrm{SSA}=1.0$ with holding $\mathrm{ANG}=1.0$ constant (FIX3-FIX2). 


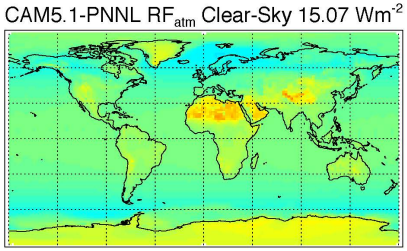

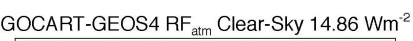
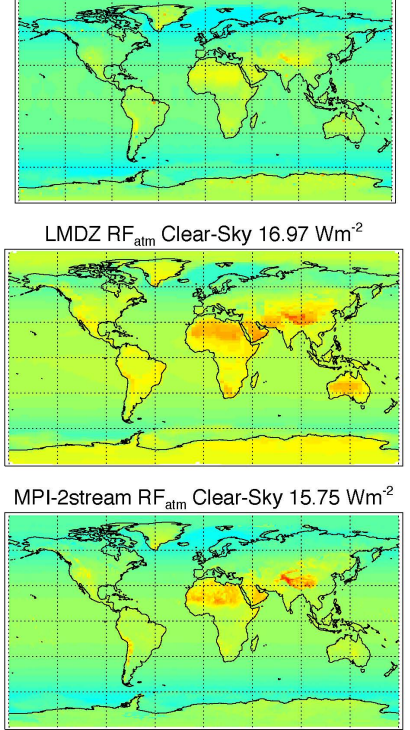

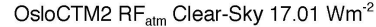

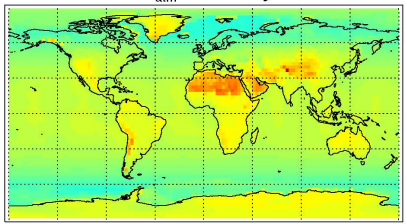

SPRINTARS RF $\mathrm{atm}_{\mathrm{atm}}$ Clear-Sky $15.29 \mathrm{Wm}^{-2}$
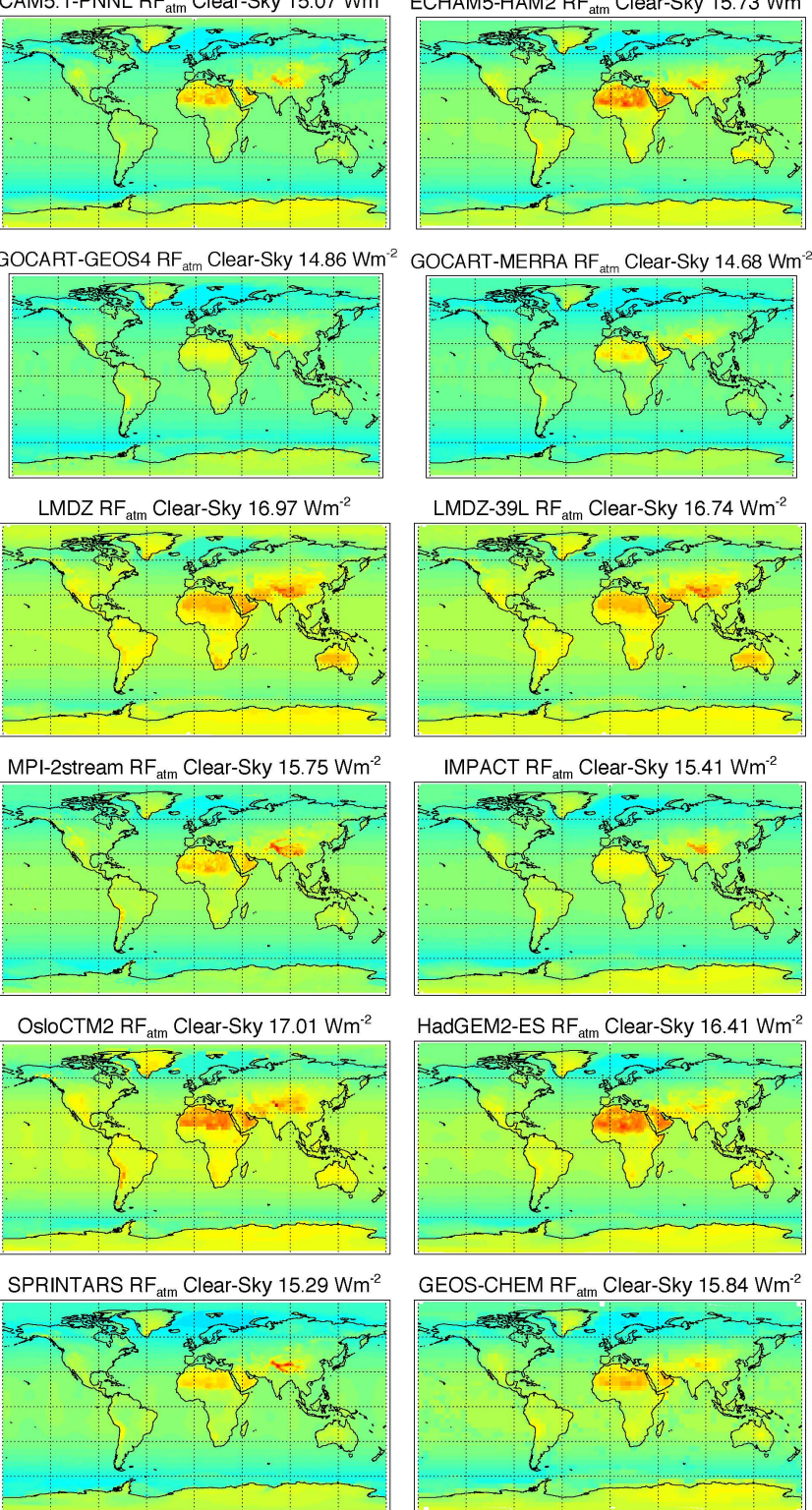

LMDZ-39L RF atm $_{\text {Clear-Sky } 16.74 \mathrm{Wm}^{-2}}$

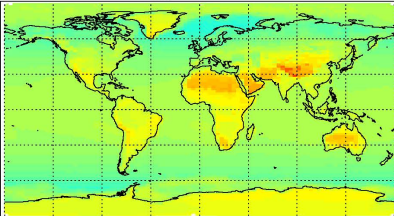

IMPACT RF $_{\text {atm }}$ Clear-Sky $15.41 \mathrm{Wm}^{-2}$

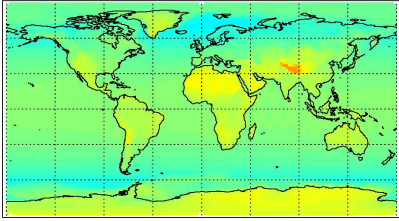

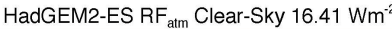

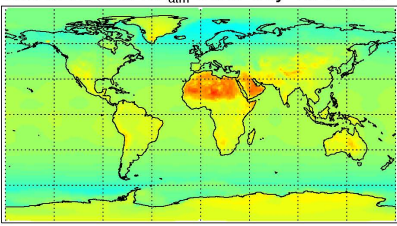

GEOS-CHEM RF ${ }_{\text {atm }}$ Clear-Sky $15.84 \mathrm{Wm}^{-2}$
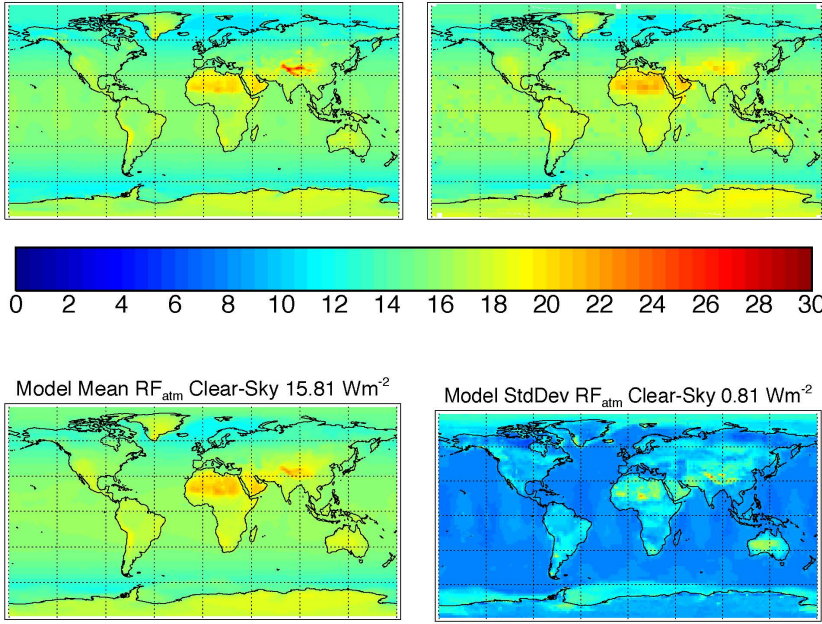

Fig. 14. Annual mean short-wave clear-sky atmospheric radiative forcing (absorption) between experiments with SSA $=0.8$ and $\mathrm{SSA}=1.0$ with holding $\mathrm{ANG}=1.0$ constant (FIX3-FIX2).
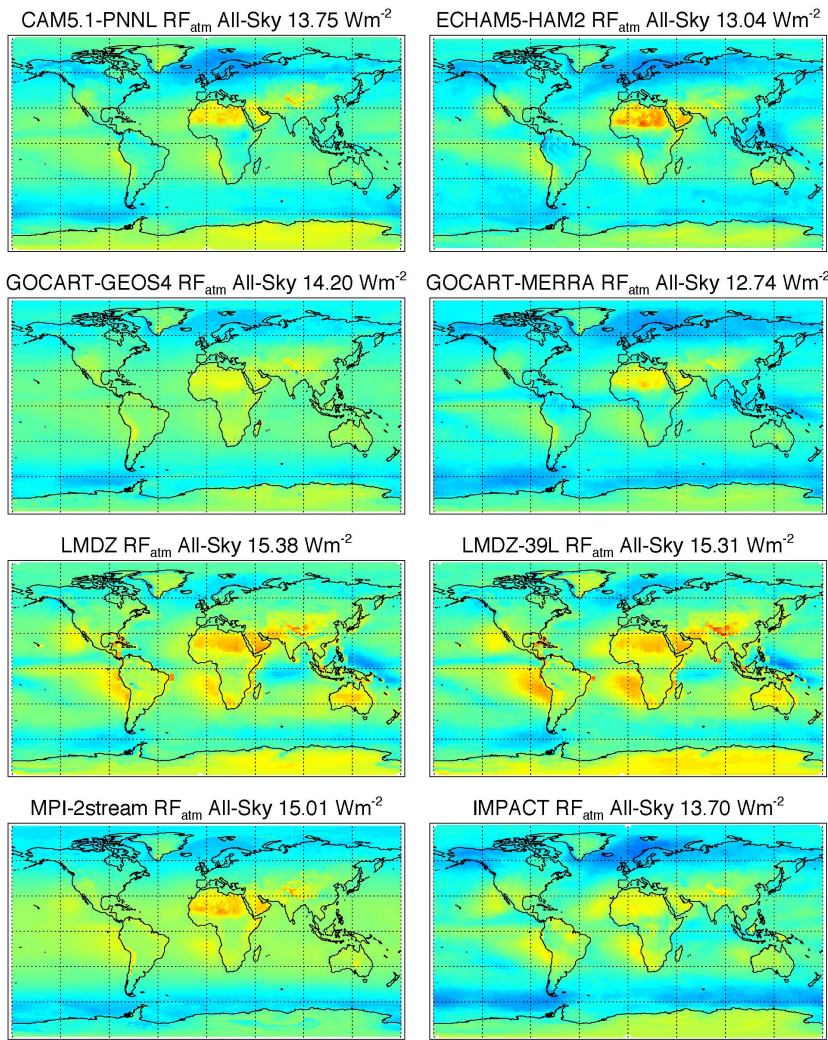

OsloCTM2 $\mathrm{RF}_{\text {atm }}$ All-Sky 13.72 $\mathrm{Wm}^{-2}$
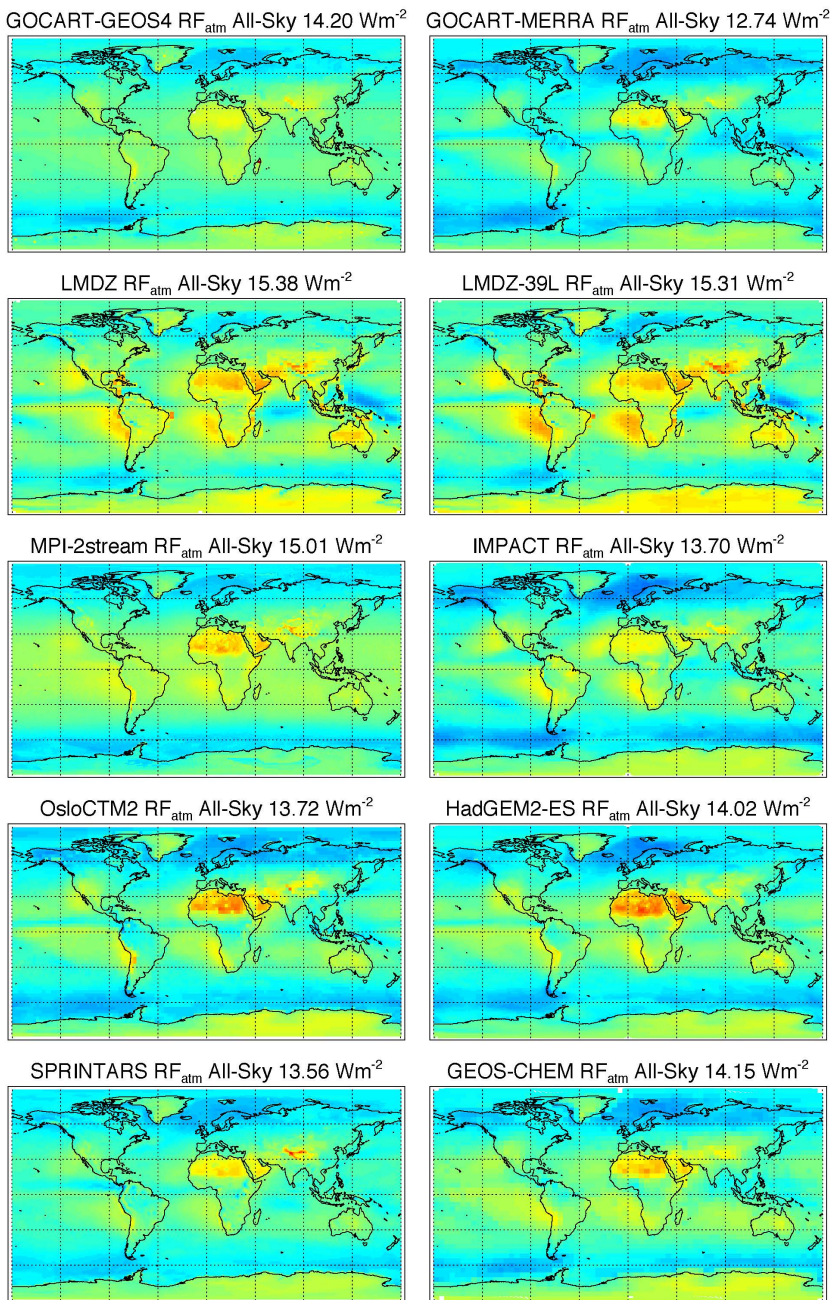

LMDZ-39L RF $\mathrm{R}_{\text {atm }}$ All-Sky $15.31 \mathrm{Wm}^{-2}$

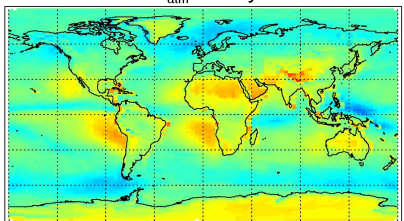

IMPACT RF $\mathrm{F}_{\text {atm }}$ All-Sky $13.70 \mathrm{Wm}^{-2}$

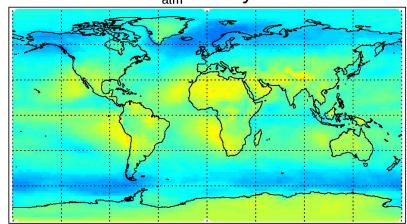

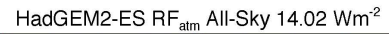

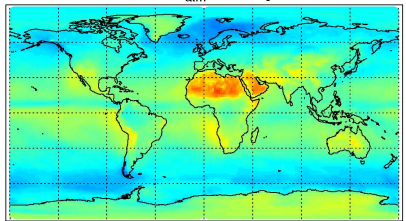

GEOS-CHEM RF ${ }_{\text {atm }}$ All-Sky $14.15 \mathrm{Wm}^{-2}$
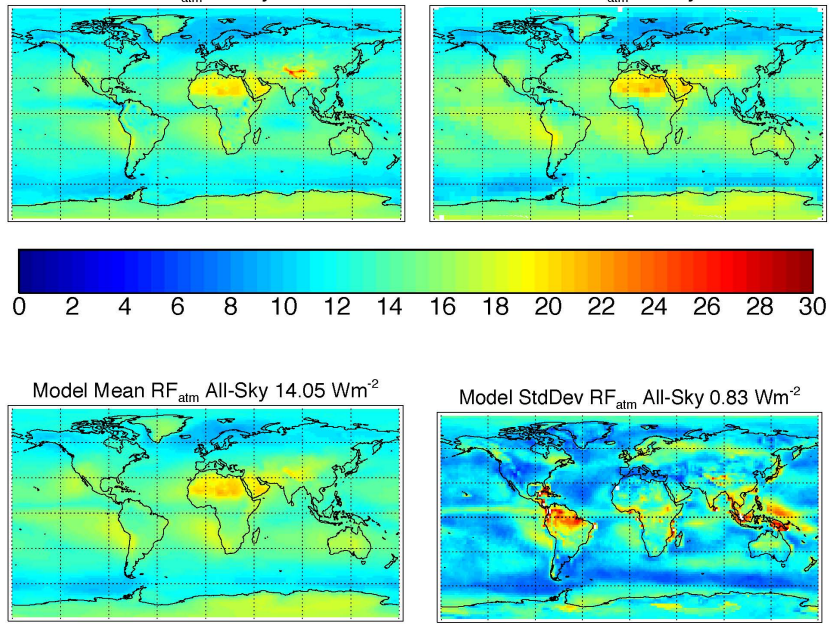

Fig. 15. Annual mean short-wave all-sky atmospheric radiative forcing (absorption) between experiments with SSA $=0.8$ and $\mathrm{SSA}=1.0$ with holding $\mathrm{ANG}=1.0$ constant (FIX3-FIX2). 
large relative standard deviations of $43 \%$ and $97 \%$ respectively.

Interestingly, the variability of the TOA forcings is lower for the absorbing scenario after subtraction of the scattering case (Fig. 16c), both in terms of the absolute standard deviation ( 0.45 clear-sky and $0.62 \mathrm{Wm}^{-2}$ all-sky) and relative standard deviations ( $8 \%$ clear-sky and $11 \%$ all-sky).

\subsection{Attribution of forcing differences to host model effects}

In this section we focus on the attribution of the simulated forcing differences to the underlying differences in the host model configurations.

As a first step, the total effect of clouds on aerosol radiative forcing is quantified through the difference of all-sky minus clear-sky radiative forcings, shown for the scattering case FIX2-FIX0 as multi-model mean and standard deviation in Fig. 17. In the global mean, clouds shield the prescribed scattering aerosol layer from radiation and make the TOA radiative forcing more positive by $2.64 \mathrm{Wm}^{-2}$. As expected, positive all-clear sky TOA forcing perturbations as well as its standard deviation are largest in areas of high cloud-fractions.

For the case with scattering and absorption (FIX3-FIX0) shown in Fig. 18, the additional effect of absorption enhancement for absorbing aerosol above low-level clouds enhances the forcing perturbation of clouds to $2.67 \mathrm{Wm}^{-2}$. The intermodel variability is largest for the stratocumulus decks off the west coasts of the Americas and Africa, that are highly variable across models. Note that even for the case with absorption, the dominant contribution to the positive forcing perturbation of clouds stems from the reduction of the negative high-latitude forcings over dark ocean surfaces.

While the preceding analysis provides valuable insight into the overall effects of clouds on aerosol radiative forcing, it does not provide an answer to a key question in the assessment of aerosol radiative forcing uncertainties: how much does the inter-model spread in host-model properties, including cloud properties, affect aerosol radiative forcing?

To investigate this question in the absence of experiments with prescribed changes in cloud or surface properties, we explore the sensitivity of TOA SW forcing to local variations in surface or cloudy albedo across the models.

Cloudy albedo is defined here as the TOA albedo due to clouds:

$A_{\text {cld }}=\frac{F_{\text {all }}^{\uparrow}-F_{\text {clr }}^{\uparrow}}{F_{\text {all }}^{\downarrow}}$,

where arrows indicate down and upwelling radiative fluxes $(F)$, defined at TOA and all-or clear-skies, as indicated. Likewise, surface albedo is defined as the ratio of up- to down-welling flux at the surface.

Seeking to separate the influence of surface albedo and clouds, we decompose the host model error $\Delta \mathrm{RF}_{\mathrm{TOA}}^{\text {all }}$ as total differential, which allows us to compare the relative magnitude of the individual host model effects:

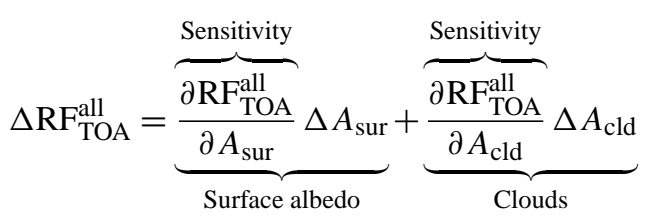

where $\Delta$ indicate the inter-model variabilities, $\mathrm{RF}_{\mathrm{TOA}}^{\mathrm{all}}$ is the TOA all-sky radiative forcing, $A_{\text {sur }}$ the surface albedo and $A_{\text {cld }}$ the cloudy albedo, as defined above.

For this analysis, the models have been remapped to a common Gaussian grid with $1.875^{\circ} \times 1.875^{\circ}$ resolution. Various interpolation schemes were considered (e.g. nearest neighbour, linear or distance-weighted) but the choice did not significantly alter our findings. As ECHAM5-HAM2 does not provide clear-sky TOA upward radiative fluxes it has been excluded from this analysis.

We define sensitivity as in Eq. (2) as the slope of a regression of TOA SW forcing against either cloud or surface albedo (Fig. 19), with each data pair representing a different model. In these plots, we use hatching to indicate regions where the sign of the sensitivity may change (due to removing a model). In the plots of forcing errors, we use hatching to indicate where the variation (due to removing a model) in errors is less than $30 \%$.

In the slope plots, the hatching tends to occur for small (absolute) values. These are the areas where sign of the slope is uncertain. In the error plots, the hatching occurs for large values. These are the areas where the uncertainty in the error is small. The conclusion for both types of plot is essentially the same: wherever we see a strong signal, it also tends to be a reliable signal.

Variation in surface albedo across models is mainly due to sea ice, land ice and desert surfaces as can be seen in the Standard Deviation row of Fig. 19. The surface albedo sensitivity for FIX2-FIX0 shown in Fig. 19 is broadly speaking positive (increasing forcing with increasing surface albedo). Unambiguous positive albedo sensitivity is found in many places, notably in the Arctic and Antarctic sea ice regions, Australia, Saudi Arabia and Eurasia as well as northern North America and southern South America.

We evaluate the forcing error owing to surface diversity as the albedo sensitivity times the albedo perturbation, which is expressed as inter-model standard deviation of the surface albedo for each grid-box. For the scattering case FIX2-FIX0, the surface albedo errors are of the order of about $1 \mathrm{~W}^{-2}$, with regional maxima in high surface albedo areas with large inter-model variability.

The impact of surface albedo on the surface albedo sensitivity increases substantially when considering the absorptive case FIX3-FIX0 but sensitivity patterns remain largely the same. The surface albedo forcing error shows similar patterns as in the scattering case but regional maxima are of the 
(a)

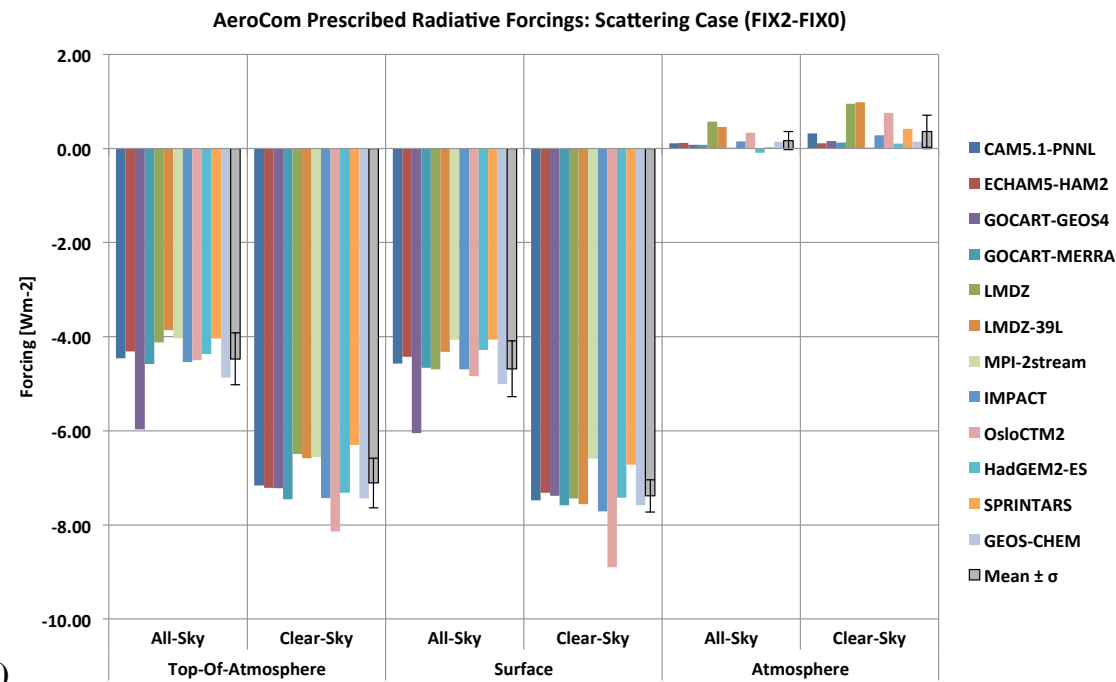

(b)
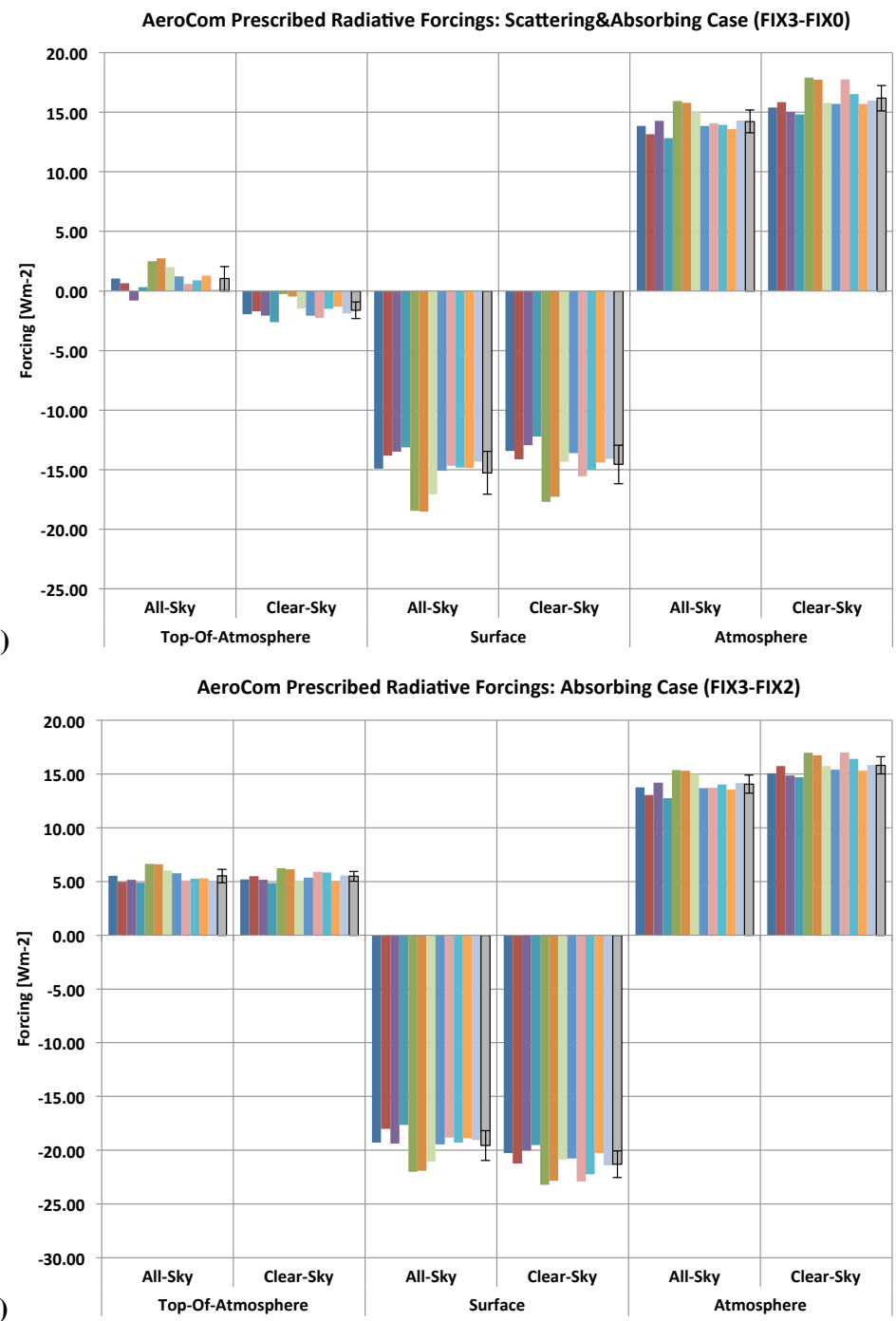

Fig. 16. Annual global-mean short-wave clear-sky and all-sky top-of-atmosphere, surface and atmospheric radiative forcing (absorption) between (a) experiments with $\mathrm{AOD}=0.2$ and $\mathrm{AOD}=0.0$ for $\mathrm{SSA}=1.0$, (b) experiments with $\mathrm{AOD}=0.2$ and $\mathrm{AOD}=0.0$ for $\mathrm{SSA}=0.8$ and (c) experiments with $\mathrm{AOD}=0.2$ for $\mathrm{SSA}=0.8$ and $\mathrm{SSA}=1.0$. 
Table 3. Summary of annual-global mean radiative forcings for the FIX0,FIX2,FIX3 and the FIX1 intercomparison experiments.

\begin{tabular}{|c|c|c|c|c|c|c|c|}
\hline & $\begin{array}{l}\text { Model } \\
\text { Units }\end{array}$ & $\begin{array}{c}\mathrm{RF}_{\mathrm{TOA}}^{\text {all }} \\
{\left[\mathrm{Wm}^{-2}\right]}\end{array}$ & $\begin{array}{c}\mathrm{RF}_{\mathrm{TOA}}^{\mathrm{clr}} \\
{\left[\mathrm{Wm}^{-2}\right]}\end{array}$ & $\begin{array}{r}\mathrm{RF}_{\mathrm{TOA}}^{\text {all }} / \mathrm{AOD} \\
{\left[\mathrm{Wm}^{-2}\right]}\end{array}$ & $\begin{array}{r}\mathrm{RF}_{\mathrm{atm}}^{\mathrm{all}} \\
{\left[\mathrm{Wm}^{-2}\right]}\end{array}$ & $\begin{array}{r}\mathrm{RF}_{\mathrm{atm}}^{\mathrm{clr}} \\
{\left[\mathrm{Wm}^{-2}\right]}\end{array}$ & $\begin{array}{r}\mathrm{RF}_{\mathrm{atm}}^{\mathrm{all}} / \mathrm{AAOD} \\
{\left[\mathrm{Wm}^{-2}\right]}\end{array}$ \\
\hline \multirow{15}{*}{ 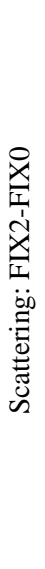 } & CAM5.1-PNNL & -4.46 & -7.16 & -22.30 & 0.11 & 0.32 & \\
\hline & ECHAM5-HAM2 & -4.31 & -7.21 & -21.55 & 0.12 & 0.11 & \\
\hline & GOCART-GEOS4 & -5.97 & -7.22 & -29.85 & 0.08 & 0.16 & \\
\hline & GOCART-MERRA & -4.58 & -7.45 & -22.90 & 0.08 & 0.13 & \\
\hline & LMDZ & -4.12 & -6.49 & -20.60 & 0.57 & 0.95 & \\
\hline & LMDZ-39L & -3.86 & -6.58 & -19.30 & 0.46 & 0.98 & \\
\hline & MPI-2stream & -4.03 & -6.56 & -20.15 & 0.03 & 0.03 & \\
\hline & IMPACT & -4.54 & -7.43 & -22.70 & 0.15 & 0.28 & \\
\hline & OsloCTM2 & -4.50 & -8.14 & -22.50 & 0.34 & 0.76 & \\
\hline & HadGEM2-ES & -4.37 & -7.32 & -21.85 & -0.09 & 0.10 & \\
\hline & SPRINTARS & -4.04 & -6.30 & -20.20 & 0.02 & 0.42 & \\
\hline & GEOS-CHEM & -4.87 & -7.44 & -24.35 & 0.14 & 0.14 & \\
\hline & Mean & -4.47 & -7.11 & -22.43 & 0.17 & 0.36 & \\
\hline & StdDev & 0.55 & 0.53 & 3.05 & 0.19 & 0.34 & \\
\hline & RelStdDev & $12 \%$ & $7 \%$ & $14 \%$ & $115 \%$ & $94 \%$ & \\
\hline \multirow{15}{*}{ 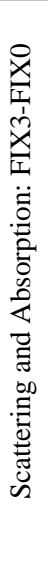 } & CAM5.1-PNNL & 1.06 & -1.96 & 5.30 & 13.86 & 15.39 & 347 \\
\hline & ECHAM5-HAM2 & 0.66 & -1.71 & 3.30 & 13.16 & 15.84 & 329 \\
\hline & GOCART-GEOS4 & -0.80 & -2.08 & -4.00 & 14.28 & 15.03 & 357 \\
\hline & GOCART-MERRA & 0.32 & -2.60 & 1.60 & 12.81 & 14.82 & 320 \\
\hline & LMDZ & 2.50 & -0.24 & 12.50 & 15.95 & 17.92 & 399 \\
\hline & LMDZ-39L & 2.74 & -0.46 & 13.70 & 15.78 & 17.72 & 395 \\
\hline & MPI-2stream & 2.01 & -1.45 & 10.05 & 15.04 & 15.78 & 376 \\
\hline & IMPACT & 1.22 & -2.08 & 6.10 & 13.86 & 15.69 & 347 \\
\hline & OsloCTM2 & 0.60 & -2.24 & 3.00 & 14.07 & 17.77 & 352 \\
\hline & HadGEM2-ES & 0.89 & -1.50 & 4.45 & 13.93 & 16.51 & 348 \\
\hline & SPRINTARS & 1.28 & -1.32 & 6.40 & 13.58 & 15.71 & 340 \\
\hline & GEOS-CHEM & 0.04 & -1.89 & 0.20 & 14.30 & 15.98 & 358 \\
\hline & Mean & 1.04 & -1.63 & 5.22 & 14.22 & 16.17 & 355 \\
\hline & StdDev & 1.01 & 0.70 & 5.07 & 0.95 & 1.07 & 24 \\
\hline & RelStdDev & $97 \%$ & $43 \%$ & $97 \%$ & $7 \%$ & $7 \%$ & $7 \%$ \\
\hline \multirow{15}{*}{ 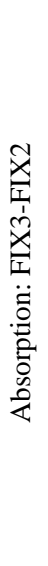 } & CAM5.1-PNNL & 5.52 & 5.20 & 27.60 & 13.75 & 15.07 & 344 \\
\hline & ECHAM5-HAM2 & 4.97 & 5.50 & 24.85 & 13.04 & 15.73 & 326 \\
\hline & GOCART-GEOS4 & 5.17 & 5.15 & 25.85 & 14.20 & 14.86 & 355 \\
\hline & GOCART-MERRA & 4.89 & 4.85 & 24.45 & 12.74 & 14.68 & 319 \\
\hline & LMDZ & 6.62 & 6.25 & 33.10 & 15.38 & 16.97 & 385 \\
\hline & LMDZ-39L & 6.60 & 6.12 & 33.00 & 15.31 & 16.74 & 383 \\
\hline & MPI-2stream & 6.04 & 5.10 & 30.20 & 15.01 & 15.75 & 375 \\
\hline & IMPACT & 5.75 & 5.35 & 28.75 & 13.70 & 15.41 & 343 \\
\hline & OsloCTM2 & 5.10 & 5.90 & 25.50 & 13.72 & 17.01 & 343 \\
\hline & HadGEM2-ES & 5.26 & 5.82 & 26.30 & 14.02 & 16.41 & 351 \\
\hline & SPRINTARS & 7.41 & 4.81 & 37.05 & 12.88 & 15.19 & 322 \\
\hline & GEOS-CHEM & 4.91 & 5.55 & 24.55 & 14.15 & 15.84 & 354 \\
\hline & Mean & 5.51 & 5.48 & 27.56 & 14.05 & 15.81 & 351 \\
\hline & StdDev & 0.62 & 0.45 & 3.08 & 0.83 & 0.81 & 21 \\
\hline & RelStdDev & $11 \%$ & $8 \%$ & $11 \%$ & $6 \%$ & $5 \%$ & $6 \%$ \\
\hline \multirow{7}{*}{ 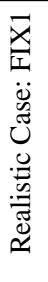 } & ECHAM5-HAM2 & -0.53 & -1.10 & -13.25 & 1.31 & 1.46 & 452 \\
\hline & GOCART-GEOS4 & -1.09 & -1.38 & -27.25 & 1.36 & 1.39 & 469 \\
\hline & GOCART-MERRA & -0.91 & -1.46 & -22.50 & 1.23 & 1.37 & 424 \\
\hline & OsloCTM2 & -0.48 & -1.03 & -12.00 & 1.38 & 1.60 & 476 \\
\hline & Mean & -0.75 & -1.24 & -18.75 & 1.32 & 1.46 & 455 \\
\hline & StdDev & 0.29 & 0.21 & 7.35 & 0.07 & 0.10 & 23 \\
\hline & RelStdDev & $39 \%$ & $17 \%$ & $39 \%$ & $5 \%$ & $7 \%$ & $5 \%$ \\
\hline
\end{tabular}




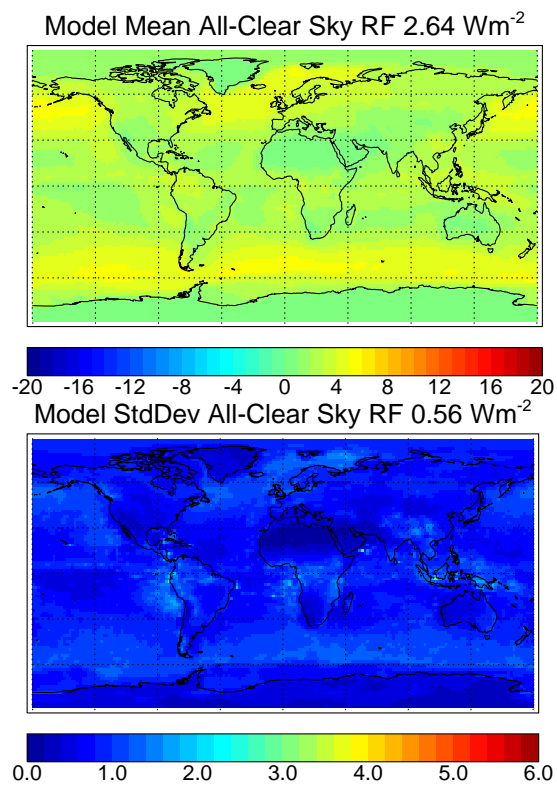

Fig. 17. Annual multi-model mean and standard deviation difference between all-sky and clear-sky top-of-atmosphere radiative forcing between experiments FIX2 and FIX0 with AOD $=0.2$ and $\mathrm{AOD}=0.0$ distributed over the lowest two kilometers, holding $\mathrm{SSA}=1.0$ and $\mathrm{ANG}=1.0$ constant. Model fields have been remapped to a resolution of $1.875^{\circ} \times 1.875^{\circ}$.

order of about $3 \mathrm{~W}^{-2}$ over the high surface albedo areas of Australia, snow-covered high latitudes and sea-ice areas.

Sensitivity to cloudy albedo for the scattering case FIX2FIX0 shows a more complex picture with regions of both positive or negative sensitivity. Note that positive sensitivity regions are generally unambiguous (light hatching), while regions of negative sensitivity generally are less certain. The sign of sensitivity to cloud albedo is often ambiguous in regions of high surface albedo (sea and land ice). Again, the absorbing case FIX3-FIX0 shows the same sensitivity patterns but in starker contrast. Concentrating on the positive sensitivity regions, we see they usually occur off the coast where there are stratocumulus decks. Sensitivity to cloudy albedo may be expected to be positive in most cases: when scattering or weakly absorbing aerosols are hidden below a layer of clouds or when absorbing aerosols are found above clouds. In the case of strongly absorbing aerosol below clouds there is a chance of negative sensitivity. Possibly this is the case for Siberia and high latitudes. Several cases of negative sensitivity over land adjacent to positive sensitivity over ocean can be seen over Australia and Central America. Since our aerosol profiles are fixed, this could be explained if cloud altitudes are higher over land than over ocean.

The cloud albedo forcing errors, again expressed as cloudy albedo sensitivity times the local standard deviation of the cloudy albedo, for the scattering case FIX2-FIX0 are widespread over oceanic regions with large cloud cover, such as the storm-tracks, sub-tropical stratocumulus decks and

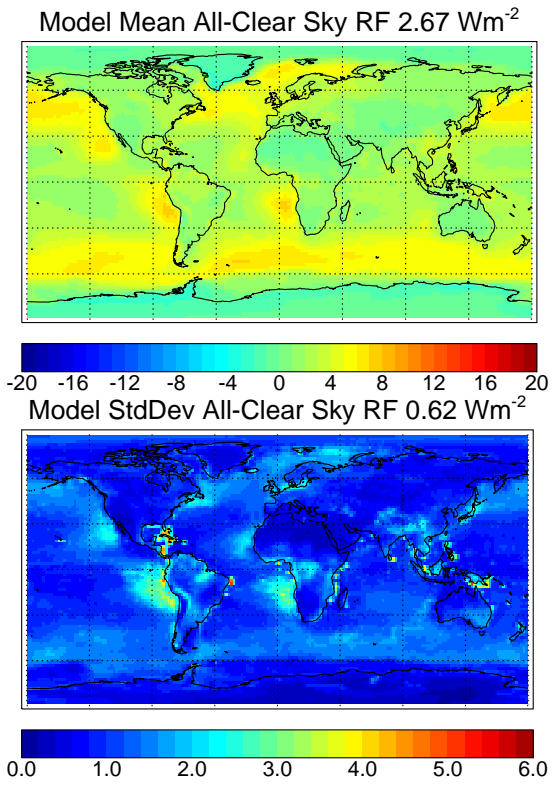

Fig. 18. Annual multi-model mean and standard deviation difference between all-sky and clear-sky top-of-atmosphere radiative forcing between experiments FIX3 and FIX0 with AOD $=0.2$ and $\mathrm{AOD}=0.0$ distributed over the lowest two kilometers, holding $\mathrm{SSA}=0.8$ and $\mathrm{ANG}=1.0$ constant. Model fields have been remapped to a resolution of $1.875^{\circ} \times 1.875^{\circ}$

in regions of tropical convection and reach about $1.5 \mathrm{~W}^{-2}$. Strong forcing perturbations, of about $3 \mathrm{Wm}^{-2}$ highlight the importance of the correct representation low-level stratocumulus cloud decks for the TOA radiative forcing of absorbing aerosol.

If we assume that the errors in radiative forcing due to either surface $\left(E_{\mathrm{s}}\right)$ or cloudy $\left(E_{\mathrm{cld}}\right)$ albedo variation are independent, the remaining unexplained error can be defined as $E^{2}-E_{\mathrm{s}}^{2}-E_{\mathrm{cld}}^{2}$, where $E$ is the total error in aerosol radiative forcing (standard deviation in aerosol radiative forcing across the models). This unexplained error is shown alongside the errors due to surface and cloud albedo in Fig. 19. While the unexplained forcing errors show spatial correlation with either the surface albedo or cloudy albedo errors, potentially due to the co-variability of error sources or limitations of this analysis, it is important to note that their magnitude is significantly lower than the errors due to surface albedo or cloud effects. However, the light hatching in the plots of the unexplained forcing errors suggests that these are nevertheless not zero.

\subsection{Realistic aerosol radiative properties}

Complementing the highly idealised studies with prescribed globally constant aerosol radiative properties, we conducted with a sub-set of the models (ECHAM5-HAM2, GOCART-GEOS4, GOCART-MERRA, OsloCTM2) the AeroCom Prescribed FIX1 study with prescribed monthly 

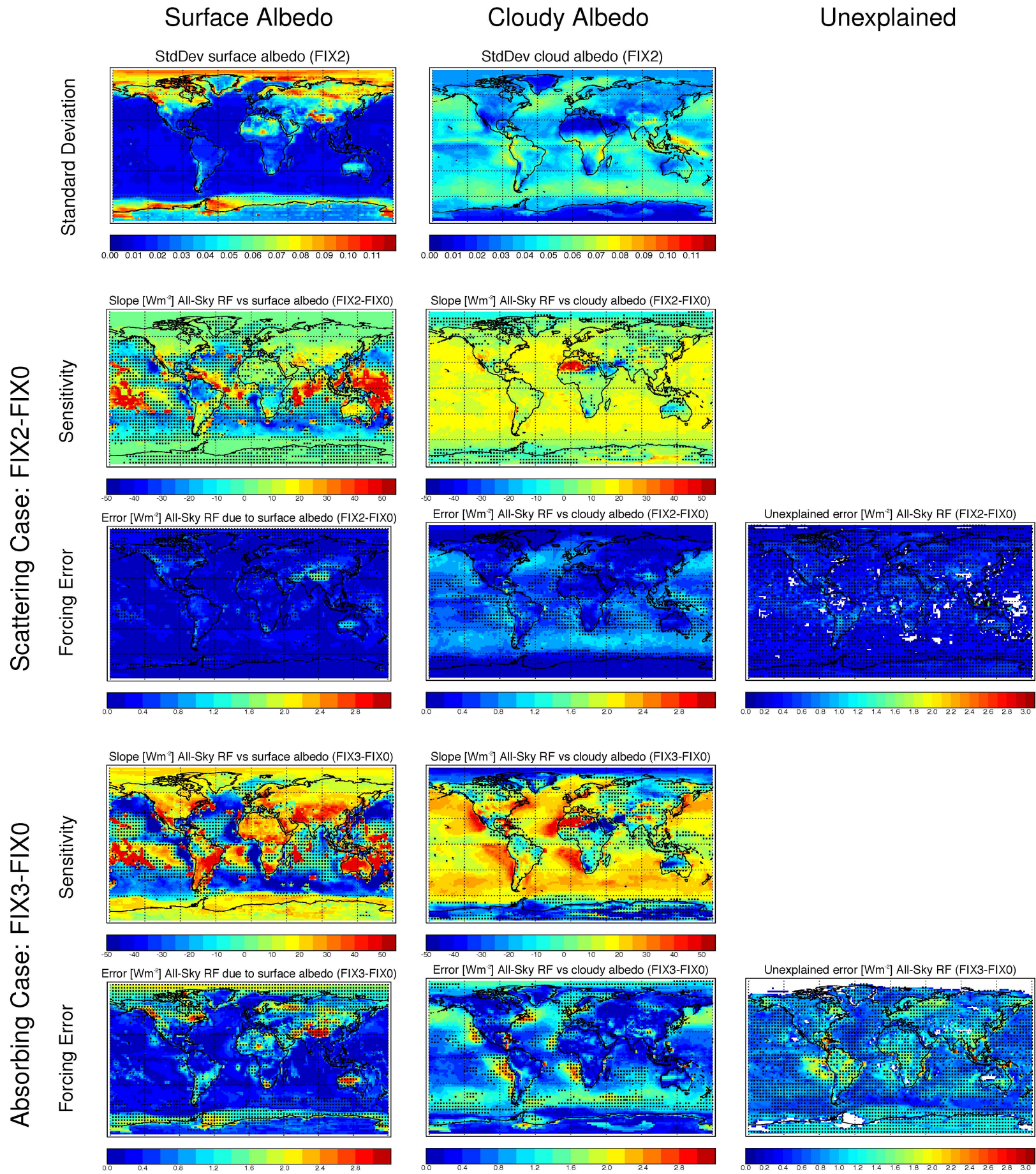

Unexplained

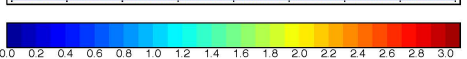

Fig. 19. Decomposition of the impact of host model errors on aerosol radiative forcings. The top row shows the standard deviations in surface and cloud albedo among the models. The sensitivity (linear regression coefficient) of aerosol radiative forcing to either surface or cloud albedo in the models is shown in the second row (for the pure scattering FIX2-FIX0 case) and the fourth row (for the absorbing FIX3-FIX0 case). The forcing error due to either surface or cloud albedo (standard deviation in albedo times sensitivity) is shown in rows 3 and 5. Assuming independent errors, the (remaining) unexplained error in the radiative forcing is shown in the right most column, row 3 and 5 . Here the white areas denote regions where the sum of squared errors due to surface or cloud albedo is larger than the deviation in aerosol radiative forcing across the models. The hatching in the sensitivity plots indicates that the sign of the sensitivity may change (due to removing a model). The hatching in the forcing error plots indicates low uncertainty $(<30 \%)$ in the error. Based on annual averaged fluxes for the models CAM-PNNL, GOCART-GEOS, GOCART-MERRA, LMDZ, LMDZ-39L, MPI-2stream, IMPACT, OsloCTM2, HadGEM2-ES, SPRINTARS, GEOS-CHEM remapped to a resolution of $1.875^{\circ} \times 1.875^{\circ}$. 

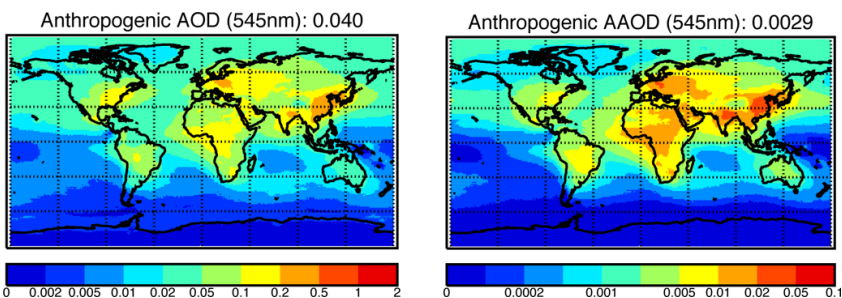

Fig. 20. Annual-mean prescribed anthropogenic aerosol optical depth (AOD) and absorption aerosol optical depth (AAOD) at $545 \mathrm{~nm}$ as used in the FIX1 experiment.

mean, three-dimensional, spatially and spectrally resolved aerosol radiative properties. Simulations were performed for pre-industrial (PI) and present-day (PD) aerosol radiative properties. Prescribed aerosol radiative properties are illustrated as anthropogenic contributions (PD-PI) in Fig. 20.

It is clear that neither the total nor the anthropogenic AOD is spatially uniform. Also, results from the accompanying study of Samset et al. (2013) suggest that the differences in the vertical profiles account for a large fraction of the diversity in black carbon radiative forcing. Therefore, it is clear that the large variability in forcing efficiencies in the simplified experiments with globally uniform radiative properties cannot simply be scaled globally. For example, significant forcing efficiencies are evident in high-latitude regions (c.f. Figs. 6 and 9), however, neither total nor particularly anthropogenic AOD is significant in those areas.

Simulated TOA radiative forcings from the models are shown in Fig. 21 (clear-sky) and in Fig. 22 (all-sky). Note that ECHAM5-HAM2 reports adjusted forcing so that the results for this case with a contribution of absorption may be affected by semi-direct effects. Simulated clear-sky forcing patterns spatially match the anthropogenic AOD shown in Fig. 20 with negative radiative forcings in the major source and outflow areas of anthropogenic pollution. Some positive radiative forcings are simulated over high surface albedo areas over Africa, with strong positive forcings simulated by ECHAM5-HAM2 and OsloCTM2, in agreement with the model behaviour in the idealised FIX3-FIX0 experiment (Fig. 8). The annual inter-model global mean clear-sky radiative forcing is $-1.24 \mathrm{Wm}^{-2}$ with a relative standard deviation of $17 \%$. All-sky radiative forcings follow roughly the same patterns but compared to the clear-sky forcing are reduced to a mean of $-0.75 \mathrm{Wm}^{-2}$ and the relative standard deviation increases to $39 \%$. Note that the reduction in forcings from clear-sky to all sky varies between a factor of 1.3 (GOCART-GEOS4) and 2.1 (ECHAM5-HAM2), which could be affected by very low cloudy albedos in GOCARTGEOS4.

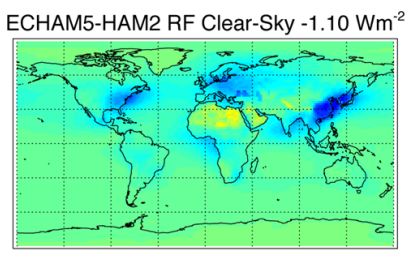

GOCART-GEOS4 RF Clear-Sky $-1.38 \mathrm{Wm}^{-2}$
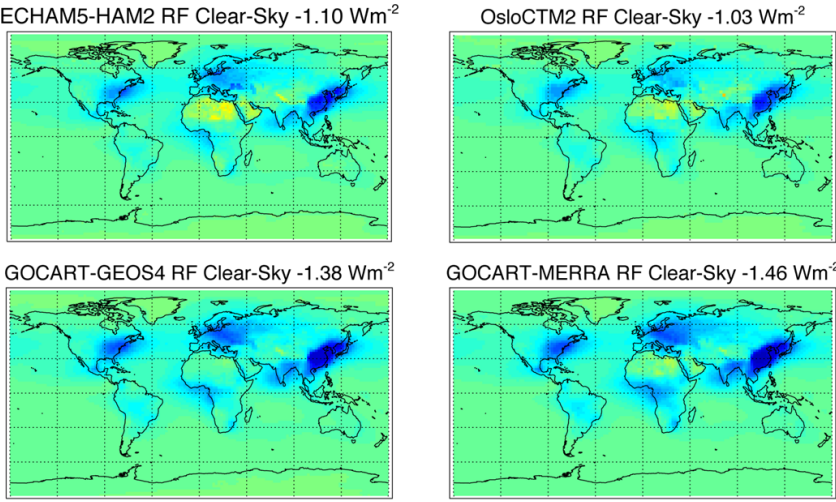

GOCART-MERRA RF Clear-Sky $-1.46 \mathrm{Wm}^{-2}$
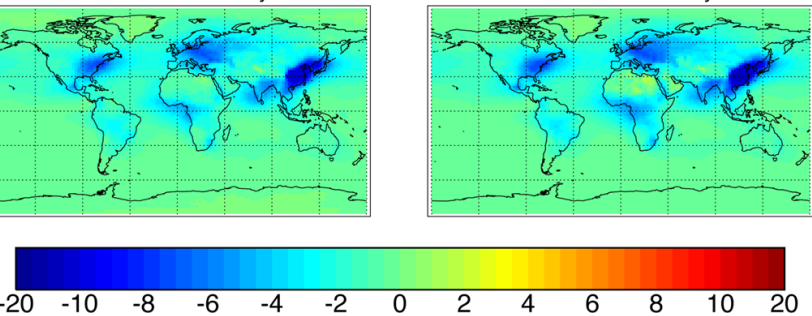

Fig. 21. Annual mean short-wave clear-sky top-of-atmosphere radiative forcing $(\mathrm{RF})$ between present day and pre-industrial experiments with identical aerosol radiative properties based on an early release of Kinne et al. (2013).

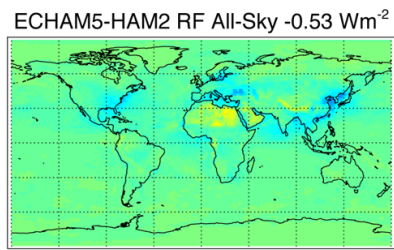

GOCART-GEOS4 RF All-Sky -1.09 $\mathrm{Wm}^{-2}$
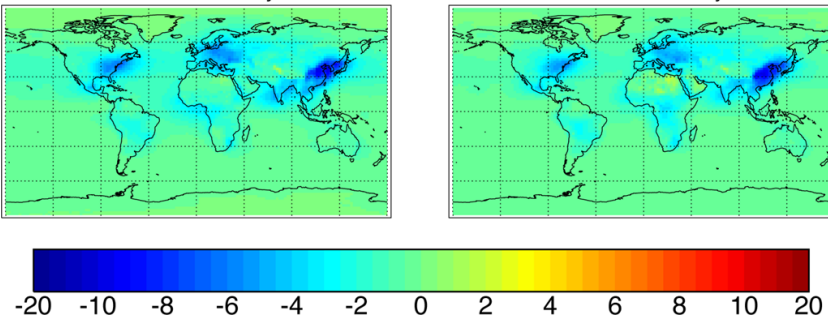

Fig. 22. Annual mean short-wave all-sky top-of-atmosphere radiative forcing (RF) between present day and pre-industrial experiments with identical aerosol radiative properties based on an early release of Kinne et al. (2013).

\section{Conclusions and implications}

In this intercomparison study we systematically assess the effect of host model uncertainties on aerosol radiative forcing. In a multi-model estimate of aerosol radiative forcing, following the AeroCom Intercomparison protocol, host model effects are isolated through prescription of identical aerosol radiative properties in all models.

The analysis is performed at two levels of complexity: (i) an idealised setup with globally constant aerosol radiative properties prescribed in the host models over lowest two kilometers; (ii) a realistic aerosol forcing scenario with prescribed monthly mean, three-dimensional, spatially and spectrally resolved aerosol radiative properties. 
Despite the prescription of identical aerosol radiative properties, simulated aerosol radiative forcings show considerable diversity, challenging the widespread assumption of multi-model forcing diversity as a measure of the uncertainty in the global representation of aerosol.

For the case of purely scattering aerosol $(\mathrm{AOD}=0.2$, $\mathrm{SSA}=1.0)$ in the idealised setup, the simulated global mean radiative forcings of $-7.11 \mathrm{Wm}^{-2}$ clear-sky and $-4.47 \mathrm{Wm}^{-2}$ all-sky, have a relative standard deviation of $7 \%$ and $12 \%$ respectively. This compares to an all-sky sulfate (almost purely scattering) aerosol radiative forcing relative standard deviation of $34 \%$ in the AeroCom Direct Radiative Effect experiment with interactive aerosol for which additionally sulfate burdens vary with a RSD of $25 \%$ (Myhre et al., 2013). The mean radiative forcing normalised by AOD is $-22.43 \mathrm{Wm}^{-2}$ with a RSD of $14 \%$, comparable to a sulfate mean of $16.1 \mathrm{Wm}^{-2}$ with a RSD of $24 \%$ in Myhre et al. (2013).

For the case of partially absorbing aerosol with $\mathrm{AOD}=1.0$ and SSA $=0.8$, the simulated global mean radiative forcings are $-1.63 \mathrm{Wm}^{-2}$ clear-sky and $1.04 \mathrm{Wm}^{-2}$ all-sky, while the relative standard deviation increases to $43 \%$ and $97 \%$, respectively. The complex dependence of RF on the singlescattering albedo does not allow for a sensible scaling of TOA radiative forcing by AOD or AAOD. However, comparison of all-sky atmospheric radiative forcing normalised by absorption optical depth at a wavelength of $550 \mathrm{~nm}$ provides further insights into the importance of host model effects on aerosol absorption. The global multi-model mean is $355 \mathrm{Wm}^{-2}$ with a comparably small RSD of $7 \%$. This compares to a mean of $525 \mathrm{Wm}^{-2}$ in Myhre et al. (2013) with an RSD of $31 \%$. However, it should be noted that the latter values are skewed by the spectral dependence with strong shortwave absorption in some models: e.g. while IMPACT gives typical mid-range normalised atmospheric radiative forcing of $347 \mathrm{Wm}^{-2}$ in this study, it reports $935 \mathrm{Wm}^{-2}$ in Myhre et al. (2013).

The set-up of previous assessments of global aerosol radiative forcing, convoluting the uncertainty in simulated aerosol distributions and properties with host model uncertainties, has not allowed attribution of forcing differences to specific host model effects beyond the global mean.

Here, we isolate the total impact of clouds on aerosol radiative forcing through the difference and inter-model variability between clear-sky and aerosol radiative forcings in our idealised set-ups with globally constant aerosol radiative properties. While in the global-mean the effects of clouds on TOA radiative forcing for the scattering scenario are $2.64 \mathrm{Wm}^{-2}$ and $2.67 \mathrm{Wm}^{-2}$ for the absorbing scenario, regionally these effects reach about $10 \mathrm{Wm}^{-2}$. The variability is largest in regions of low-level stratocumulus decks, which are simulated very inconsistently across the models.

To specifically attribute the diversity in aerosol radiative forcing to host model differences, we remap the models on a common grid and calculate for each grid-box the sensitivity of TOA radiative forcing to the model simulated surface and cloudy albedos as slope of a linear inter-model regression. The product of the sensitivity with the albedo perturbation, expressed as inter-model standard deviation, provides a measure of the forcing error owing to the inter-model spread in the respective host-model component.

The forcing sensitivity to surface albedos shows generally positive values, which increase considerably for the absorbing scenario. Corresponding forcing errors are about $1 \mathrm{Wm}^{-2}$ for the scattering and reach $3 \mathrm{Wm}^{-2}$ for the absorbing case.

The forcing sensitivity to cloudy albedo shows predominantly positive but also areas with negative sensitivities, with both effects amplified for the absorbing scenario. In particular for the absorbing scenario, negative sensitivities tend to occur over high albedo surfaces, where cloud shielding reduces the positive forcing contribution of absorbing aerosol. Corresponding forcing errors are highest in regions with high cloud-fractions reaching about $1 \mathrm{Wm}^{-2}$ in the storm tracks for the scattering case. The spatial distribution of the forcing error for the absorbing case, with maxima of about $3 \mathrm{Wm}^{-2}$ in areas of low-level stratocumulus decks, confirms the importance of these cloud regimes for the forcing variability of absorbing aerosol. An estimate of errors in radiative forcing unexplained by either surface or cloudy albedo variation indicates that these unexplained errors, including radiative transfer, have lower values than the errors due to surface albedo or cloud effects.

To assess the global implications we can scale our forcing standard deviation for the scattering case for the corresponding mean to match the simulated sulfate radiative forcing of $-0.32 \mathrm{Wm}^{-2}$ in AeroCom Phase II (Myhre et al., 2013), which gives a diversity with standard deviation of $0.04 \mathrm{Wm}^{-2}$. This host model diversity could explain about $36 \%$ of the overall sulfate forcing diversity of $0.11 \mathrm{Wm}^{-2}$ in the AeroCom Direct Radiative Effect experiment. In terms of RF normalised by AOD, host model effects introduce a diversity with RSD of $14 \%$, which compares to an overall RF diversity for sulfate aerosol of $34 \%$ in AeroCom Direct.

From our analysis it becomes clear that host model effects have a significant spatio-temporal variability that may not match the aerosol perturbation in question, so the derived global mean diversities may not be directly comparable to AeroCom Direct. However, recalculating the simulated forcing diversity as a weighted average, using the ECHAM5HAM2 anthropogenic optical depth as a weighting factor, only slightly changes the global mean $\mathrm{RF}_{\mathrm{TOA}}^{\text {all }}$ from -4.47 to $-4.84 \mathrm{Wm}^{-2}$ and reduces the inter-model absolute (relative) standard deviations from 0.59 to $0.53 \mathrm{Wm}^{-2}(13 \%$ to $11 \%)$.

A realistic quantification of host model uncertainty without attribution to specific host model effects - is provided in the scenario with globally spatio-temporally varying spectrally resolved aerosol radiative properties. In 
this experiment, performed with a subset of four model configurations, annual global-mean radiative forcing is $-1.24 \mathrm{Wm}^{-2}$ clear-sky with a relative standard deviation of $17 \%$ and $-0.75 \mathrm{Wm}^{-2}$ all-sky for which the relative standard deviation increases to $39 \%$.

This compares to an annual global-mean radiative forcing of $-0.67 \mathrm{Wm}^{-2}$ clear-sky with a relative standard deviation of $27 \%$ and $-0.27 \mathrm{Wm}^{-2}$ all-sky with a relative standard deviation of $56 \%$ in the AeroCom Phase II direct radiative forcing experiment (Myhre et al., 2013).

The significant forcing differences between FIX1 and AeroCom Direct, despite a relatively comparable anthropogenic AOD of 0.040 and 0.031 , respectively, can be understood in the context of significant differences in the AAOD of 0.0029 and 0.0016 , respectively. The complex dependency of TOA radiative forcing on aerosol absorption complicates a direct comparison of these forcing results, and explains the fairly weak correspondence of $\mathrm{RF}_{\mathrm{TOA}}^{\mathrm{all}}$ between the FIX1 and AeroCom Direct experiments: ECHAM5-HAM2, GOCARTMERRA and OsloCTM2 report $-0.53,-0.91,-0.48 \mathrm{Wm}^{-2}$ in FIX1 and $-0.15,-0.36,-0.17 \mathrm{Wm}^{-2}$ in AeroCom Direct.

Clearly, aerosol absorption tends to increase the simulated forcing diversity. This is attributable to the complex dependence of forcing on the effective surface albedo and the importance of co-location of aerosol and cloud layers. Interestingly, atmospheric absorption itself is simulated fairly consistently among models: e.g. for the scenario with prescribed $\mathrm{SSA}=0.8$ and a fixed $\mathrm{ANG}=1.0$, its relative standard deviation is only about $7 \%$.

To summarise the key findings of the AeroCom Prescribed intercomparison study:

- Current models (GCMs, CTMs, offline) used in aerosol radiative forcing calculations show considerable diversity in model parameters relevant for the calculation of aerosol radiative forcing. Surface albedos and cloud fraction both show a global mean inter-model relative standard deviation of $4 \%$ and $9 \%$, respectively; regionally, the variability is significantly larger.

- The effects of surface albedo and cloud properties are clearly discernible in the global patterns of radiative forcing of a globally uniform aerosol layer, in particular for absorbing aerosol.

- Significant differences in atmospheric forcings (absorption) for the purely scattering case, for which three models simulate significant enhancement of molecular absorptions, highlight the contribution of structural differences in the radiation schemes to the overal host model errors, further investigated in a companion study (Randles et al., 2013).

- Even for identically prescribed aerosol radiative properties, the simulated clear-sky and all-sky aerosol radiative forcings show significant diversity. Compared to the TOA all-sky forcing diversity for the purely scattering case with absolute (relative) standard deviation of $0.55 \mathrm{Wm}^{-2}(12 \%)$, the forcing diversity is considerably larger for partially absorbing aerosol, with absolute (relative) standard deviations of of $1.04 \mathrm{Wm}^{-2}(97 \%)$.

- However, the TOA forcing variability owing to absorption (subtracting the scattering case from the case with scattering and absorption) is low, with relative standard deviations of $8 \%$ clear-sky and $11 \%$ all-sky. Also the simulated atmospheric forcing (absorption) shows only small variabilities with relative standard deviations of $7 \%$ clear-sky and all-sky.

- Aerosol radiative forcing errors due to host model components are largest in regions of uncertain host model fields, such as the extended stratocumulus decks off the western coasts of the continents or areas with poorly constrained surface albedos, such as deserts or sea ice covered areas.

- Although the simulated multi-model "diversity" in aerosol direct radiative forcing estimates is often perceived as a measure of the uncertainty in the representation of aerosols on global scales, the uncertainties in the actual forcing calculation for a known global distribution of global aerosol radiative properties are significant and merit further attention.

While this study is a step forward in our understanding of uncertainties in aerosol radiative forcing estimates, the demonstrated importance of host model effects demands further work. For example, a more systematic evaluation of models' surface albedos may be a relatively straightforward and promising task and relevant datasets are beginning to emerge (e.g. Cescatti et al., 2012). Although a systematic independent variation or even prescription of surface albedos and cloud properties is a common suggestion, their actual implementation in GCMs is not trivial and raises consistency issues as they will inevitably introduce unphysical radiation imbalances.

The significant difference in the diversity of the normalised atmospheric forcing $\left(\mathrm{RF}_{\mathrm{atm}}^{\mathrm{all}} / \mathrm{AAOD}\right)$, between this experiment with prescribed radiative properties $(\mathrm{RSD}=7 \%)$ as compared to the AeroCom Direct Radiative Effect experiment $(\mathrm{RSD}=31 \%)$ (Myhre et al., 2013), is an interesting finding. The analysis from the AeroCom Direct experiment highlights the importance of the uncertain spectral dependence of absorbing aerosol that could explain these differences and should be further explored.

Ultimately, only continued careful evaluation and consistent improvement of the physics underlying the used host models will allow us to reduce uncertainties in aerosol radiative forcing estimates themselves. 
Appendix A

\section{Zonal-mean plots}

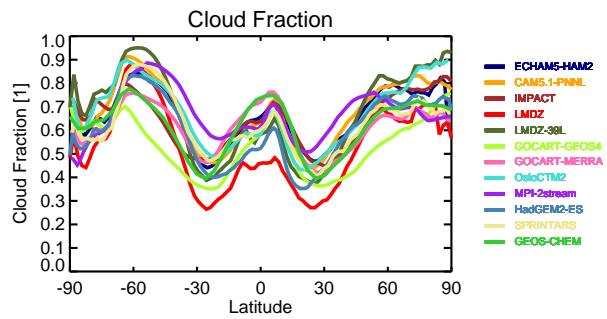

Fig. A1. Annual zonal-mean cloud fractions for experiment FIX0 $(\mathrm{AOD}=0.0)$.
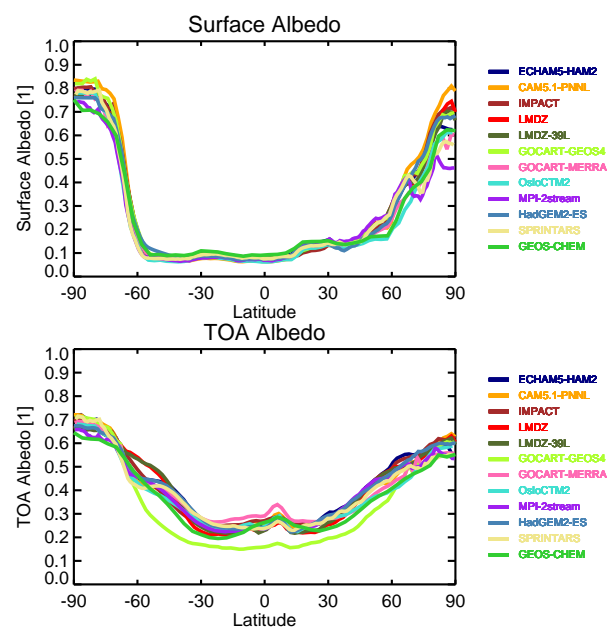

Fig. A2. Annual zonal-mean broadband short-wave surface and top-of-atmosphere albedos for experiment FIX0 ( $\mathrm{AOD}=0.0$, $\mathrm{SSA}=0.8, \mathrm{ANG}=1.0$ ).
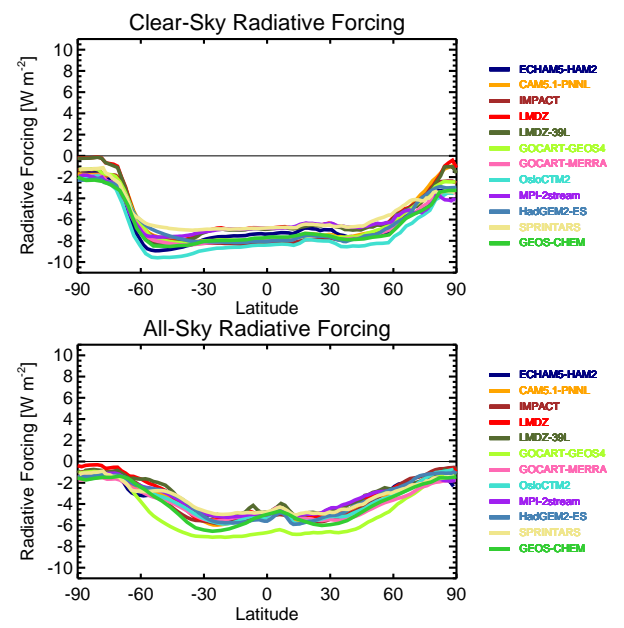

Fig. A3. Annual zonal-mean short-wave clear-sky and all-sky top-of-atmosphere radiative forcing between experiments with $\mathrm{AOD}=0.2$ and $\mathrm{AOD}=0.0$ distributed over the lowest two kilometers, holding SSA $=1.0$ and $\mathrm{ANG}=1.0$ constant.
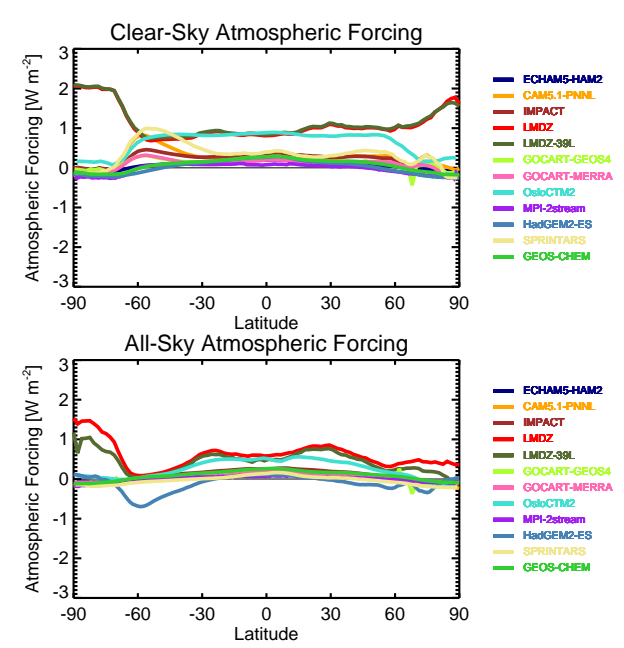

Fig. A4. Annual zonal-mean short-wave all-sky atmospheric radiative forcing (absorption) between experiments with $\mathrm{AOD}=0.2$ and $\mathrm{AOD}=0.0$ distributed over the lowest two kilometers, holding $\mathrm{SSA}=1.0$ and $\mathrm{ANG}=1.0$ constant (FIX2-FIX0).
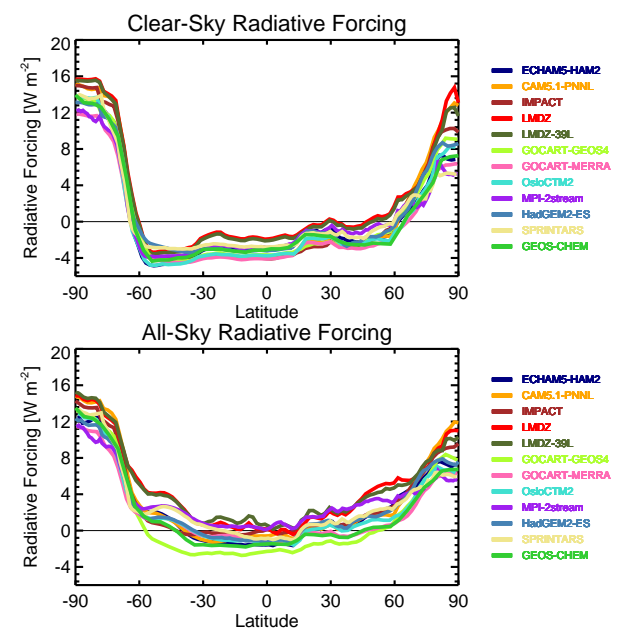

Fig. A5. Annual zonal-mean short-wave clear-sky and all-sky top-of-atmosphere radiative forcing between experiments with $\mathrm{AOD}=0.2$ and $\mathrm{AOD}=0.0$ distributed over the lowest two kilometers, holding $\mathrm{SSA}=0.8$ and $\mathrm{ANG}=1.0$ constant. 

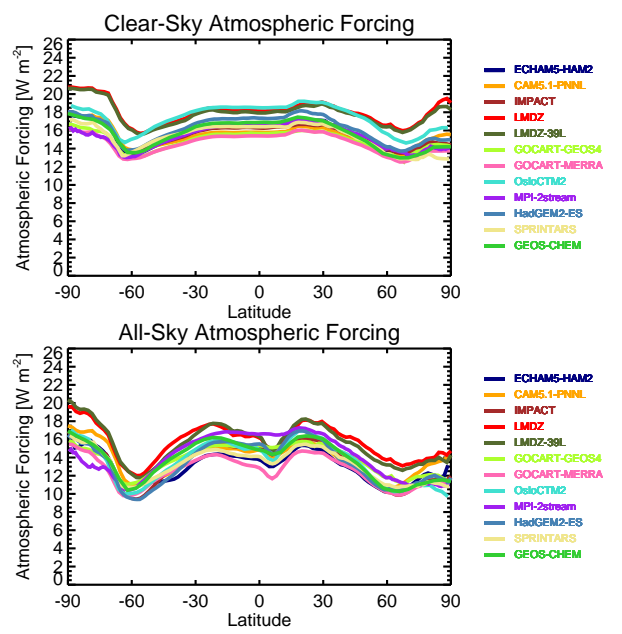

Fig. A6. Annual zonal-mean short-wave all-sky atmospheric radiative forcing (absorption) between experiments with $\mathrm{AOD}=0.2$ and $\mathrm{AOD}=0.0$ distributed over the lowest two kilometers, holding $\mathrm{SSA}=0.8$ and $\mathrm{ANG}=1.0$ constant (FIX3-FIX0).
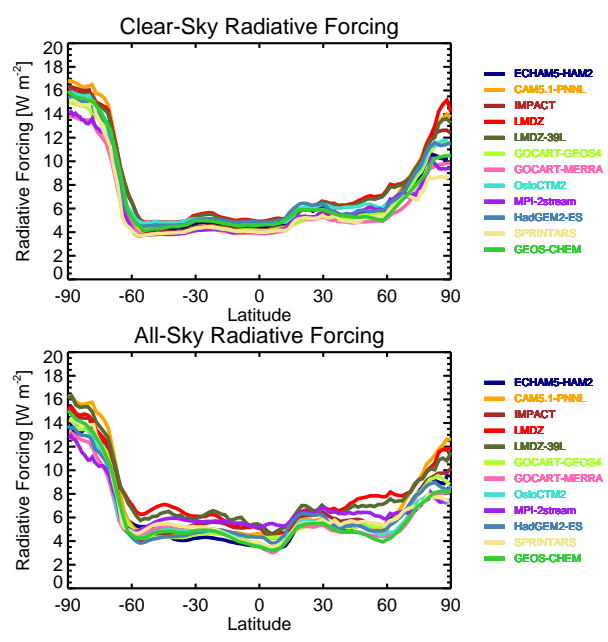

Fig. A7. Annual zonal-mean short-wave clear-sky and all-sky top-of-atmosphere radiative forcing with $\mathrm{AOD}=0.2$ distributed over the lowest two kilometers between experiments with $\mathrm{SSA}=0.8$ and $\mathrm{SSA}=1.0$ with holding $\mathrm{ANG}=1.0$ constant (FIX3-FIX2).
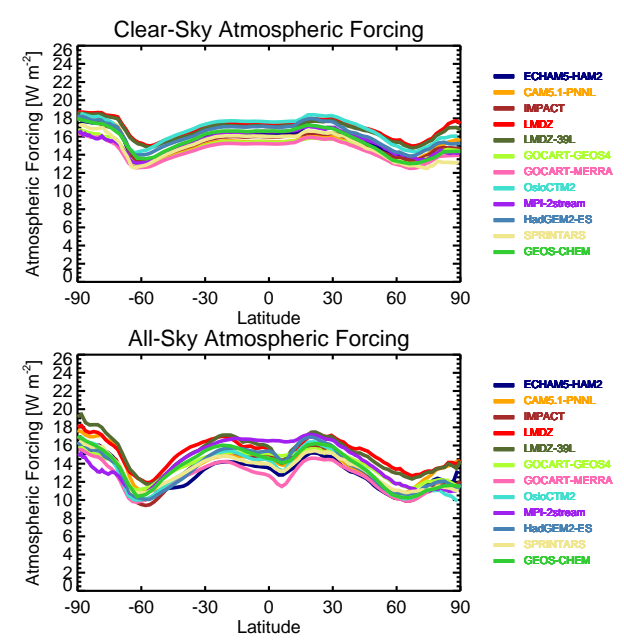

Fig. A8. Annual zonal-mean short-wave all-sky atmospheric radiative forcing (absorption) between experiments with $\mathrm{SSA}=0.8$ and $\mathrm{SSA}=1.0$ with holding $\mathrm{ANG}=1.0$ constant $(\mathrm{FIX} 3-\mathrm{FIX} 2)$.
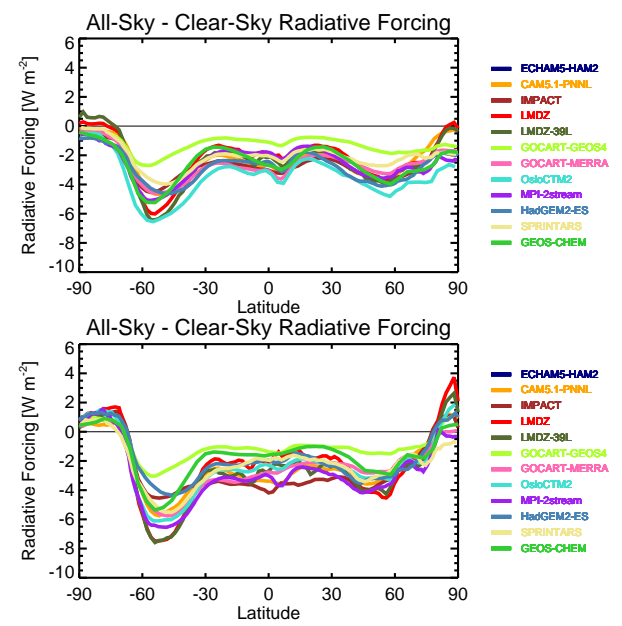

Fig. A9. Annual zonal-mean short-wave difference between all-sky and clear-sky top-of-atmosphere radiative forcing between experiments with $\mathrm{AOD}=0.2$ and $\mathrm{AOD}=0.0$ and (a) $\mathrm{SSA}=1.0$, (b) $\mathrm{SSA}=0.8$ distributed over the lowest two kilometers, holding $\mathrm{ANG}=1.0$ constant. 
Acknowledgements. This work has been supported by the UK Natural Environment Research Council project AEROS on aerosol uncertainties [NE/G006148/1]. We would like to thank J. Griesfeller (MetNo) for his support with the AeroCom database and Z. Kipling (Oxford) for his helpful comments on the manuscript. S. Ghan was supported by the US Department of Energy Office of Science Decadal and Regional Climate Prediction using Earth System Models (EaSM) program. The Pacific Northwest National Laboratory (PNNL) is operated for the DOE by Battelle Memorial Institute under contract DE-AC06-76RLO 1830. X. Ma and F. $\mathrm{Yu}$ were funded by the US National Aeronautics and Space Administration and National Science Foundation. N. Bellouin was supported by the Joint DECC/Defra Met Office Hadley Centre Climate Programme (GA01101). T. Takemura was supported by the Funding Program for Next Generation World-Leading Researchers by the Cabinet Office, Government of Japan (GR079).

Edited by: E. Highwood

\section{References}

Albrecht, B. A.: Aerosols, cloud microphysics, and fractional cloudiness, Science, 245, 1227-1230, 1989.

Ångström, A.: Atmospheric turbidity, global illumination and planetary albedo of the earth, Tellus, 14, 435-450, 1962.

Bellouin, N., Boucher, O., Haywood, J., and Reddy, M. S.: Global estimate of aerosol direct radiative forcing from satellite measurements, Nature, 438, 1138-1141, doi:10.1038/nature04348, 2005.

Bellouin, N., Rae, J., Jones, A., Johnson, C., Haywood, J., and Boucher, O.: Aerosol forcing in the Climate Model Intercomparison Project (CMIP5) simulations by HadGEM2-ES and the role of ammonium nitrate, J. Geophys. Res. Atmos., 116, D20206, doi:10.1029/2011JD016074, 2011.

Boucher, O., Schwartz, S., Ackerman, T., Anderson, T., Bergstrom, B., Bonnel, B., Chylek, P., Dahlback, A., Fouquart, Y., Fu, Q., Halthore, R., Haywood, J., Iversen, T., Kato, S., Kinne, S., Kirkevag, A., Knapp, K., Lacis, A., Laszlo, I., Mishchenko, M., Nemesure, S., Ramaswamy, V., Roberts, D., Russell, P., Schlesinger, M., Stephens, G., Wagener, R., Wang, M., Wong, J., and Yang, F.: Intercomparison of models representing direct shortwave radiative forcing by sulfate aerosols, J. Geophys. Res. Atmos., 103, 16979-16998, 1998.

Cagnazzo, C., Manzini, E., Giorgetta, M. A., Forster, P. M. D. F., and Morcrette, J. J.: Impact of an improved shortwave radiation scheme in the MAECHAM5 General Circulation Model, Atmos. Chem. Phys., 7, 2503-2515, doi:10.5194/acp-7-2503-2007, 2007.

Cescatti, A., Marcolla, B., Vannan, S. K. S., Pan, J. Y., Roman, M. O., Yang, X., Ciais, P., Cook, R. B., Law, B. E., Matteucci, G., Migliavacca, M., Moors, E., Richardson, A. D., Seufert, G., and Schaaf, C. B.: Intercomparison of MODIS albedo retrievals and in situ measurements across the global FLUXNET network, Remote Sens. Environ., 121, 323-334, doi:10.1016/j.rse.2012.02.019, 2012.

Chand, D., Wood, R., Anderson, T., Satheesh, S., and Charlson, R.: Satellite-derived direct radiative effect of aerosols dependent on cloud cover, Nature Geosci., 2, 181-184, 2009.
Chin, M., Ginoux, P., Kinne, S., Torres, O., Holben, B. N., Duncan, B. N., Martin, R. V., Logan, J. A., Higurashi, A., and Nakajima, T.: Tropospheric aerosol optical thickness from the GOCART model and comparisons with satellite and Sun photometer measurements, J. Atmos. Sci., 59, 461-483, 2002.

Chou, M., Suarez, M. J., Ho, C. H., Yan, M., and Lee, K. T.: Parameterizations for cloud overlapping and shortwave single-scattering properties in the Goddard GCM, J. Climate, 11, 201-214, 1998.

Collins, W., Rasch, P., Boville, B., Hack, J., McCaa, J., Williamson, D., Briegleb, B., Bitz, C., Lin, S., and Zhang, M.: The formulation and atmospheric simulation of the Community Atmosphere Model version 3 (CAM3), J. Climate, 19, 2144-2161, 2006.

Collins, W. J., Bellouin, N., Doutriaux-Boucher, M., Gedney, N., Halloran, P., Hinton, T., Hughes, J., Jones, C. D., Joshi, M., Liddicoat, S., Martin, G., O’Connor, F., Rae, J., Senior, C., Sitch, S., Totterdell, I., Wiltshire, A., and Woodward, S.: Development and evaluation of an Earth-System model - HadGEM2, Geosci. Model Dev., 4, 1051-1075, doi:10.5194/gmd-4-10512011, 2011.

Edwards, J. M. and Slingo, A.: Studies with a flexible new radiation code. I: Choosing a configuration for a largescale model, Q. J. Roy. Meteorol. Soc., 122, 689-719, doi:10.1002/qj.49712253107, , 1996.

Forster, P., Ramaswamy, V., Artaxo, P., Berntsen, T., Betts, R., Fahey, D. W., Haywood, J., Lowe, J. L. D. C., Myhre, G., Nganga, J., Prinn, R., Raga, G., Schulz, M., and Dorland, R. V.: Climate Change 2007: The Physical Science Basis, Contribution of Working Group I to the Fourth Assessment Report of the Intergovernmental Panel on Climate Change, chap. Changes in Atmospheric Constituents and in Radiative Forcing, Cambridge University Press, Cambridge, UK and New York, NY, USA, 2007.

Ghan, S., Liu, X., Easter, R. C., Zaveri, R., Rasch, P. J., and Eaton, J.-H. Y.: Toward a minimal representation of aerosols in climate models: Comparative decomposition of aerosol direct, semi-direct and indirect radiative forcing, J. Climate, doi:10.1175/JCLI-D-11-00650.1, 2012.

Graßl, H.: Albedo reduction and radiative heating of clouds by absorbing aerosol particles, Contrib. Atmos. Phys., 48, 199-210, 1975.

Halthore, R., Crisp, D., Schwartz, S., Anderson, G., Berk, A., Bonnel, B., Boucher, O., Chang, F., Chou, M., Clothiaux, E., Dubuisson, P., Fomin, B., Fouquart, Y., Freidenreich, S., Gautier, C., Kato, S., Laszlo, I., Li, Z., Mather, J., Plana-Fattori, A., Ramaswamy, V., Ricchiazzi, P., Shiren, Y., Trishchenko, A., and Wiscombe, W.: Intercomparison of shortwave radiative transfer codes and measurements, J. Geophys. Res. Atmos., 110, D11206, doi:10.1029/2004JD005293, 2005.

Hansen, J. E., Sato, M., and Ruedy, R.: Radiative forcing and climate response, J. Geophys. Res., 102, 6831-6864, 1997.

Haywood, J. M. and Shine, K. P.: The effect of anthropogenic sulfate and soot on the clear-sky planetary radiation budget, Geophys. Res. Lett., 22, 603-606, 1995.

Hourdin, F., Musat, I., Bony, S., Braconnot, P., Codron, F., Dufresne, J.-L., Fairhead, L., Filiberti, M.-A., Friedlingstein, P., Grandpeix, J.-Y., Krinner, G., LeVan, P., Li, Z.-X., and Lott, F.: The LMDZ4 general circulation model: climate performance and sensitivity to parametrized physics with emphasis on tropical convection, Clim. Dynam., 27, 787-813, doi:10.1007/s00382006-0158-0, 2006. 
Hourdin, F., Grandpeix, J.-Y., Rio, C., Bony, S., Jam, A., Cheruy, F., Rochetin, N., Fairhead, L., Idelkadi, A., Musat, I., Dufresne, J.L., Lahellec, A., Lefebvre, M.-P., and Roehrig, R.: LMDZ5B: the atmospheric component of the IPSL climate model with revisited parameterizations for clouds and convection, Clim. Dynam., doi:10.1007/s00382-012-1343-y, 2012.

Iacono, M., Delamere, J. S., Mlawer, E. J., Shephard, M. W., Clough, S. A., and Collins, W. D.: Radiative forcing by long-lived greenhouse gases: Calculations with the AER radiative transfer models, J. Geophys. Res., 113, D13103, doi:10.1029/2008jd009944, 2008.

Kinne, S., Schulz, M., Textor, C., Guibert, S., Balkanski, Y., Bauer, S. E., Berntsen, T., Berglen, T. F., Boucher, O., Chin, M., Collins, W., Dentener, F., Diehl, T., Easter, R., Feichter, J., Fillmore, D., Ghan, S., Ginoux, P., Gong, S., Grini, A., Hendricks, J., Herzog, M., Horowitz, L., Isaksen, I., Iversen, T., Kirkevåg, A., Kloster, S., Koch, D., Kristjansson, J. E., Krol, M., Lauer, A., Lamarque, J. F., Lesins, G., Liu, X., Lohmann, U., Montanaro, V., Myhre, G., Penner, J., Pitari, G., Reddy, S., Seland, O., Stier, P., Takemura, T., and Tie, X.: An AeroCom initial assessment - optical properties in aerosol component modules of global models, Atmos. Chem. Phys., 6, 1815-1834, doi:10.5194/acp-6-1815-2006, 2006.

Kinne, S., O’Dowell, D., Stier, P., Kloster, S., Zhang, K., Schmidt, H., Rast, S., Giorgetta, M., Eck, T. F., and Stevens, B.: HACv1: A new global aerosol climatology for climate studies, J. Adv. Model. Earth Syst., submitted, 2013.

Liao, H. and Seinfeld, J.: Effect of clouds on direct aerosol radiative forcing of climate, J. Geophys. Res. Atmos., 103, 3781-3788, 1998.

Liu, X., Penner, J. E., and Herzog, M.: Global modeling of aerosol dynamics: Model description, evaluation, and interactions between sulfate and nonsulfate aerosols, J. Geophys. Res., 110, D18206, doi:10.1029/2004JD005674, 2005.

Lohmann, U. and Feichter, J.: Global indirect aerosol effects: a review, Atmos. Chem. Phys., 5, 715-737, doi:10.5194/acp-5-7152005, 2005.

Ma, X., Yu, F., and Luo, G.: Aerosol direct radiative forcing based on GEOS-Chem-APM and uncertainties, Atmospheric Chemistry and Physics, 12, 5563-5581, doi:10.5194/acp-12-55632012, 2012.

Mann, G. W., Carslaw, K. S., Reddington, C. L., Pringle, K. J., Schulz, M., Asmi, A., Spracklen, D. V., Ridley, D. A., Woodhouse, M. T., Zhang, K., Feichter, J., Rast, S., Stier, P., Ghan, S. J., Easter, R. C., Liu, X., Lee, Y. H., Adams, P. J., Tost, H., Lelieveld, J., van Noije, T. P. C., Strunk, A., Vignati, E., Bellouin, N., Dalvi, M., Johnson, C. E., Bergman, T., Kokkola, H., Bauer, S. E., von Salzen, K., Yu, F., Luo, G., Petzold, A., Heintzenberg, J., Clarke, A., Ogren, J. A., Gras, J., Baltensberger, U., Kaminski, U., Jennings, S. G., Weller, R., and Viisainen, Y.: Intercomparison and evaluation of aerosol microphysical properties among AeroCom global models of a range of complexity, Atmos. Chem. Phys. Discuss., submitted, 2013.

Marchand, R., Ackerman, T., Smyth, M., and Rossow, W. B.: A review of cloud top height and optical depth histograms from MISR, ISCCP, and MODIS, J. Geophys. Res. Atmos., 115, D16206, doi:10.1029/2009JD013422, 2010.

McCormic, R. A. and Ludwig, J. H.: Climate modifications by atmospheric aerosols, Science, 156, 1358-1359, 1967.
Meador, W. E. and Weaver, W. R.: Two-stream approximation to radiative transfer in planetary atmospheres: a unified description of existing methods and new improvement, J. Atmos. Sci., 37, 630-643, 1980.

Morcrette, J.-J.: Radiation and Cloud Radiative Properties in the European Centre for Medium Range Weather Forecasts Forecasting System, J. Geophys. Res., 96, 9121-9132, doi:10.1029/89JD01597, 1991.

Myhre, G.: Consistency Between Satellite-Derived and Modeled Estimates of the Direct Aerosol Effect, Science, 325, 187-190, doi:10.1126/science.1174461, 2009.

Myhre, G., Berglen, T. F., Johnsrud, M., Hoyle, C. R., Berntsen, T. K., Christopher, S. A., Fahey, D. W., Isaksen, I. S. A., Jones, T. A., Kahn, R. A., Loeb, N., Quinn, P., Remer, L., Schwarz, J. P., and Yttri, K. E.: Modelled radiative forcing of the direct aerosol effect with multi-observation evaluation, Atmos. Chem. Phys., 9, 1365-1392, doi:10.5194/acp-9-1365-2009, 2009.

Myhre, G., Samset, B. H., Schulz, M., Balkanski, Y., Bauer, S., Berntsen, T. K., Bian, H., Bellouin, N., Chin, M., Diehl, T., Easter, R. C., Feichter, J., Ghan, S. J., Hauglustaine, D., Iversen, T., Kinne, S., Kirkevåg, A., Lamarque, J.-F., Lin, G., Liu, X., Lund, M. T., Luo, G., Ma, X., van Noije, T., Penner, J. E., Rasch, P. J., Ruiz, A., Seland, Ø., Skeie, R. B., Stier, P., Takemura, T., Tsigaridis, K., Wang, P., Wang, Z., Xu, L., Yu, H., Yu, F., Yoon, J.-H., Zhang, K., Zhang, H., and Zhou, C.: Radiative forcing of the direct aerosol effect from AeroCom Phase II simulations, Atmos. Chem. Phys., 13, 1853-1877, doi:10.5194/acp-13-18532013, 2013.

Oreopoulos, L., Mlawer, E., Delamere, J., Shippert, T., Cole, J., Fomin, B., Iacono, M., Jin, Z., Li, J., Manners, J., Räisänen, P., Rose, F., Zhang, Y., Wilson, M. J., and Rossow, W. B.: The Continual Intercomparison of Radiation Codes: Results from Phase I, J. Geophys. Res., 117, D06118, doi:10.1029/2011JD016821, 2012.

Pincus, R., Batstone, C. P., Hofmann, R. J. P., Taylor, K. E., and Glecker, P. J.: Evaluating the present-day simulation of clouds, precipitation, and radiation in climate models, J. Geophys. Res., pp. 113, D14209, doi:10.1029/2007JD009334, 2008.

Probst, P., Rizzi, R., Tosi, E., Lucarini, V., and Maestri, T.: Total cloud cover from satellite observations and climate models, Atmos. Res., doi:10.1016/j.atmosres.2012.01.005, 2012.

Randles, C. A., Kinne, S., Myhre, G., Schulz, M., Stier, P., Fischer, J., Doppler, L., Highwood, E., Ryder, C., Harris, B., Huttunen, J., Ma, Y., Pinker, R. T., Mayer, B., Neubauer, D., Hitzenberger, R., Oreopoulos, L., Lee, D., Pitari, G., Di Genova, G., Quaas, J., Rose, F. G., Kato, S., Rumbold, S. T., Vardavas, I., Hatzianastassiou, N., Matsoukas, C., Yu, H., Zhang, F., Zhang, H., and $\mathrm{Lu}$, P.: Intercomparison of shortwave radiative transfer schemes in global aerosol modeling: results from the AeroCom Radiative Transfer Experiment, Atmos. Chem. Phys., 13, 2347-2379, doi:10.5194/acp-13-2347-2013, 2013.

Samset, B. H., Myhre, G., Schulz, M., Balkanski, Y., Bauer, S., Berntsen, T. K., Bian, H., Bellouin, N., Diehl, T., Easter, R. C., Ghan, S. J., Iversen, T., Kinne, S., Kirkevåg, A., Lamarque, J.F., Lin, G., Liu, X., Penner, J. E., Seland, Ø., Skeie, R. B., Stier, P., Takemura, T., Tsigaridis, K., and Zhang, K.: Black carbon vertical profiles strongly affect its radiative forcing uncertainty, Atmos. Chem. Phys., 13, 2423-2434, doi:10.5194/acp-13-24232013, 2013. 
Schulz, M., Textor, C., Kinne, S., Balkanski, Y., Bauer, S., Berntsen, T., Berglen, T., Boucher, O., Dentener, F., Guibert, S., Isaksen, I. S. A., Iversen, T., Koch, D., Kirkevåg, A., Liu, X., Montanaro, V., Myhre, G., Penner, J. E., Pitari, G., Reddy, S., Seland, $\varnothing$., Stier, P., and Takemura, T.: Radiative forcing by aerosols as derived from the AeroCom present-day and pre-industrial simulations, Atmos. Chem. Phys., 6, 5225-5246, doi:10.5194/acp-65225-2006, 2006.

Sekiguchi, M. and Nakajima, T.: A k-distribution-based radiation code and its computational optimization for an atmospheric general circulation model, J. Quant. Spectrosc. Radiat. Transfer, 109, 2779-2793, 2008.

Stamnes, K., Tsay, S., Wiscombe, W., and Jayaweera, K.: Numerically Stable Algorithm For Discrete-Ordinate-Method RadiativeTransfer In Multiple-Scattering And Emitting Layered Media, Appl. Optics, 27, 2502-2509, 1988.

Stier, P., Feichter, J., Kinne, S., Kloster, S., Vignati, E., Wilson, J., Ganzeveld, L., Tegen, I., Werner, M., Balkanski, Y., Schulz, M., Boucher, O., Minikin, A., and Petzold, A.: The aerosol-climate model ECHAM5-HAM, Atmos. Chem. Phys., 5, 1125-1156, doi:10.5194/acp-5-1125-2005, 2005.

Stier, P., Seinfeld, J. H., Kinne, S., and Boucher, O.: Aerosol absorption and radiative forcing, Atmos. Chem. Phys., 7, 5237-5261, doi:10.5194/acp-7-5237-2007, 2007.

Takemura, T., Nozawa, T., Emori, S., Nakajima, T. Y., and Nakajima, T.: Simulation of climate response to aerosol direct and indirect effects with aerosol transport-radiation model, J. Geophys. Res., 110, D02202, doi:10.1029/2004JD005029, 2005.

Taylor, K. E., Stouffer, R. J., and Meehl, G. A.: An Overview of CMIP5 and the Experiment Design, B. Am. Meteor. Soc., 93, 485-498, 2012.

Textor, C., Schulz, M., Guibert, S., Kinne, S., Balkanski, Y., Bauer, S., Berntsen, T., Berglen, T., Boucher, O., Chin, M., Dentener, F., Diehl, T., Easter, R., Feichter, H., Fillmore, D., Ghan, S., Ginoux, P., Gong, S., Grini, A., Hendricks, J., Horowitz, L., Huang, P., Isaksen, I., Iversen, I., Kloster, S., Koch, D., Kirkevåg, A., Kristjansson, J. E., Krol, M., Lauer, A., Lamarque, J. F., Liu, X., Montanaro, V., Myhre, G., Penner, J., Pitari, G., Reddy, S., Seland, $\varnothing$., Stier, P., Takemura, T., and Tie, X.: Analysis and quantification of the diversities of aerosol life cycles within AeroCom, Atmos. Chem. Phys., 6, 1777-1813, doi:10.5194/acp-6-1777-2006, 2006.
Twomey, S.: Pollution and the planetary albedo, Atmos. Environ., 8, 1251-1256, 1974.

Wang, M. and Penner, J. E.: Aerosol indirect forcing in a global model with particle nucleation, Atmos. Chem. Phys., 9, 239-260, doi:10.5194/acp-9-239-2009, 2009.

Yu, F. and Luo, G.: Simulation of particle size distribution with a global aerosol model: contribution of nucleation to aerosol and CCN number concentrations, Atmos. Chem. Phys., 9, 76917710, doi:10.5194/acp-9-7691-2009, 2009.

Yu, H., Kaufman, Y. J., Chin, M., Feingold, G., Remer, L. A., Anderson, T. L., Balkanski, Y., Bellouin, N., Boucher, O., Christopher, S., DeCola, P., Kahn, R., Koch, D., Loeb, N., Reddy, M. S., Schulz, M., Takemura, T., and Zhou, M.: A review of measurement-based assessments of the aerosol direct radiative effect and forcing, Atmos. Chem. Phys., 6, 613-666, doi:10.5194/acp-6-613-2006, 2006.

Zhang, K., O’Donnell, D., Kazil, J., Stier, P., Kinne, S., Lohmann, U., Ferrachat, S., Croft, B., Quaas, J., Wan, H., Rast, S., and Feichter, J.: The global aerosol-climate model ECHAM-HAM, version 2: sensitivity to improvements in process representations, Atmos. Chem. Phys., 12, 8911-8949, doi:10.5194/acp-12-89112012, 2012. 